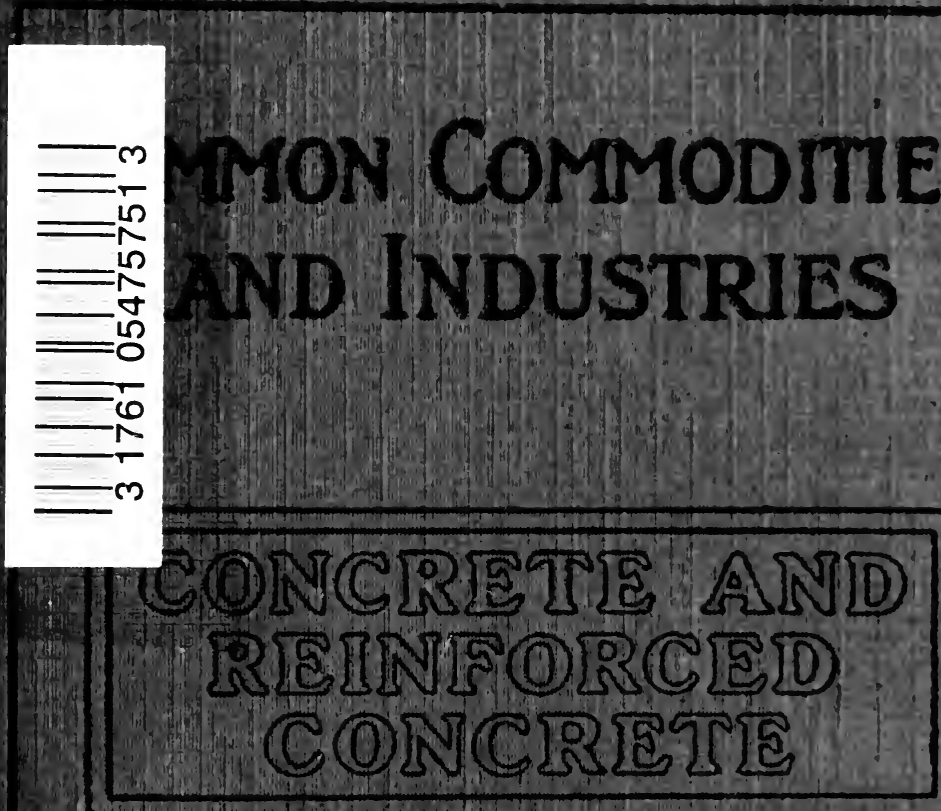

W. Noble Jwelvetrees 


\section{Digitized by the Internet Archive . in 2007 with funding from Microsoft Corporation}





\section{CONCRETE AND REINFORCED CONCRETE}




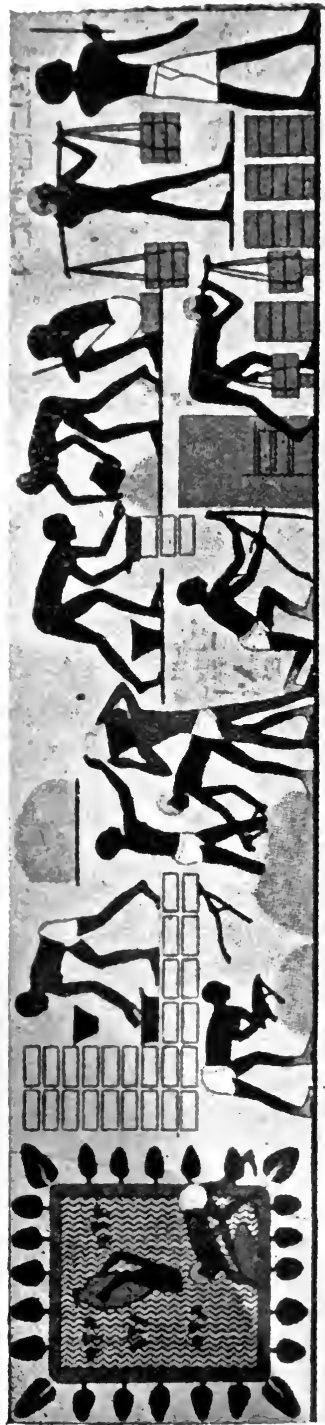

AHHEH HAH
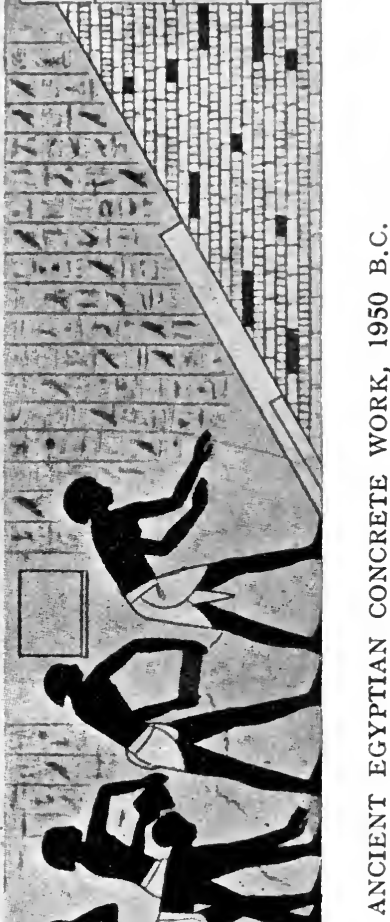

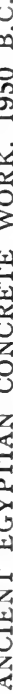

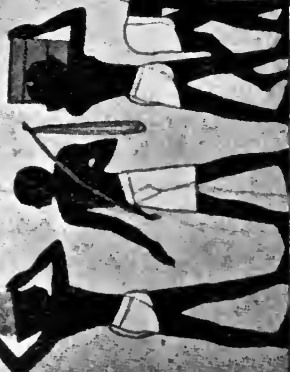


PITMAN'S COMMON COMMODITIES

\section{AND INDUSTRIES}

\section{CONCRETE AND}

R E I N F O R C E D

\section{CONCRETE}

BY

$W^{a}{ }^{\text {ther }}$ NOBLE TWELVETREES

M.I.Mech.E., M.Soc.C.E. (France), Etc.

Past President of the Society of Engineers (Incorporated); Vice-President of the British Section, French Society of Civil Engineers

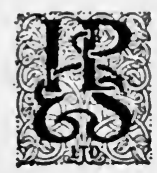

LONDON

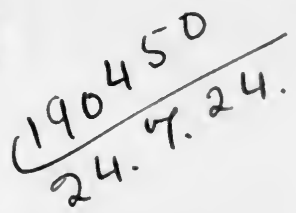

SIR ISAAC PITMAN \& SONS, LTD. PARKER STREET, KINGSWAY, W.C.2 BATH, MELBOURNE, TORONTO, NEW YORK 


\section{COMMON GOMMODITIES AND INDUSTRIES SERIES}

Each book in crown 8vo, illustrated, 3/- net

TEA. IBY A. IBBETSON

COFFEE HY B. B. KeABLE

sulak. By Geo. Martineau, C.B.

OILS. By C. Ainsworti Mitchell, B.A., F.I.C.

WHEAT. BY ANDREW MILlaR

RUBBER. BY C. BEADLE and H. P. Stevens, M.A., Ph.D., F.I.C.

IRON AND STEEL. BY C. HOOD

COPPER. By H. K. PICARD

COAL. By Francis H. WILSON, M.I.Min.E.

TIMBER. By W. BULLOCK

cotTON. BY R. J. PeAKe

SILK. BY LUTHER HOOPER

WOOL. BY J.A. HuNTER

LINEN. BY ALFRED S. MOORE

TOBACCO. BY A. E. TANNER

LEATHER. BY K. J. ADCOCK

KNITTED FABRICS. BY J. CHAMBERLAIN and J. H. QUILTER

CLAYS. BY ALFRED B. SEARLE

PAPER. BY HARRY A. MADDOX

SOAP. By William A. Simmons, B.Sc. (Lond.), F.C.S.

THE MOTOR INDUSTRY. By HORACE WYATT, B.A.

GLASS AND GLASS MAKING. By Percival Marson

GUMS AND RESINS. By E. J. PARRY, B.Sc., F.I.C., F.C.S.

THE BOOT AND SHOE INDUSTRY. By J.S. HARDING

GAS AND GAS MAKING. BY W. H. Y. WEBBER

FURNITURE. By H. E. BINSTEAD COAL TAR. BY A. R. WARNES

PETROLEUM. By A. LidgetT

SALT. BY A. F. CALVERT

ZINC. BY T. E. LONES, M.A., LL.D., B.S.

PHOTOGRAPHY. By WM. Gamble ASBESTOS. By A. LEONARD SUMMERS

SILVER. By BeNJAMIN White

CARPETS. By Reginald S. Brinton

PAINTS AND VARNISHES. BY A.S. JenNings

CORDIGE AND CORDAGE HEMP AND FIBRES. BY T. WOODHOUSE and P. KILGOUR
ACIDS AND ALKALIS. By G. H. J. ADLAM

eleCtricity. By R. E. Neale, B.Sc., Hons.

ALUMINIUM. By Captain G. MORTIMER

GOLD. By Benjanty White

BUTTER AND CHEESE. BY C. W. Walker-Tisuale and Jean JoNES

THE BRITISH CORN TRADE By A. BARKER

LEAD. By J. A. Smythe, D.Sc.

ENGRAVING. BY T. W. LASCElles

STONES AND QUARRIES. BY J. AlleN Howe, O.B.E., B.Sc., M.I.M.M.

EXPLOSIVES. By S. I. LeVy, B.A., B.Sc., F.I.C.

THE CLOTHING INDUSTRY. By B. W. POOLE, M.U.K.A.

TELEGRAPHY, TELEPHONY, AND WIRELESS. By J. POOLE, A.M.I.E.E.

PERFUMERY. BY E. J. PARRY THE ELECTRIC LAMP INDUSTRY. By G. AR NCLIFFe PERCIVAL

COLD STORAGE AND ICE MAKING. BV B. H. SPRINGETT

GLOVES AND THE GLOVE TRADE. By B. E. Ellis

JUTE. By T. Woodhouse and P. Kilgour

DRUGS IN COMMERCE. By J. HUMPHREY

THE FILM INDUSTRY. By Davidson Boughey

CYCLE INDUSTRY. BY W. GREW

SULPHUR. BY Harold A. AUden

TEXTILE BLEACHING. By Alec B. Steven.

PLAYER PIANO. By D. Miller WILSON

WINE AND THE WINE TRADE. BY ANDRE L. SIMON

IRONFOUNDING. BY B. WHITELEY COTTON SPINNING. BY A.S. WADE ALCOHOL. BY C. SIMMONDS

CONCRETE.

By W. NOBLE 


\section{PREFACE}

In the present day the uses of concrete are so diversified and so extensive that there is some justification for the statement that this is the Concrete Age. To be perfectly fair, however, we must admit that the Iron Age has not yet passed away, and that iron and steel continue to find employment in constructive work, sometimes in competition with concrete, and sometimes in harmonious co-operation with that material as exemplified in the combination known as Reinforced Concrete.

The objects of this book are to set forth the essential nature of concrete, to describe briefly the materials of which it is composed, the manner in which these materials are proportioned and mixed, the methods adopted in practice for the application of the product; to state as clearly and concisely as possible the fundamental principles of reinforced concrete, and to illustrate by references to typical examples of construction the remarkable characteristics of that happy union of concrete and steel.

Owing to the limited amount of space at his disposal, the author has necessarily been compelled to abstain from dealing with some ramifications of the subject, and to touch lightly upon others. In the treatment adopted he has endeavoured to give such particulars as will not only be of interest to the general reader, but also of service to those engaged in the practical application of concrete to engineering and building construction. 


\section{THE KLEINE $\overline{\frac{\text { PATENT }}{T}}$}

FIRE RESISTING FLOORS ROOFS AND STAIRCASES

\section{OF \\ R E I N F O R C E D HOLLOW BRICKS}

WITH OR WITHOUT CENTRING

\section{ESTABLISHED 1905}

EXTRACT from Mr. Twelvetrees' Report on the Fire Test of the Kleine Floors conducted by him on June 27th, 1907-

"Finally, the results of the tests prove" "conclusively that all three floors behaved" "in a perfectly satisfactory manner, the" "resistance of the construction to fire and" "water leaving nothing to be desired. The" "behaviour of Floor A was particularly" "noteworthy in respect of its fire-resisting" "and load-bearing capacity, after $e x$ posure to" "thermal influences and strains more severe" "than those obtaining in actual practice."

\section{KLEINE PATENT FIRE RESISTING} FLO0RING SYNDICATE LTD. OFFICES : 133-136 HIGH HOLBORN, W.C.1 


\section{CONTENTS}

CHAP.

PAGE

I. ORIGIN AND HISTORY OF CONCRETE. - 1

II. RAW MATERIALS $\quad$ - $\quad$ - $\quad$ - 12

III. PROPORTIONING CONCRETE . . . 23

IV. MIXING CONCRETE • . . . 33

V. DEPOSITING MIXED CONCRETE . . 45

VI. MOULDS AND SHUTTERING • . $\quad 57$

VII. SURFACE TREATMENT OF CONCRETE • . 70

VIII. CONCRETE BLOCKS AND MOULDED PRODUCTS 83

IX. PHYSICAL PROPERTIES OF CONCRETE • . 91

X. REINFORCED CONCRETE . . . . 108

XI. CONCRETE SHIPBUILDING . . . 124

INDEX . . . . . . . . 135 


\section{ILLUSTRATIONS}

ANCIENT EGYPTIAN CONCRETE WORK

PAGE

Frontispiece FIG.

1. SANDSTONE

2. PUDDING STONE

3. CONCRETE

4. DOME OF THE PANTHEON, ROME

5. SAXON CEMENT WORKS, CAMBRIDGE .

6. ROTARY KILNS, SOUTHAM CEMENT WORKS, RUGBY

7. GRAVEL (TWO-THIRDS FULL SIZE) . . . 24

8. SAND (TWO-THIRDS FULL SIZE) . . . 24

9. SAND WASHER

10. EARLY SCREENING APPARATUS .

11. CONCRETE MIXER AT ROYAL LIVER BUILDING, LIVERPOOL.

12. PLAN OF CONCRETING PLANT AT MASSACHUSETTS INSTITUTE OF TECHNOLOGY • . . • . 43

13. GRAVITY CONCRETING PLANT AT THE U.S.A. BUREAU OF ENGRAVING AND PRINTING .

14. BATTERIE DES MAURES. A NOTEWORTHY EXAMPLE OF CAISSON CONSTRUCTION . $\quad$ • $\quad$ • 54

15. CYLINDER PIERS WITH PRECAST BRACING . • $\mathbf{5 5}$

16. SHUTTERING FOR SHEDS AT MANCHESTER DOCKS $\mathbf{5 9}$

17. MOULD FOR COLUMNS . . . . . 61

18. MOULD FOR BEAMS $\quad$ • $\quad$ • $\quad$. 62

19. MOULD FOR WALLS $\quad$. $\quad$. $\quad$ • $\quad$. 64

20. CENTRING FOR RISORGIMENTO BRIDGE, ROME • 65

21. SHUTTERING FOR 1,000-TON BARGE • • . 66

22. LION CHAMBERS, GLASGOW . . . 71

23. STUCCO FINISHES . . . . . . 74

24. GRANITE OR MARBLE CHIP FINISH • • • 75

25. ETCHED FINISH WITH KEY BORDER • • • 76

26. EXPOSED AGGREGATE . . • . 77

27. FACTORY BUILDING WITH TOOLED SURFACES . 79

28. A CONCRETE RESIDENCE . . . . . 81

29. STATUE OF ST. JOSEPH AT ESPALY . . . 87

30. MOULDED CONCRETE WORK • $\quad$ • $\quad$ • 88 
no.

31. MOULDED ENTRANCE FOR SCHOOL .

32. CHURCH OF THE BLESSED SACRAMENT, NEW YORK

33. DIAGRAM REPRESENTING PLAIN CONCRETE BEAM

34. DIAGRAM SHOWING STRESSES IN PLAIN CONCRETE

\section{BEAM}

35. DIAGRAM SHOWING FAILURE OF PLAIN CONCRETE

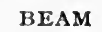
BEAM

36.

37.

38. DIAGRAMS ILLUSTRATING THE APPLICATION OF

39. REINFORCEMENT TO A CONCRETE BEAM .

40.

41. TYPICAL ARRANGEMENT OF REINFORCEMENT IN HENNEBIQUE BEAMS AND COLUMNS

42. BUILDINGS AT TUNIS AFTER SUBSIDENCE

43. $\{$ REINFORCED BRICKWORK (KLEINE FLOOR SYSTEM) 122

45. THE LAMBOT BOAT, BUILT 1849 • 125

46. LAUNCH OF A 1,000-TON BARGE . . 127

47. S.S. "ARMISTICE," 1,150 TONS DEADWEIGHT

CAPACITY . . . . . . . . . 129

48. THE SHOREHAM MYSTERY SHIPS . . 131 


\section{CONCRETE AND \\ REINFORCED CONCRETE}

\section{CHAPTER I \\ ORIGIN AND HISTORY OF CONCRETE}

OLDER by countless ages than any of the manufactured products commonly designated "materials of construction," concrete was first produced by the hand of Nature in the form of rock, many varieties of which have been made familiar to us by their extensive use in buildings, bridges, viaducts, piers, and other architectural and engineering works.

Concrete was next produced by man, who in this, as in other cases, has always been ready to copy the processes of nature, the form of artificial rock, or stone, described as "concrete" having been widely used for many thousands of years, and being employed in the present day more widely than ever before.

Derived from the Latin word concretus, meaning grown together, compounded, hardened, the term concrete might be applied with equal appropriateness to natural stone, and to its artificial equivalent. Speaking in general terms, each of these classes of material, which, as a matter of convenience may be distinguished as stone and concrete, respectively, consists of an agglomeration of particles held together by some cementitious substance and consolidated under more or less heavy pressure. 
For instance, sandstone is formed by the cementation and consolidation of sand, as shown in Fig. 1, which has been reproduced from a microphotograph, and is essentially akin to the fine concrete, technically designated " mortar," formed by binding together particles of

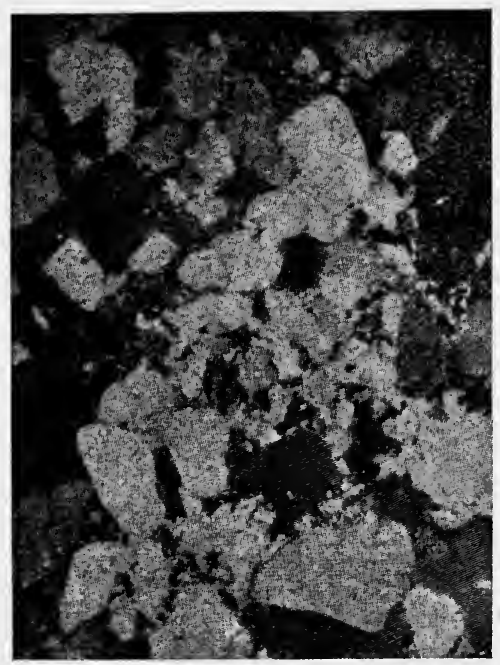

FIg. 1. SANDSTONE

sand by means of lime or cement. Again, the natural rock known as conglomerate, or pudding-stone, consists of pebbles cemented together in very much the. same way as the pebbles are held together in concrete composed of gravel and lime, or gravel and cement.

Comparison of Figs. 2 and 3 will suffice to show how closely akin are natural rock and the artificial variety of stone termed concrete, Fig. 2 representing a piece of 
pudding-stone, and Fig. 3 showing a piece of modern concrete.

As there are many varieties of natural stone, so also there are various kinds of concrete. In the latter, the inert material, or aggregate, may consist of gravel, fragments of broken stone, or any hard and durable substance, cemented together with lime, hydraulic $l \mathrm{ime}$,

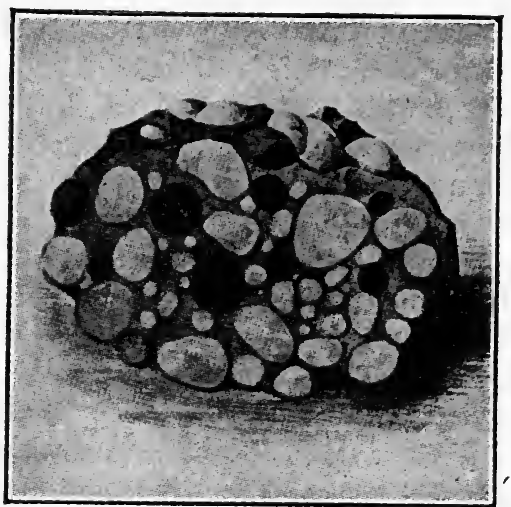

FIG. 2. PUDDING STONE

Portland cement, or some other kind of cement, water being added in every case to set up the chemical action necessary for the setting of the cementitious

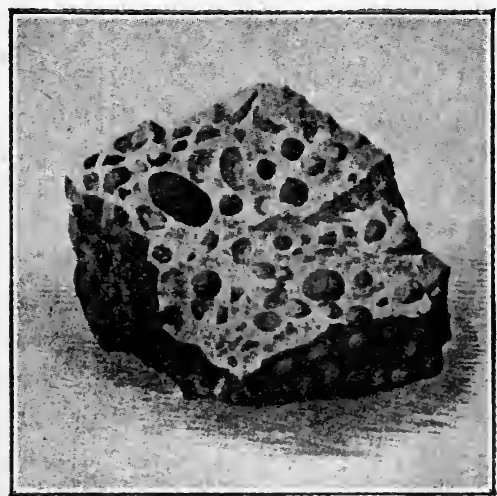

FIG. 3. CONCRETE material. The sizes of the particles constituting the aggregate may vary considerably, and so also may the proportion of cementitious material in a given volume of concrete. In ancient concrete, large pieces of 'stone were frequently used as aggregate, and lime, or lime 
mixed with some other substance to produce a kind of cement, was employed to bind the aggregate together, so as to form a compact mass. In modern concrete the aggregate consists of particles of comparatively small sizes, which are varied so that the particles may fit together as closely as possible, and so reduce to a minimum the vacant spaces, or voids, between the particles of aggregate. With the object of reducing the voids still further, sand is mixed with the coarser material, the sand also comprising particles of graduated sizes. Thus the amount of space to be filled by the cement is greatly reduced, and the density of the resulting concrete is proportionately increased. Portland cement, a product far superior to any kind of cement used in ancient times, is now almost universally employed in modern concrete, and is invariably employed in the best classes of work.

The precise antiquity of concrete cannot be stated, but it is interesting to know that portions of concrete buildings have been discovered in Mexico and Peru, dating back to prehistoric times. That the ancient Egyptians were thoroughly familiar with the material is proved by a fresco in the Temple of Ammon at Thebes, depicting hieroglyphically the making and use of concrete in the year 1950 B.c.

The Frontispiece to this book is taken from a photograph of the fresco where, commencing at the left-hand, we haye the drawing of water from a lake, the slaking of lime in the first heap, and the digging of sand for the preparation of mortar shown in the second heap. The carrying of mortar and the making of bricks for facing the concrete core should also be noted, as well as the inspectors, two armed with rods, and one with a whip, for the persuasion of backward workers. Another feature showing how faithfully details are depicted 
in the fresco is the representation of mortar adhering to the feet and hands of the workmen. The building of a solid.concrete wall faced with brickwork is illustrated in the lower part of the fresco, the story of which is told by the hieroglyph birds in the background.

This illustration is reproduced from the American journal Concrete, where it is described by Mr. Nathan C. Johnson, who says that he possesses a piece of this very concrete bearing the imprint of a man's hand, by which it had evidently been slapped into place-a truly remarkable link between the present generation and of men who lived nearly 4,000 years ago.

In later times, concrete was used on a large scale by the ancient Grecians, and very widely by the ancient Romans. As far back as 500 B.c. concrete was applied as a material of construction by the Romans, and from that date onwards was increasingly used, being usually faced with brickwork or masonry. During the reign of Julius Caesar, concrete became quite common in foundation work and in the massive parts of masonry buildings. In the time of Augustus, concrete construction became almost universal in building work and in the construction of sewers, aqueducts and bridges.

The dome of the Pantheon, built A.D. 123, is the finest example of ancient concrete work extant. The dome is $142 \mathrm{ft}$. in diameter, with an opening of $30 \mathrm{ft}$. diameter at the top, as illustrated in Fig. 4.

The examination of buildings erected by the Romans shows that a general custom was to employ concrete as a core between interior and exterior facing walls, or in building walls faced upon one side. From early writings it appears that in cases where a facing was considered unnecessary, the Romans made use of shuttering in the form of boards laid edgewise and filled the intervening space with cement and stones of various 
sizes mixed together. For this class of work, therefore, Roman practice was very similar to that followed in the present day.

Many remains of Roman and Norman structures in this country furnish additional proof of the durability of concrete made in by-gone times. Portions of the

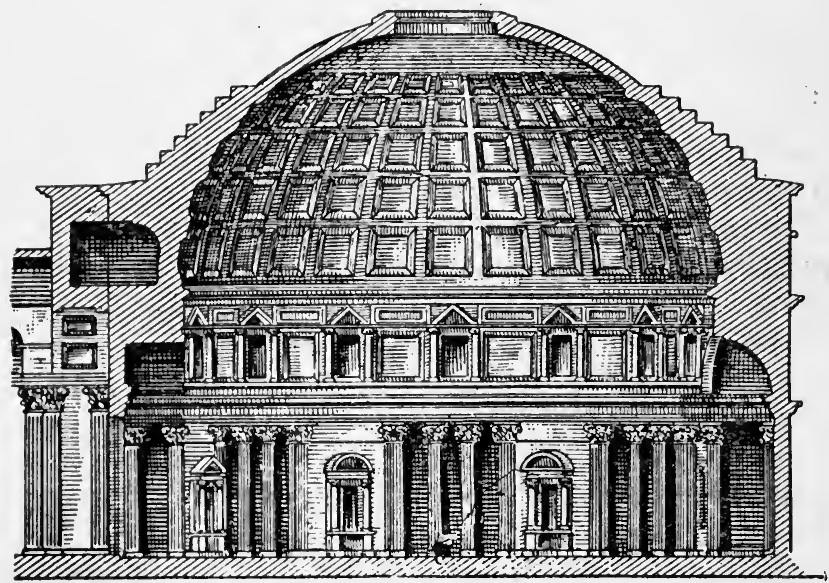

FIG. 4. DOME OF THE PANTHEON, ROME

Roman walls which once surrounded the city of London are to be found at various points in the modern city. One interesting fragment in the basement of a building near the Tower comprises rows of Kentish ragstone alternate with tiles, both courses laid in cement which is harder than either the stone or the tile. Another section of the old wall unearthed when the General Post Office was extended by the addition of two reinforced concrete buildings was found to be in an equally satisfactory condition.

The wonderful manner in which the walls of castles 
and other buildings scattered throughout Great Britain have endured centuries of exposure, is apparently due to the fact that the species of hydraulic cement employed in the concrete core was also run into the joints of the facing walls, thus binding the whole together in a monolithic mass. In structures of this kind, the practice was to commence with the outer facing walls, and to fill the intervening space with fragments of stone, not large enough for the courses of exterior masonry, as well as with stone chippings and dust. The whole of the work was then consolidated by pouring in a semiliquid mass of mortar composed of lime and sand, so as to fill up all voids and to form a central core of concrete effectively bonded with the exterior facing walls. The lime was frequently treated by the addition of some other substance rendering it capable of setting in the presence of water, and of withstanding the effects of the weather. In this way the lime was converted into a species of hydraulic cement, which, although inferior to the modern product, has sufficiently justified its claim to permanent durability.

The relative endurance of concrete and stone masonry is illustrated by the walls of the Benedictine Abbey built about A.D. 1121 at Reading. The walls of this structure are believed to have been faced on both sides with squared blocks of stone, the core being of concrete which remains to this day, although the masonry has long since disappeared.

When we bear in mind the way in which the surface of masonry is eaten away by long exposure, even when the stone is of the hardest and most durable nature, it is surprising to find that concrete surfaces maintain their integrity for all time. The piece of early Egyptian concrete already mentioned as bearing the imprint of a man's hand, is a case in point, others being furnished $2-(1463 \mathrm{D})$ 
by concrete work in ancient castles, where the surfaces of the material still bear the marks caused by the boards of the shuttering employed by the builders.

During the middle ages, concrete appears to have been neglected in this country, although used to some extent on the Continent. Smeaton was one of the engineers to bring the material once more to the front about A.D. 1774, but the small progress made may be judged by the fact that in his work on Limes and Cements, published in 1847, General Pasley refers to concrete as " a recent improvement " first adopted with success in the foundations of the Penitentiary at Millbank. The same writer accounts for this revival of concrete as a structural material in the following words-

" In excavating for one of the piers of Waterloo Bridge, the workmen had a good deal of difficulty, owing to the very compact state of the gravel forming the bed of the river, which everywhere else had been found perfectly loose. The effect had been produced by the accidental sinking of a bargeload of lime over the spot some time before, which had cemented the gravel into a solid mass, resembling the calcareous conglomerates of Nature which are gradually formed by a similar process."

General Pasley's apparent ignorance of what had been done by the Romans and Normans is somewhat unaccountable especially as his investigation into the properties of limes and cements was being conducted at Chatham, within a short distance of Rochester Castle-one of the best examples of Roman concrete work extant.

Another curious statement in General Pasley's work is to the effect that the use of lime concrete for the formation of a sea wall at Brighton, some years before 1847, was, to the best of his belief, the first application of concrete other than for foundations. 
In the second half of the nineteenth century, the employment of concrete began to be revived on an extensive scale in general building and engineering construction, and in various public works of exceptional magnitude. The progress of concrete was materially aided by the invention of Portland cement, so called because of the resemblance of the material when set, or hardened, to the well known stone quarried in the Isle of Portland. This product is immeasurably superior to the crude forms of cement made by the ancient Romans, and to the hydraulic limes and cements produced in this country before the introduction of Portland cement.

Experience gained in the use of concrete on a large scale led to improved methods of proportioning the constituents and of preparing them for use. Improvements have been made concurrently in the manufacture of cement, which is now prepared under conditions giving assurances of the highest possible quality and unfailing reliability.

Within the past quarter of a century, a further impetus to concrete construction has been given by the development of reinforced concrete. This is a combination of concrete, prepared in the most scientific manner, with steel rods disposed in such a way that the two materials work together to the best possible advantage. The result is the formation of a kind of elastic stone which can be employed advantageously in structures of all kinds, and in forms of design very much akin to those adopted for structural steel.

Thanks to this development, the uses of concrete have been very widely extended, and in addition to massive structures, such as the Thames Embankment, the National Harbour at Dover, and other monumental works in ordinary concrete, we now have reinforced 
concrete in the form of water towers, long span bridges of slender proportions, and even of ocean-going steamships up to 7,500 tons capacity, to say nothing of architectural and engineering structures of practically every type.

The general principles of reinforced concrete are discussed in another chapter, but it may be mentioned here that the theory of the combination was by no means unknown to the Romans, by whom iron and copper were employed in many important works as reinforcement for concrete. This is another instance of the fact that despite the many advantages and the accumulated knowledge enjoyed by those living in the present century, the intellectual capacity of mankind has not materially increased with the passing of the ages.

The universal employment of concrete was aptly expressed not very long ago in an address delivered to an American association of cement users as follows-

"Our ancestors progressed from the Stone Age to the Iron Age; we seem to be passing from the Steel Age to the Cement Stone or Concrete Age. We tread on concrete walks, travel in concrete subways, over concrete bridges ; live and work in concrete buildings ; store our grain in concrete elevators; draw our water from concrete reservoirs and cisterns ; sanitate our cities with concrete sewers : and are finally buried in concrete vases deposited in concrete tombs, and our numerous virtues are inscribed on concrete monuments."

This comprehensive summary might be supplemented to-day by the inclusion of concrete bodies for motor and railway vehicles, concrete roadways, concrete barges and steamships, and the numerous adaptations of concrete in offensive and defensive works which were brought about by the great European War. 
An unexpected tribute to concrete was paid by Andrew Carnegie in a conference at Washington on the conservation of the natural resources of the United States. This great steel maker then said-" "The use of concrete, simple and reinforced, is already reducing the consumption of structural steel. The materials for cement and concrete abound in every part of the country, and while the arts of making and using them are still in their infancy, the products promise to become superior to steel and stone in strength, durability and convenience, and economy and use."

If the conservation of iron and steel is necessary in a country with the almost boundless resources of the United States, it is still more so in Great Britain, where large imports have to be made of ore and other material for steel manufacture. On the other hand, we have an abundance of chalk, limestone and clay for cement making, and an equal abundance of stone, gravel, shingle and sand for use in preparing concrete. Consequently, the adoption of this material, whether alone or in combination with steel, may be commended as a means of helping to conserve the wealth of the country by utilizing natural resources, and reducing the need for imports to a corresponding extent. 


\section{CHAPTER II}

\section{RAW MATERIALS}

As stated in the preceding chapter, concrete is composed of cement or lime, sand, aggregate and water. In modern practice Portland cement is almost invariably used as the cementitious material, ordinary lime, hydraulic lime, and certain varieties of cement being employed only in inferior classes of work.

In the following paragraphs the raw materials of concrete are discussed under separate heads for convenient reference.

Portland Cement. This variety of cement is essentially a British invention, having been patented in 1824 by Joseph Aspdin, a Leeds bricklayer. It was first used on anything like an extensive scale by Brunel in the construction of the Thames Tunnel in 1848. Since the foundation of the industry in the early days of last century, Portland cement has been greatly improved in quality by the strict regulation of the proportions of the materials under the constant supervision of scientific chemists, the perfect clinkering of the mixture and the fine grinding of the clinker.

As defined in the British Standard Specification, Portland cement is " manufactured by intimately mixing together calcareous and argillaceous materials, burning them at a clinkering temperature, and grinding the resulting clinker."

The three essential components of the "calcareous and argillaceous materials" are lime, alumina and silica. These may be obtained from limestone rock 
or chalk and clay, or from deposits such as those in the Blue Lias formations of Warwickshire and elsewhere. In either case, the proportions of the three components must be carefully regulated so that the resulting cement

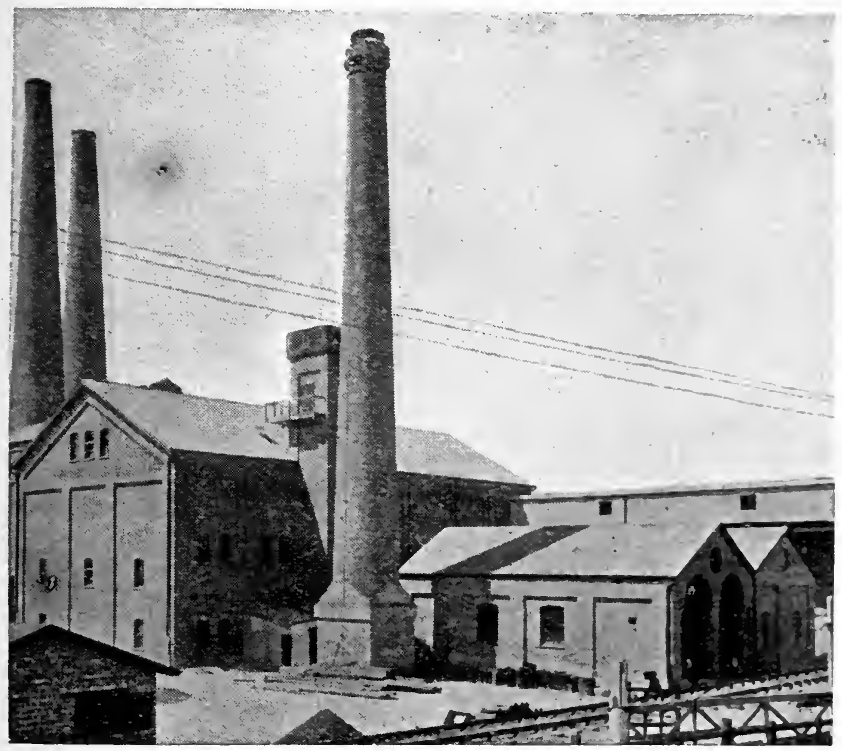

FIG. 5. SAXON CEMENT WORKS, CAMBRIDGE

shall comply with an established standard of chemical composition.

Fig. 5 is a general view of the Saxon Portland Cement Works, Cambridge; and Fig. 6 illustrates part of the rotary kiln installation of Southam Cement Works, near Rugby.

The finished cement is tested at the works for the satisfaction of the makers, and before use on important 
contracts is also tested by or on behalf of the purchaser. The tests prescribed in the British Standard Specification relate to $(a)$ Fineness, $(b)$ Chemical composition, (c) Tensile strength (neat cement), (d) Tensile strength

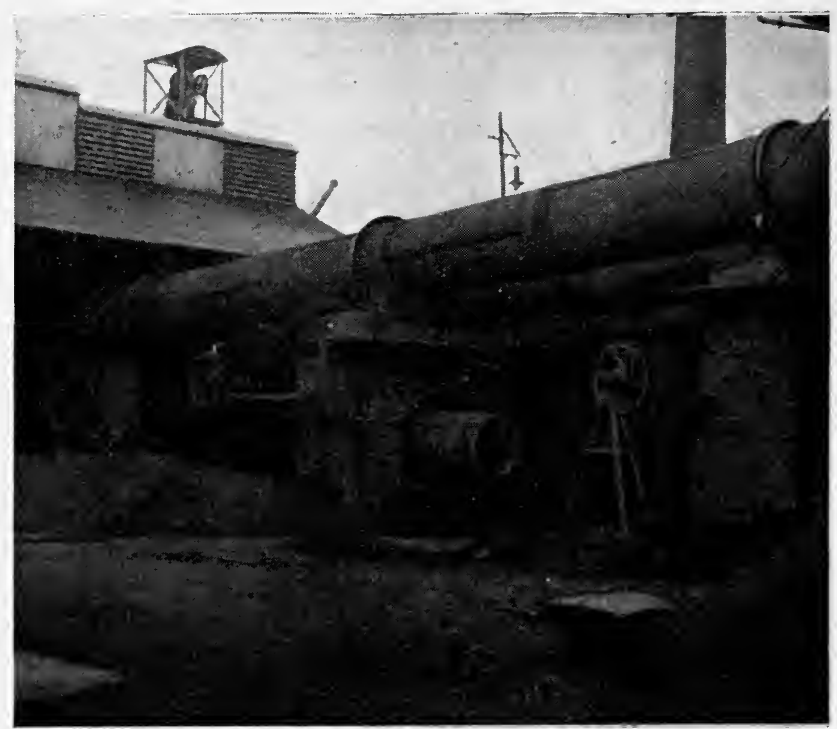

Fig. 6. ROTARY KILNS, SOUTHAM CEMENT WORKS, RUGBY

(cement and sand), (e) Setting time, $(f)$ Soundness. If the product is capable of passing these tests in a satisfactory manner it can be used without the slightest hesitation.

Fineness of grinding is highly important, mainly for the reason that finely ground clinker is far more active and therefore more economical than cement containing 
an undue percentage of relatively coarse particles. The fineness of cement is determined by means of sieves, and the Standard specification provides that the residue on a sieve having 32,400 meshes per square inch shall not exceed 14 per cent, or on a sieve with 5,776 meshes per square inch shall not exceed 1 per cent. Chemical composition is, of course, determined by analysis, and, as a matter of fact, it is customary for the composition of the cement to be tested analytically at every stage of manufacture in the cement works as well as by tests of the finished product by the maker, apart from any test required by the purchaser. Tensile strength is ascertained by testing briquettes, or specimens of standard form and dimensions, in a suitable machine. The Standard Specification requires that the breaking strength of briquettes of neat cement at an age of 7 days shall be not less than $450 \mathrm{lb}$. per square inch, the required breaking strength of briquettes made of cement and sand in the proportion of $1: 3$ being not less than $200 \mathrm{lb}$. per square inch at the same age. The specification provides further that the breaking strength in each case at an age of 28 days shall be not less than that calculated in the following formulæ-

\section{Neat Cement-}

Breaking strength at 7 days

40,000

Breaking strength at 7 days

\section{Cement and Sand-}

Breaking strength at 7 days

$$
\frac{10,000}{\text { Breaking strength at } 7 \text { days. }}
$$

Thanks to the introduction of a patented hydrating process, the setting time of the finished cement can be scientifically regulated during the operation of grinding the clinker. Thus, it is possible to produce cement complying with any practical requirements as to time 
of setting. In the Standard Specification, it is required that unless a specially quick-setting cement is specified the initial setting time shall be not less than 20 minutes, and the final setting time not more than 10 hours. In the case of quick-setting cement, the initial setting time specified is not less than 2 minutes, and the final setting time not more than 30 minutes Tests of setting time are performed by means of the Vicat apparatus, an appliance provided with a weighted needle for determining initial setting time, and another needle fitted with a cup-like attachment for the determination of final setting time. The initial setting time is the period which elapses between the time when the cement is filled into the mould and the time at which the needle ceases to pierce the test block completely, and the cement is considered as finally set when the special needle makes an impression on the surface of the block, but the circular attachment fails to do so.

In ordinary construction, slow-setting cement is desirable for the reason that the transportation of concrete from the mixer to the points where it is to be used, and the operations of depositing and tamping the material, necessarily occupy a certain space of time during which concrete made with quick-setting cement would commence to set. The undesirability of such a contingency is shown by the fact that if concrete is worked or handled while the process of setting is going on, the crystallization of the cement is seriously disturbed. The interlocking crystals are broken up, and the strength and cohesion of the material are much reduced.

The best qualities of Portland cement as manufactured in the present day are quite sound, and free from any tendency to expand when used in constructive work. Purchasers can easily satisfy themselves as 
to the soundness of the cement supplied by the tests described in the British Standard Specification.

These tests are in accordance with the "Le Chatelier" method, in which a portion of neat cement paste is placed in a small split metal cylinder with two pointers, one attached at either side of the gap in the cylinder. The cylinder, or mould, is placed upon a small glass plate, and the cement filled in is covered by another glass plate with a small weight on the top. The whole is then submerged in water at a temperature of from $58^{\circ}$ to $64^{\circ} \mathrm{Fahr}$., and left for 24 hours. The distance between the indicator points is then measured, and the apparatus with its contents again immersed in water, which is boiled and kept boiling for 6 hours. After removal and cooling, the distance between the indicator points is again measured, the difference between the two measurements representing the expansion of the cement, which should not exceed 10 millimetres when the cement has been aerated for 24 hours, or 5 millimetres after it has been aerated for 7 days.

Natural Cement. This variety of cement has been made for many years in this country, and is produced on a somewhat extensive scale on the Continent and in America. Natural cement was first manufactured in Great Britain from septaria or nodules of clay and calcareous matter found at various places on the coasts of Kent and Essex. Originally known as Parker's cement, this product was afterwards designated Roman cement, one variety being designated Medina cement after the river in the Isle of Wight, where septaria also occur.

In other countries, natural cement is made from mineral deposits containing varying proportions of limestone and clay, and providing in a very rough and ready way the principal raw materials for cement 
manufacture. Unfortunately, those engaged in this branch of the cement industry use the material just as it comes from the quarry or other source, without making any attempt to regulate the proportions of the constituents. The rock is placed in the kiln and burnt, without any preliminary treatment, and is afterwards ground in the usual manner.

Before the outbreak of war in 1914, lárge quantities of natural cement were imported into the United Kingdom, chiefly from Belgium, much of this variable and unreliable material having been sold as "Portland Cement " or as "Best Portland Cement."

Many serious failures have resulted from the use of natural cement, which will never comply with all the requirements of the British Standard Specification.

Slag Cement. This is another kind of inferior cement made from blast furnace slag, and differing widely in chemical composition from genuine Portland cement. Although attractive owing to its relatively low cost, slag cement deteriorates quickly when stored, and cannot be relied upon to give durable results.

Hydraulic Lime. Made from deposits similar to those furnishing the raw material for natural cements, hydraulic lime is produced by calcining at moderate temperature limestone or chalk containing clay, either alone or in combination with alkalies and metallic oxides, in proportions sufficient to render the resulting material capable of setting under water.

If the proportion of clay happens to be large enough, a variety of natural cement can be produced by continuing the process of calcination until the whole of the lime has entered into chemical combination with other constituents. The line of demarkation between hydraulic lime and natural cement is most conveniently drawn by classifying as lime those products which 
contain uncombined lime capable of slaking in the presence of water, and as cement those in which all the lime has entered into combination, thus permitting the process of setting to take place without the slaking characteristics of lime.

Common lime can be rendered hydraulic by the addition of certain substances, either before or after calcination. Thus, Scott's or selenitic cement consists of lime containing a small proportion of an alkaline sulphate, usually calcium sulphate, and the hydraulic lime, or cement, used by the ancient Romans was produced by the admixture of pozzuolana with ordinary lime. Pozzuolana, trass and similar natural products are varieties of argillaceous earth calcined by volcanic heat, and it is interesting to note that they are used to-day in the manner and for the purpose originated over 2,000 years ago by the Romans.

Rich or Fat Lime is produced by burning pure or nearly pure limestone or chalk, the resulting quick lime slaking rapidly when mixed with water, swelling up and evolving great heat, the result being slaked or hydrated lime.

Poor Lime is obtained by calcining limestone or chalk containing inert matter, the product slaking more slowly and less completely than rich lime.

Water. Apart from other considerations, water is an all-important constituent of concrete in two respects(1) that it has the effect of commencing the series of reactions which result in the setting of the cement, and (2) that it remains as a permanent constituent of the concrete in the form of water of crystallization. For the purpose of chemical combination, the proportion of water in concrete should be equal to at least $\mathbf{8}$ per cent of the weight of the cement, but in practice a much greater proportion is requisite to provide for flowability, 
arrangements being made where practicable for the surplus water to drain away.

Recent investigations by Professor Duff A. Abrams, of the Lewis Institute, Chicago, have brought out the extremely important part played by water in concrete mixtures, and have led to the conclusion that water is the most important ingredient in concrete. As baldly stated in this way, the conclusion may appear to be quite untenable at first sight. The importance of water is, however, clearly denoted by the facts ascertained by Professor Abrams, who shows that small variations in the proportion used produce greater variations in the strength and other properties of concrete than similar variations due to the relative quantities of other ingredients. This point is illustrated by the following conclusions stated by Professor Abrams-

(1) In a one-bag batch, the use of one pint more water than is necessary to produce a plastic mixture has the effect of reducing the strength of the concrete to the same extent as would result from the omission of from $2 \mathrm{lb}$. to $3 \mathrm{lb}$. of cement from the batch.

(2) The mere use of richer mixtures generally encourages a feeling of security, whereas in many instances nothing more is thereby accomplished than the waste of cement consequent upon an excess of mixing water.

(3) As small variations in the amount of water cause a much wider change in the strength than similar variations in the proportion of cement or the size and grading of the aggregate, it is important to use the smallest proportion of water that will produce concrete of a plastic or workable consistency.

Fresh water should always be used, and care should be taken to see that it is free from earthy, vegetable, and organic matter, acids and alkaline substances in suspension or solution. 
Sand or Fine Material. The duty of sand, or other fine material, in concrete is to fill up, as far as possible, the spaces or voids between the particles of aggregate, or coarse material. From the theoretical standpoint there is obviously no objection to the employment, as a substitute for sand, of small well graded particles of hard stone. Wherever stone screenings are so used they must be free from dust and foreign substances generally. Sand for concrete should be composed of grains of hard and durable stone free from impurities. The sand, or stone screenings, if the latter are employed instead of sand, should be of varying sizes from about $\frac{1}{8}$ in. gauge downwards. Fine sand and sand with grains of approximately uniform size are equally undesirable for the reason that for given mixtures of cement and sand they produce mortars of less density and strength than those obtained by the use of coarser and well graded sands. This remark applies with equal force to fine material consisting of small particles of stone.

Aggregate or Coarse Material. The coarse material in the best qualities of concrete consists of gravel, shingle, or broken stone of hard, close-grained and durable character. Limestone and other varieties of rock containing large proportions of calcium carbonate are undesirable in concrete for buildings owing to the fact that they may be disintegrated at high temperatures in case of fire ; coke and coal residues of combustible nature are equally undesirable; and broken brick is generally inadvisable because it yields concrete of low compressive strength.

Among materials which should not be employed as aggregate for reinforced concrete are-coal residues, including ashes, cinders, clinkers, coke breeze, pan breeze, blast furnace slag, copper slag, refuse destructor clinker, 
and forge breeze. During quite recent years, the desirability of producing light-weight concrete for shipbuilding purposes has led to the introduction, in the United States, of a special variety of burnt clay as aggregate. Concrete made with this material, which is so light that it will float in water, has been favourably reported upon by the United States Shipping Board, by whom it has been found satisfactory in respect of compressive strength and impermeability. Several large steamships have been constructed of such concrete for the American Government, and it is clear that if the behaviour of these vessels confirms the claims made on behalf of the material, a very wide field will be opened up for the employment of light-weight concrete in engineering and building construction.

Speaking generally, aggregates should be free from sand, earth, clay, quarry refuse and other foreign matter. Where sandy gravel, or Thames ballast, is employed, the sand should be screened out, leaving as aggregate all particles of about $\frac{1}{8}$ in. gauge and above. The sand, if of suitable quality, can afterwards be mixed with the cement and aggregate in the predetermined proportions.

The pebbles, or the fragments of broken stone, used as aggregate, should be varied as much as possible in size, and carefully graded so as to reduce the proportion of voids to a minimum. In building construction and in reinforced concrete work, the particles usually range from $\frac{1}{8}$ in. up to $\frac{3}{4}$ in. gauge. For some classes of work still finer concrete is necessary, and on the other hand, in mass concrete work the aggregate may often be graded up to $2 \frac{1}{2}$ in. gauge or more with advantage. 


\section{CHAPTER III}

\section{PROPORTIONING CONCRETE}

WhATEVER may be the nature of the raw materials, or whatever the purpose to which concrete is to be applied, it is always important that the constituents should be employed in the most advantageous manner. With this object in view, careful attention should be directed to the influence exerted by the nature of the aggregate and sand, the sizes of the particles, the proportions in which particles of different sizes are used, the proportion and quality of the cement, and the consistency of the mixture.

As a general axiom, it may be said that the density of concrete is the most reliable index to its strength, impermeability and economy. The density of concrete is represented by the ratio of the volume of solid matter to the total volume of the concrete. Maximum density corresponds with maximum efficiency, and is to be obtained by using aggregate and sand, each with particles of varied and well graded sizes, so that the voids or spaces between the largest pieces of aggregate are occupied, as far as practicable, by stones of the next largest size, and thereafter by particles of progressively decreasing dimensions until the spaces remaining to be filled are small enough to give the sand or other fine material the opportunity of continuing the process to a stage where the cement and water come into play and occupy all the remaining spaces. Fig. 7 shows a sample of gravel which has passed through a $1 \frac{1}{4}$ in. sieve and been held on a $\frac{1}{4}$ in. sieve, and Fig. 8 shows 
sand after passing a $\frac{1}{4}$ in. sieve. The particles in these two illustrations are two-thirds full size.

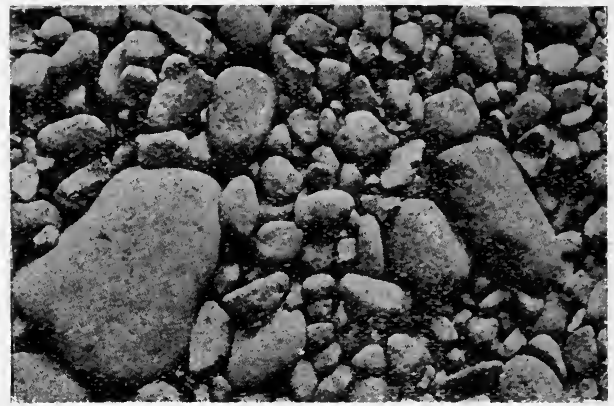

FIG. 7. GRAVEL (TWO-THIRDS FULL SIZE)

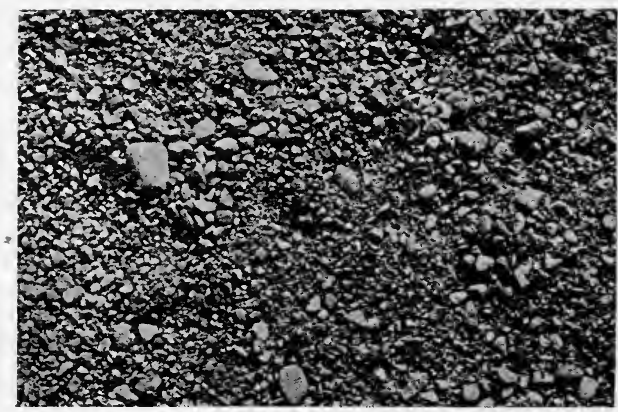

FIG. 8. SAND (TWO-THIRDS FULL SIZE)

It is quite evident that if in a given volume of concrete the aggregate and sand are so graded and proportioned that the concrete is composed principally of stone, the amount of cement paste, consisting of cement and water, necessary for binding the whole mass together 
will be very much less than the amount required in a case where the same care has not been taken to reduce the proportion of voids by proper grading and proportioning of the coarse and fine material. As the latter cost very much less than Portland cement, economy is attained by packing them together as closely as possible, to say nothing of the increased strength thereby secured. The employment of cement for the purpose of making up for the effects of badly proportioned aggregate and sand is merely a waste of good and expensive material, and should always be avoided.

The general principles governing the proportioning of concrete may be thus stated-

(1) For a given mixture of aggregate and sand, the strongest concrete is one containing the largest percentage of cement.

(2) For a given percentage of cement and given kinds of aggregate and sand, the strongest concrete is one obtained by combining the coarse and fine materials so as to give concrete of maximum density.

Various methods are adopted with the object of obtaining concrete of maximum density, some of these being described in the following paragraphs.

Proportioning by Voids. This method is based upon the undeniably correct principle of measuring the voids, that is to say the spaces between the particles, in the aggregate and the sand, using enough cement paste, or cement and water, to fill the voids in the sand, and enough cement paste and sand to fill the voids in the aggregate, care being taken to provide an excess of cement paste sufficient to coat all the particles thoroughly.

The voids in aggregate and sand may be determined approximately either by direct measurement or by computations based upon the specific gravity of the material and the weight of a unit volume of the particles. 
Proportioning concrete by the direct measurement of voids can be carried out as described below, but for various reasons which will be afterwards mentioned, the method cannot be relied upon for accurate results.

The mode of procedure is as follows-Take a vessel of ascertained capacity ; fill it with the aggregate to be used, shaking down and levelling the material at the top of the vessel ; add water from a vessel containing a known volume until it reaches the upper surface of the aggregate in the vessel. Then by deducting the volume of water remaining in the vessel from the original volume therein, we can find the volume of water used in filling the voids in the aggregate. Therefore, an equal volume of sand should be added with the object of filling the voids. The voids in the sand can be ascertained in a similar manner, the volume of water added being an index to the volume of cement paste necessary to fill the voids in the sand.

A more accurate method of determination is to weigh a given volume of the material, whether aggregate or sand, and from the weight so ascertained to calculate the weight per cubic foot. Then if the specific gravity of the material is known, it is easy to compute either the volume or the percentage of voids.

In any event, the method of proportioning concrete by voids gives results that are only approximately correct. Thus, the percentage of voids in the aggregate varies considerably with the compactness of the material as affected by manipulation when it is being filled into the measuring vessel, and the percentage of voids in the sand is greatly affected by variations of moisture. Moreover, it is impossible to drive out all the air when water is poured into aggregate and sand, and so further errors arise. Again, it does not follow that the actual volume of voids in the aggregate will correspond with 
the quantity of sand required to fill the voids, principally because the grains of sand tend to thrust apart the particles of aggregate, while some proportion of the sand is usually too coarse to fit into the spaces between the particles of aggregate. Further complication arises from the fact that the cement paste covering the grains of sand virtually increases their dimensions, and thereby tends to increase the voids, a similar tendency being due to the superficial tension of the water used.

Bearing all these disturbing factors in mind, it is necessary to provide an excess of at least 10 per cent of cement paste in the sand, and an excess of at least 10 per cent of cement paste and sand in the aggregate, to provide for contingencies.

Proportioning by Trial Mixtures. A comparatively simple and reliable method of proportioning concrete is based upon the examination of trial mixtures. Briefly described, the method consists in placing a defined weight of several mixtures, one at a time, in a cylindrical vessel, tamping the concrete, and noting the height of the upper surface. After the first mixture has been dealt with the cylinder is emptied, cleaned and used in the same manner for the trial of any required number of mixtures. In this way it is easy to find proportions giving the lowest height of concrete in the cylinder. the mixture giving the lowest height evidently possessing the greatest density.

The materials employed in mixing the concrete should be carefully weighed on an ordinary pair of scales, and the cylindrical vessel can be formed by closing one end of the piece of iron or steel tubing, a convenient size being from 9 in. to 12 in. diameter, and from 12 in. to $15 \mathrm{in}$. high. Tamping should be performed in as uniform a manner as possible, in order to reduce to a minimum any variations due to the human element. 
Proportioning by Arbitrary Standards. A method often adopted for settling the proportions of concrete to be used in different classes of work is to select one or other of the mixtures recommended in some handbook or code of regulations. This method is a very convenient one, although leading to wide discrepancies in results owing to differences in measurement of the materials. For instance, concrete ostensibly mixed by one contractor in the proportions of 1 part of cement, 2 parts of sand, and 4 parts of aggregate by measure, may be no better than a batch of concrete produced by another contractor who has measured the materials in the proportions of say, $1: 3: 6$.

The reasons for so anomalous a result are due to variations of packing and measurement of cement, and to variations in the nature and grading of the sand and aggregate. Experience shows that the actual weight of cement placed in a gauge box of one cubic foot capacity depends very much upon the ingenuity of the man engaged in the operation of filling in the cement. The weight of cement per cubic foot may be reduced to less than $70 \mathrm{lb}$. by ingenious filling, and it is quite easy in this way for a clever man to save a couple of hundredweights of cement a day. On the other hand, cement may be packed so closely in the gauge box as to bring the weight up to $120 \mathrm{lb}$. per cubic foot. These figures show a range of over 70 per cent in the quantity of cement instead of the uniformity supposed to be given by the prescribed method of measurement.

The influence of the sand and aggregate is clearly indicated by variations in the quantities of material required to produce one cubic yard of concrete of any given mixture. Such variations depend upon the nature of the materials selected and the percentages of voids 
in the sand and aggregate, and show that the adoption of an arbitrary standard is not advisable in general practice. The resulting concrete may happen to fulfil requirements satisfactorily, but it may be of less than the anticipated strength and dangerously porous, or, on the other hand, may involve the use of a larger amount of cement, and greater cost than would be found necessary under a more scientific method of proportioning concrete.

Proportioning by Mechanical Analysis. This is an extremely scientific method devised by Mr. W. B. Fuller and Mr. Sanford E. Thompson, two American engineers who have devoted much study to the correct proportioning of concrete.

Mechanical analysis is performed by separating the particles of a sample of aggregate, sand or cement into the various sizes of which it is composed, so that the results can be plotted in a diagram to form a curve, each ordinate of which is the percentage of the weight of the total sample passing through a sieve having holes of a diameter represented by the distance of the ordinate from the origin in the diagram.

The objects of mechanical analysis curves, as applied to sand and aggregate for making concrete are (1) To show graphically the sizes and relative sizes of the particles, (2) To indicate what sized particles are required to make any given mixture of sand and aggregate more nearly perfect, and so to enable the engineer to improve the mixture by the addition or substitution of other sizes of particles, and (3) To provide data for determining the best proportions of different kinds of sand and aggregate.

Practical experience shows that the best possible mixture of cement, sand and aggregate is one giving a mechanical analysis curve which is of parabolic form, 
and representing the combination of a curve approaching an ellipse for the sand, and a tangential straight line for the aggregate. The ellipse extends to a diameter equal to one-tenth the diameter of the maximum size of the particles of aggregate, and beyond this point the aggregate is to be graded uniformly.

Mechanical analysis diagrams afford very precise means of determining the best proportions of any materials for concrete by sieving each of the materials, plotting the analyses and combining the curves, so that the result is a curve as nearly as possible similar to a curve denoting maximum density. The proportions of the different materials required to produce the new curve will show the relative quantity of each material which must be used for the concrete mixture.

The method is particularly valuable, not only as a means of ascertaining the best proportions in which the sand and aggregate should be mixed, but also for the purpose of showing how a given kind of aggregate may be improved by increasing or decreasing the proportion of one or more particular sizes of particles.

Mechanical analysis of the materials can be made from time to time during the progress of any work or contract, so as to indicate whether or not the sizes of the particles of the sand and aggregate have changed to any appreciable extent, and in that event to give an index to the manner in which the proportions should be adjusted to maintain the most suitable conditions for efficiency and economy.

In analysing any given sample of sand or aggregate, the different sizes are separated by screening the material through successive sieves of progressively increasing fineness. After sieving, the residue on each sieve is carefully weighed, and commencing with that which has passed the finest sieve, the weights of the sifted 
material are successively added, so that each sum will represent the total weight of the particles which have passed through a certain sieve. The sums so obtained are expressed as percentages of the total weight of the sample, and plotted on a diagram with diameters of the particles as abscissæ and percentages as ordinates. As it would not be appropriate in a book of this kind to discuss at length the method of plotting and combining mechanical analysis curves, those desiring further information are referred to a paper in the Transactions of the American Society of Civil Engineers, entitled "The Laws of Proportioning Concrete," where Mr. Fuller and Mr. Thompson discuss the subject at considerable length, and in full detail.

The apparatus necessary for a mechanical analysis consists of a special set of sieves, and a pair of balances for weighing. The sieves are $8 \mathrm{in}$. in diameter by 21 in. in height, the number and sizes used being dependent upon the importance of the tests. In ordinary practice the series of sieves of which particulars are given in the subjoined table are recommended for average laboratory work.

Sieves for Mechanical Analyses

\begin{tabular}{|c|c|c|}
\hline $\begin{array}{l}\text { Sieves for } \\
\text { Aggregate }\end{array}$ & \multicolumn{2}{|c|}{ Sieves for Sand. } \\
\hline $\begin{array}{l}\text { Diameter of } \\
\text { Holes. }\end{array}$ & Commercial No. & Diameter of Holes. \\
\hline 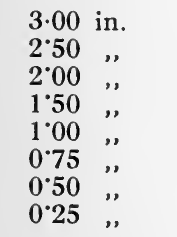 & $\begin{array}{cc}\frac{1}{4} \text { in. round } \\
\text { No. } 7 \\
\Rightarrow \quad 12 \\
\Rightarrow \quad 20 \\
", \quad 30 \\
\Rightarrow \quad 50 \\
" \quad 90 \\
\Rightarrow 200\end{array}$ & $\begin{array}{l}0.1 \overline{11} \text { in. } \\
0.056 \quad ", \\
0.0335 \quad " \\
0.0198 \quad " \\
0.0120 \quad " \\
0.0059 \quad . \\
0.0029 \quad "\end{array}$ \\
\hline
\end{tabular}


While the mechanical analysis method may appear to some of our readers as an unnecessary refinement, it clearly deserves mention in this book. A convincing proof of the practical value of the method is furnished by the fact that it has been employed by Mr. Fuller in important engineering construction for determining the proportions of concrete used in the construction of thin watertight walls, the proportions adopted having been about $1: 3: 7$, whereas for watertight concrete where the materials are proportioned by ordinary methods $1: 2: 4$, or richer mixtures are always found to be necessary. 


\section{CHAPTER IV}

\section{MIXING CONCRETE}

THE operations coming under the general head of concrete mixing, and including suitable and necessary preparation of the constituents, are in every way as important as the establishment of correct proportions.

In this chapter we will discuss preparation of the materials, mixing by hand, and mixing by machine.

Preparations of Materials for Concrete. In former times when cement manufacture had not fully attained its present high standard, it was customary to aerate cement before using it on important work, by spreading out and turning over the material in order to assist hydration of the free lime present. In the case of the best qualities of modern Portland cement the process of aeration is not only unnecessary, but causes a distinct loss of strength. Where large stocks of cement have to be held, they should be stored in bulk, rather than in bags or other packages allowing the access of air. The results of an investigation recently made at the Lewis Institute, Chicago, show that cement stored in bags for three months may lose 20 per cent of its original strength, and that it continues to suffer loss, though in a diminishing ratio, with continued storage. The tests did not include any on bulk storage, which appears to have no appreciable effect on the strength of cement.

Sand and aggregate frequently, if not always, contain silt, clay, earthy matter, or stone dust, which can only be removed by washing. Various methods of performing this operation are in general use, among them being : (1) washing the material down an inclined trough, having stationary screens in the bottom, through which water 
and impurities are carried off ; (2) washing by throwing the material on a vibrating screen, either suspended in water or subjected to a constant stream of water ; (3) washing in a rotatory drum, or a stationary drum fitted with a screw conveyor, the material travelling up a slight incline and meeting a downward stream of water. A simple form of screw conveyor washing apparatus is represented in Fig. 9, water being admitted at the upper end, and the sand or aggregate shovelled

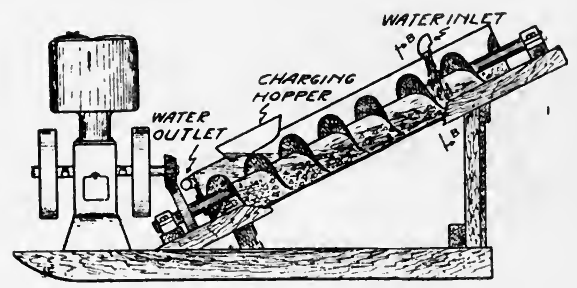

FIG. 9 . SAND WAȘHER

into a charging hopper near the lower end. By revolving the screw, the material is carried to the upper end and ejected after having been thoroughly washed by the water encountered in transit.

Sand and aggregate can be screened by hand, shovelling the material against an inclined screen, by hoisting and delivering the material by mechanical appliances upon an inclined screen, or by placing the material in a revolving screen operated mechanically. In modern practice the careful screening of the sand and aggregate into various sizes is an essential preliminary to the production of scientifically proportioned concrete.

From inscriptions on Egyptian monuments, supposed to have been made about 4000 B.C., it seems probable that sieving was practised long before the existence of 
human records. The screens used by the Greeks and Romans about 150 B.c. had meshes of hide, reeds or hair, and it was not until the fifteenth century that wire screens were introduced. Fig. 10 is from a quaint illustration in a work written by Agricola, and published in 1556. The man in the foreground is working a one-man sieving machine, while in the background

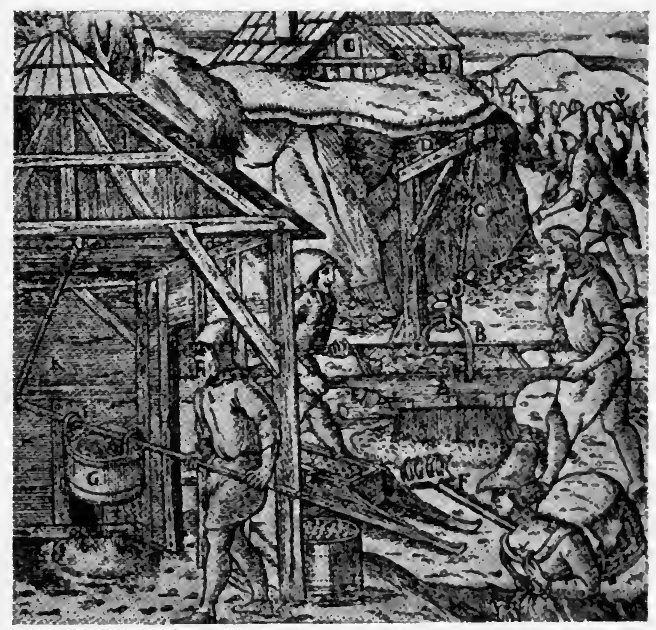

FIG. 10. EARLY SCREENING APPARATUS

two men are using a sieve suspended at the centre, this being an early type of the modern shaking screen.

In order to' avoid the wasteful rejection of pebbles, or fragments of stone, which are of larger size than the maximum permitted by specification, stone breaking machines are generally employed, although breaking is frequently done by hand, a method which is very expensive in the present condition of the labour market, 
although the results are better than those given by a machine because crushing effects are absent. The best stone breakers are constructed so as to reproduce hand breaking as closely as possible. Machines of this class are provided with two jaws brought together so as to strike a sharp blow upon the stone to be broken. Other machines known as stone crushers, tend to fracture and to pulverize the material, the dust produced being prejudicial to the concrete unless removed by suitable means.

In contracts where concrete is employed on an extensive scale, more or less elaborate plant is laid down for the preliminary treatment of sand and aggregate, so as to make the most efficient and most economical use of these materials.

Mixing by Hand. Being apparently an exceedingly simple matter, the mixing of concrete often receives much less attention in the way of supervision than is desirable, and inefficiency sometimes passes unobserved in consequence. Three points deserving special attention are the exact measurement of the materials, the thorough mixture of the cement and sand, and the addition of no more water than is necessary to produce a plastic consistency.

The materials, after careful measurement, are mixed on a timber "board" or platform, varying in size from $10 \mathrm{ft}$. to $20 \mathrm{ft}$. square, according to the extent of the contract, and if mixing has to be carried on for some time, it is good policy to cover the platform by a thin sheeting of iron or zinc, thus protecting the wood, preventing leakage of cement grout through joints, and providing a surface conducive to easy and thorough shovelling. The platform should be situated close to the place where materials are stored, and as near as possible to the site where the concrete is to be used. 
A simple method of measuring sand and aggregate is to fill them into bottomless boxes, one for each material, and of the capacity for one batch of concrete. An ordinary cement barrel with both heads removed and fitted with handles, makes a convenient measure for aggregate; and half or part of a similar barrel can be used for measuring sand. The measure is placed on the mixing platform, filled with sand or aggregate, as the case may be, and then lifted off, leaving the material behind. It is wise to proportion the cement by weight, owing to variations in the actual quantity of cement filled into a measure of any given volume. Water should always be measured in a bucket or other vessel, and not applied by a hose, as this method leads to variable consistency, and tends to wash away the cement and sand from the coarse material.

Sand should first be measured and spread out on the board in a layer of even thickness, the measured cement should next be distributed over the surface of the sand, and the whole turned over dry until thoroughly mixed. The measured aggregate should then be thrown on, and all three materials turned over three or four times dry, and for a sufficient number of times after the addition of water, which can be added most conveniently and suitably by a watering can with a rose-head, filled from the measuring bucket or vessel.

Some contractors mix concrete by measuring the aggregate on the board first, afterwards separately adding the measured sand and cement. This method, however, is not quite so economical as that first described. Another method is to measure the aggregate on the mixing board, then to measure and mix the sand and cement, and finally to shovel on the resulting mortar and mix it with the aggregate. This method is still less economical than the second one. 
Whatever may be the details of the procedure adopted in hand mixing, the most careful inspection is always necessary to ensure thoroughly mixed concrete.

Mixing by Machine. When the work to be executed is of sufficient magnitude to justify the cost, concrete can be mixed far more economically by machine than by hand. As previously stated, machine-mixed concrete is nearly always stronger than that prepared by hand, owing to the more thorough incorporation secured. The economy of concrete mixing plant is due as much to the auxiliaries employed for dealing with the raw materials as to the saving of labour by the mixing machine itself. The selection and arrangement of the appliances for handling the materials, and to a limited extent the selection of the type of mixer, depend upon local conditions, the amount of concrete required daily, and the magnitude and consequent duration of operations.

Fig. 11 is a view of a concrete mixer as installed for the construction of the Royal Liver Building, Liverpool. The machine was one of the Ransome-ver-Mehr type driven by an electric motor, and capable of turning out 4,000 cubic feet of concrete per day of nine hours. It was arranged with a staging at the back of the charging hopper, approached by two inclined barrow runs, up which sand and aggregate were conveyed from storage compartments, the cement being delivered on the staging itself. An automatic tank connected with the city mains provided for the correct supply of water for each batch of concrete. With this compact plant there was no difficulty in obtaining upwards of 200 mixings of 20 cubic feet each in a day of nine hours, the concrete produced having been most uniform in consistency and satisfactory in every way.

In the execution of important public works involving 


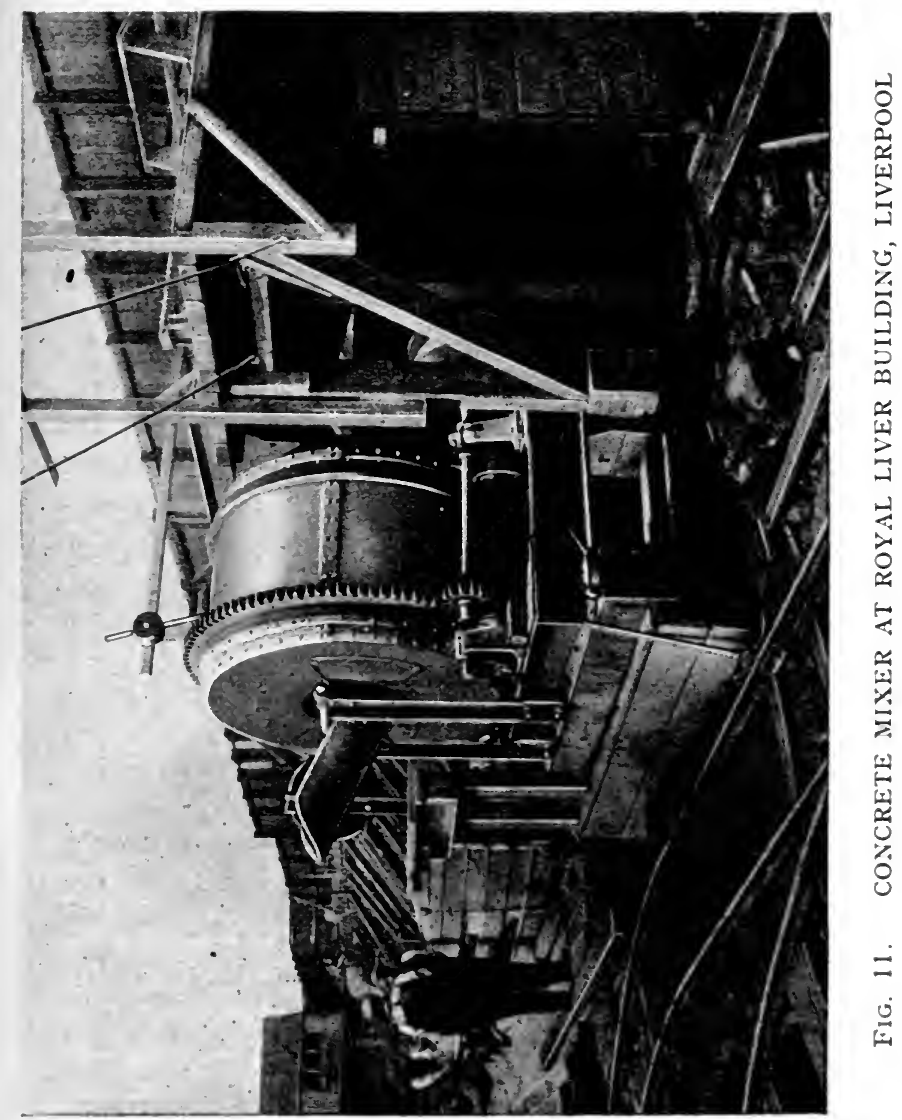


large quantities of concrete, the contractor will find it remunerative to make free use of laboursaving appliances, while in contracts of modest dimensions the mechanical equipment should be of the simplest proportions consistent with satisfactory results.

Concrete mixers naturally fall into one of two general classes-continuous mixers and batch mixers. In those of the former class, the materials are inserted more or less continuously, either by shovelling or by the aid of automatic measuring appliances, and the concrete is discharged from the outlet in an ever-flowing stream. In those of the latter case, the body of the machine is of capacity suitable for the reception of the materials required to produce one batch of concrete at a time. Having been charged, the machine is set in motion, and after thorough mixing the whole batch of concrete is discharged. It should be mentioned that some of the machines on the market are arranged for use either as continuous or as batch mixers. Therefore, the user has a choice of methods open in the case of such machines.

Speaking generally, continuous mixing is not to be recommended unless the materials are measured and added by automatic mechanical auxiliaries. If the materials are measured by hand, and shovelled into the machine while mixing is in progress, variations are almost certain to occur in the proportions, and the concrete will not be of the required uniformity. In the case of batch mixing, all the materials, first definitely measured, are placed in the drum, or receptacle, and there can be no mistake about the propor tions. The uniformity of the concrete then depends upon the efficiency of the machine used and the length of time during which it is in operation. 
So far as design and construction are concerned, concrete mixers are made in varied types. The rotary mixer, a general type adopted by many leading makers, consists essentially of a drum or receptacle in which the materials are shaken together and turned over and over, the process of mixing being aided by deflectors or projecting blades attached to the sides of the receptacle. The paddle type of mixer is one with a stationary drum or trough fitted with one or two revolving shafts, to which paddles are attached for churning up the materials. The gravity type of mixer is one where the materials are mixed by being thrown from successive baffle plates as they descend from the top to the bottom of the apparatus, or where they are mixed by flowing through successive hoppers.

Concrete mixers are made in so many varieties, for operation by hand or by power, that it would take too much space to describe examples even of the best known makes, and it would be a somewhat invidious task to select one or two machines as examples. Therefore, the reader who wishes to obtain detailed information on the subject is referred to the fully descriptive catalogues issued by all manufacturers of concrete mixers and auxiliary appliances.

Precautions in Machine Mixing. The following are some points of special importance-(1) The materials fed into the mixers must always be strictly in accordance with the specified proportions; (2) While sufficient water should be used to produce the required consistency an excess of water must be carefully avoided, or the concrete will not attain the strength contemplated by the designer; (3) The process of mixing must be continued long enough to make sure that the ingredients are thoroughly incorporated. The time allowed in a rotary mixer, measured from the completion of filling 
to the end of mixing, should be not less than one minute, and experience shows that a longer period of mixing will improve the quality of the concrete in respect of strength, and at the same time result in a smoother mixture even with less water; (4) The entire contents of the drum should be removed on the completion of each batch in the case of a batch mixer, and the interior of the mixer should be rinsed out as may be necessary to prevent any set or practically set concrete from adhering to the sides.

Concrete Mixing Plants. In - very small contracts, particularly where hand mixing is adopted, the installation of plant for the preparation of concrete is of extremely simple character-sometimes so simple, in fact, that there is nothing meriting the name of plant to be installed. Sand and aggregates are delivered in heaps near the mixing platform, cement is stored in any convenient shed or temporary shelter. The materials are washed and screened, as necessary, and either shovelled directly into the measuring boxes on the mixing platform, or wheeled there in barrows ready for shovelling into the boxes.

In large contracts, the arrangement and nature of the plant for handling raw materials is quite as important from the standpoint of economical production as the concrete mixing machinery. The design of a concrete making plant is governed by the nature of the work to be executed, and by various local conditions. Where large quantities of sand and aggregate have to be received, stored, washed, screened, and graded before conveyance to the mixers, a good deal of preliminary outlay may be justifiable in the provision of storage bunkers, runways, gangways, conveyors, hoists, trucks, and the like. Everything possible should be done to minimize hand labour, and to economize motive power 
by laying out the plant so that the materials, concurrently with their preparatory treatment, travel progressively by the shortest possible route from the point

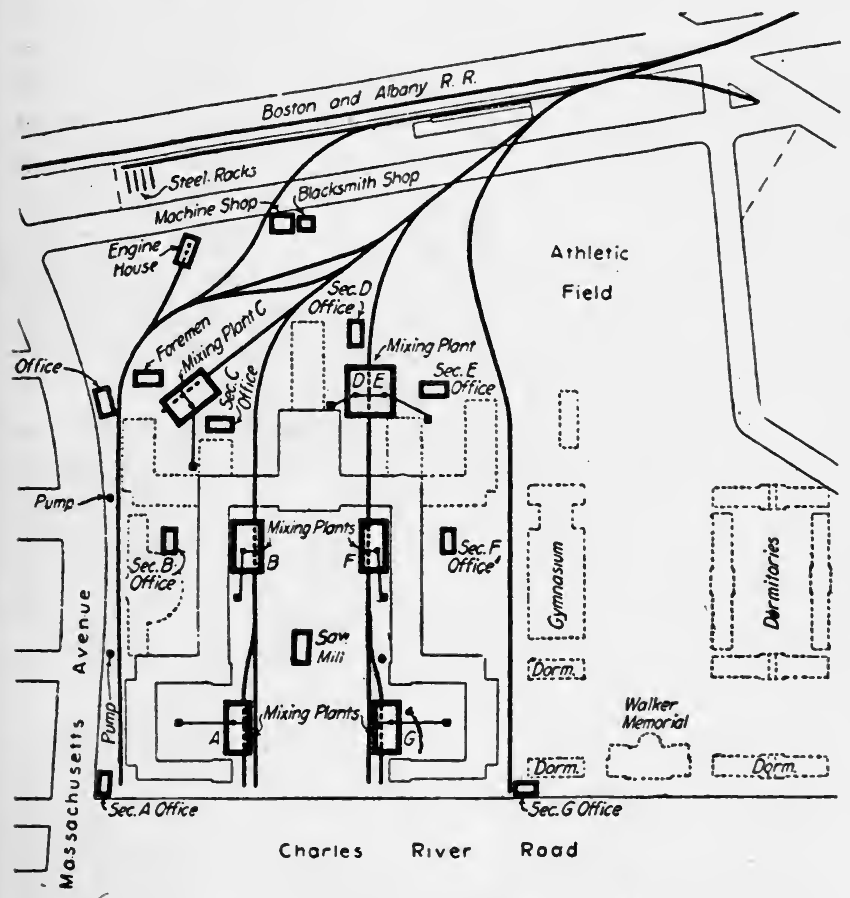

Fig. 12. PLAN OF CONCRETING PLANT AT MASSACHUSETTS INSTITUTE OF TECHNOLOGY

of reception to the mixing machine-their ultimate destination "while in the form of raw materials. In a word, the concrete-mixing department should be planned and operated very much on the lines adopted in a thoroughly up-to-date factory, and the now familiarr 
methods of mass production should be followed as closely as may be practicable and appropriate.

A typical installation is illustrated in Fig. 12, which is a plan of the contractors' plant used in erecting the new buildings of the Massachusetts Institute of Technology, Boston, U.S.A. Materials were delivered on the site by the Boston and Albany Railroad, and conveyed direct to the various concrete mixing plants by means of elevated contractors' lines carried on timber viaducts. Sand and gravel were discharged into pits with a capacity of 300 cubic yards for sand, and 400 cubic yards for gravel, and cement was stored in sheds, one for each section. The concrete mixers were installed in pits so that the materials could be run in by gravity. Mixed concrete discharged from the machines was conveyed by trucks to hoist towers, and thence distributed to the required points. 


\section{CHAPTER V}

\section{DEPOSITING MIXED CONCRETE}

FrESHLY mixed concrete should be transported to the point where it is to be used and deposited in place without any avoidable loss of time. If the concrete is not deposited promptly, the larger particles may become separated from the sand and cement, and if the cement begins to set before the concrete has been put in place, there may be a considerable loss of strength.

Concrete in small quantities is usually transported from the mixer in ordinary wheelbarrows or in twowheeled barrows of special design, now made for the purpose by most manufacturers of concrete machinery. In large works the concrete is very generally distributed in trucks running on contractors' lines serving the various points where operations are in progress. Cableways, gantries, hoists, and derricks have been extensively applied to the distribution of concrete, and the employment of hoisting towers in conjunction with gravity shoots-constituting what is known as the gravity system of distribution - has been widely adopted in the United States, although only rarely applied in this country. For use in connection with transportation plant many ingenious types of cars and buckets are available, being constructed so that the concrete can be discharged expeditiously by opening at the bottom or one side, or by means of discharge valves under ready control.

A particularly interesting and novel form of concrete construction plant was installed a few years ago in London by the contractors for H.M. New Stationery 
Office (temporarily converted for use as the King George Military Hospital). As the building consists entirely of reinforced concrete, covers an island site about two acres in extent, and rises to a height of $70 \mathrm{ft}$. above pavement level, it will readily be understood that very large quantities of concrete had to be dealt with, and that the execution of the work offered ample scope for the employment of distribution plant on an extensive scale.

In this particular case, the contractors decided to make use of steel gantries commanding the whole site. Similar gantries are generally employed in modern shipbuilding yards, but had not previously been adapted to the needs of concrete building construction. One reason which led to their evolution in the Stationery Office contract was the small amount of open space on the site for ordinary erection plant, and the virtual absence of exterior space for hoisting appliances. The members of the framework were made interchangeable, so that after the completion of the work the gantries could be taken down and re-erected in entirely different forms to suit the requirements of subsequent building contracts.

The gantries comprised a series of latticed towers connected by longitudinal and transverse girders of the same type. The towers were bolted down to concrete foundation blocks, and rose to a height of $86 \mathrm{ft} .9$ in. above foundation level. Rails were laid on the longitudinal girders for the operation of overhead electric travelling and traversing cranes by means of which the whole area was commanded and supplied with concrete and other materials. Thanks to these gantries it was possible to transport materials over freshly-laid concrete without the slightest risk, their range of action was infinitely greater than that of 
derricks, the use of contractors' lines, barrows, and trucks was entirely obviated, and building operations were conducted both economically and expeditiously The concrete mixing plant at ground floor level

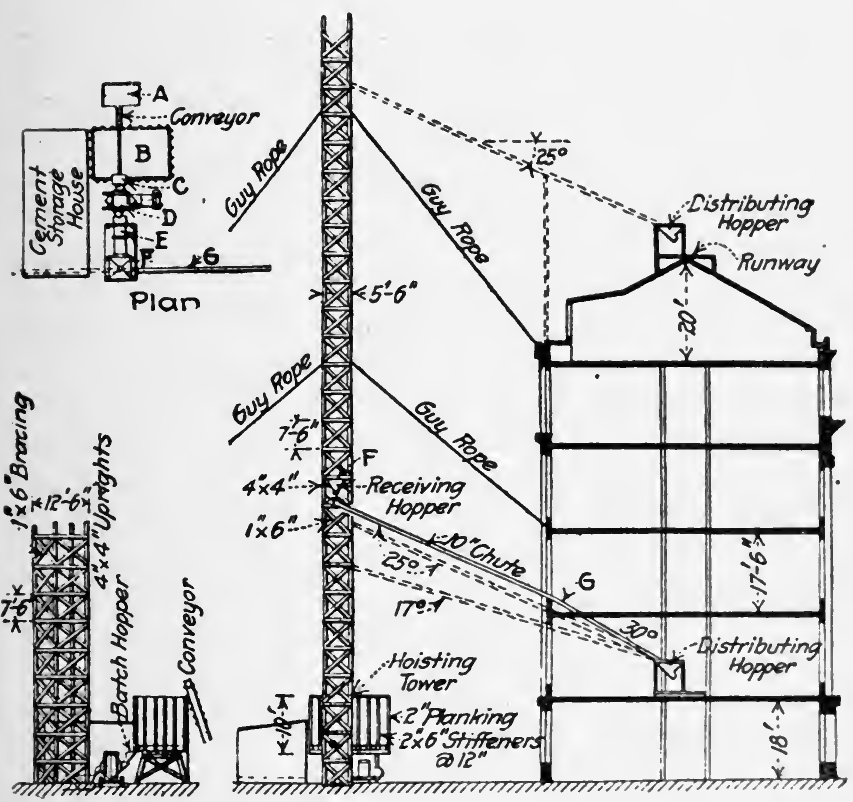

FIG. 13. GRAVITY CONCRETING PLANT AT THE U.S.A. BUREAU OF ENGRAVING AND PRINTING

comprised three Ransome electrically driven machines and all necessary auxiliaries.

Engineers and contractors in this country do not generally favour the practice of distributing mixed concrete by means of gravity plant, their principal 
objection being due to a fear that the materials may become separated, or unmixed, during transit. American engineers and contractors, on the other hand, contend that if suitable proportions are adopted, and if the concrete is properly mixed and of appropriate consistency, thoroughly reliable work can be secured by the employment of gravity plant for the transportation and deposition of concrete.

Fig. 13 is a diagram of the concreting plant used in building the U.S.A. Bureau of Engraving and Printing; a block $505 \mathrm{ft}$. long by $300 \mathrm{ft}$. wide by five storeys high. All concrete was prepared and handled by duplicate plants in two courts of the building. Each plant comprised a concrete mixer, construction tower, hoist and gravity shoots. The method of distribution is illustrated by the diagram. Sand and gravel were stored in pit $A$, transferred by a conveyor to bin $B$, measured in the hopper $C$, where cement was added, and the whole discharged into the mixer $D$. Mixed concrete was delivered into the bucket $E$, hoisted to the requisite height, and automatically tipped into the hopper $F$, passing thence into the shoot $G$ for distribution by secondary shoots or by barrows to the required points.

The makers of such plant claim that its success depends very largely upon the proper mixing of the concrete before it is filled into the hoisting buckets. The concrete should be a plastic, viscous, homogeneous mass, not so dry as to prevent it from readily levelling off on top, and a piece of stone placed on the upper surface should neither stand out nor sink in much below its own thickness, but should float freely. On no account should the mixture be "sloppy wet," as such a consistency allows the heavier particles to sink both during transport and after deposition. 
It is better, in any case, to have the concrete rather on the dry side than too wet. If too dry to flow readily, the quality of the work will not suffer, but the shoots will have to be at a greater angle with the horizontal, and their radius of action will be proportionately reduced with a distribution tower of given height.

A typical concrete gravity plant consists essentially of a steel tower, up which the mixed concrete is hoisted in buckets of special design; a receiving hopper, generally placed near the top of the tower, or two or more hoppers at different levels; and a series of gravity shoots, fed by the hopper and employed in conveying the concrete to the required points. The precise constitution of the plant for any given work is varied so as to comply with local conditions. The steel tower is built up of interchangeable sections, usually $20 \mathrm{ft}$. in length, and carried up to a suitable height. In average practice $200 \mathrm{ft}$. is considered a maximum height, although towers have been built higher in exceptional cases. The hoist bucket is mounted on a frame and arranged so that it automatically comes under the outlet from the concrete mixer on arriving at the bottom of the tower and is automatically emptied into the hopper at a predetermined elevation, or automatically discharged at any level in cases where two or more hoppers are provided on the tower. The hopper into which the concrete is discharged by the hoisting bucket is strongly built of steel plate, it is provided with clamps for attachment to the tower, and is fitted with a watertight discharge valve. If desired, the hopper can be attached to a sliding frame, permitting the level of the hopper to be quickly changed from one point to another in the tower. The gravity shoot fed from the outlet valve at the bottom of the hopper can easily be made of any length permitted by the height of the tower 
and the slope necessary for the ready flow of the concrete. All horizontal shoot sections are egg-shaped, open at the top, and vertical sections are circular. Two standard types of horizontal shoot are made, (1) with swivel-head connections, and (2) with continuous-line connections. The swivel-head shoot has a round hopper head at the upper end, and a projecting swivel plate at the lower end. When assembled, the swivel head of one section is suspended by a hook and cross bolt from the swivel plate of the section above. The continuous-line shoot has a sleeve connection with chains and keys for engaging rings on the sleeve. It will be understood that many variations of these two standard types can be made to suit local requirements.

It may be well to state that the success of gravity plant depends not only upon the use of correctly proportioned and well mixed concrete, but also upon the proper design, arrangement and operation of the plant. The slope of the shoots must be such that the concrete will flow in a uniform, continuous stream, always under perfect control. The shoots must be kept clean by running water down them whenever operations cease, even for a short time, and they should be thoroughly wetted before work is resumed after a short stoppage. Gravity plant is best suited to works where large quantities of concrete are required in the immediate vicinity of the mixing machines, and is not to be recommended for small items of work scattered over relatively wide areas.

A novel method of depositing fine concrete, cement mortar, or cement grout is one in which the cement gun is employed, this appliance being in reality a spraying machine operated by compressed air. The materials previously mixed dry are placed in the hopper provided, 
and the machine delivers the mixture, through an airlocking device and hose, to a nozzle where water is automatically added, the concrete or mortar being sprayed upon the surface to be covered with force sufficient to produce a dense, hard and durable coating of any required thickness.

The procedure adopted in depositing concrete in ordinary construction work is necessarily subject to variations conformable to the consistency of the material. For instance, in former times when concrete of dry consistency was generally used, it was usually specified that the material should be deposited in 6 in. or 8 in. layers, well rammed, and each allowed to set before the addition of the next layer. In the present day, with slow-setting cement and moderately wet mixtures, it is permissible to deposit concrete continuously to any thickness so long as it is properly consolidated as the work goes on.

Concrete of dry consistency should never be tipped or thrown from a height, as there is a distinct tendency for the larger particles to become separated from the mass. Moderately wet mixtures exhibit the same tendency when poured or dropped vertically but not to the same extent as dry mixtures. In the case of thin walls or parts requiring special care, the concrete should be shovelled into the moulds and carefully spaded next to the boards where the surface will ultimately be exposed to view. The operation known as spading consists in working a flat spade up and down the inner face of the mould, thus pushing the aggregate slightly back and allowing the cement and sand to flow against the boards where they will form a good surface to the finished work.

It is always desirable to make the concrete deposited as compact as possible by forcing out bubbles of air. 
With this object in view the material is tamped or rammed by suitable tools. For dry and medium mixtures a rammer very similar in shape to that employed in street paving can be used for general purposes, while for very wet mixtures, in which excessive ramming may force the finer material and cement to the top, a specially light form of tool is the most suitable.

In reinforced concrete work, it is very important that the concrete deposited should find its way to every part of the moulds, and between all the bars and meshes of the reinforcement. This end may be attained by the aid of rods poked through the wet concrete after deposition. An alternative method is to make use of pneumatic hammers, applied to the outside of the moulds or shuttering, the vibration set up having the effect of liberating confined air and of promoting the consolidation of the entire mass. This ingenious device was adopted with perfect success in a concrete shipyard at Shoreham, where the hulls of the vessels under construction were reinforced with rods and sheets of expanded steel, and the concrete was very thin. Consequently, ordinary methods of tamping and ramming would have been quite out of the question.

In many classes of construction it is highly important to make concrete work thoroughly monolithic. For instance, in the case of water reservoirs, tanks, swimming baths, ships and floating structures, there must be no risk of percolation at joints or along lines where the execution of work has been interrupted during meal times or at the end of the day. Sometimes it is practicable to employ two or three shifts of men, in order to make it possible for concreting to be continued without interruption. Where such procedure is out of the question, the old concrete, or that which has already set, must be thoroughly cleaned, roughened where 
necessary, wetted and coated with cement grout before the deposition of fresh concrete is resumed. Where mass concrete, subject to compressive stress alone, is in question, and the risk of percolation need not be taken into account, the only precaution necessary is the cleaning of the old concrete before the addition of new material.

Mixed concrete frequently has to be deposited under water, an operation demanding special precautions because if the material were discharged above the surface and allowed to sink to the bottom, most of the cement would be washed away, and there would be left only more or less separated sand and aggregate with a quite insufficient remnant of the cement.

To obviate anything of the kind, concrete can be lowered through water in a closed bucket with doors opening automatically at the bottom, or in a skip arranged to discharge its contents at one side. Concrete is sometimes deposited under water by means of a long tube, suspended by means of tackle, extending from above the surface to the bottom of the water, the upper end being provided with a hopper. The tube is filled with concrete, and kept full by successive additions, the concrete being allowed to flow out by hoisting the tube slightly as the work proceeds. Another method occasionally adopted is to deposit concrete in bags which are left in position, a rough and ready expedient rarely entering into modern practice.

In the execution of important subaqueous works in concrete, various methods are available which do not involve the deposition of fresh concrete below water. One method is to construct a cofferdam around the site, pumping out the water, and depositing the concrete in moulds or shuttering exactly as would be done on land. Another method adopted in the case of heavy 
pier construction is to mould large blocks of concrete on land and to lower them by means of powerful cranes upon a specially prepared bed, where the blocks are set by divers. Then, by the addition of successive

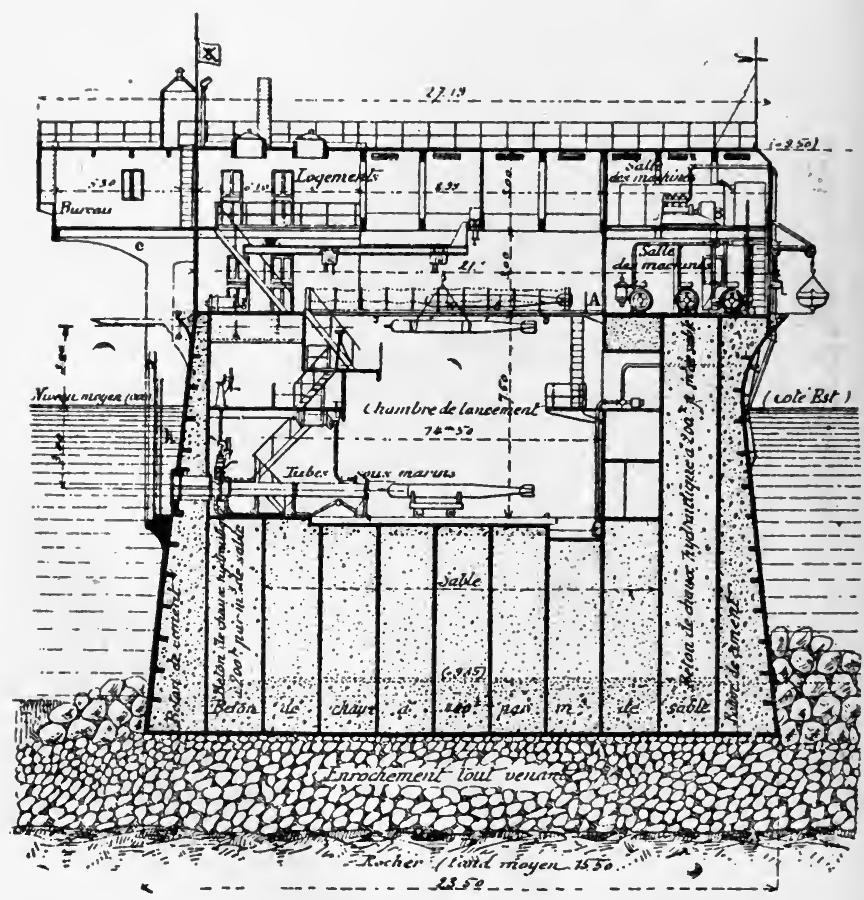

FIG. 14. BATTERIE DES MAURES. A NOTEWORTHY EXAMPLE OF CAISSON CONSTRUCTION

courses, all properly bonded together, the work is carried up above the surface of the water. A more recent method of executing subaqueous work is to construct reinforced concrete caissons on land which can be 
launched, towed into position, and sunk upon a prepared bed. Caissons have been employed in this way for forming bridge piers, the substructure of wharves and jetties, and in a few instances huge structures, intended

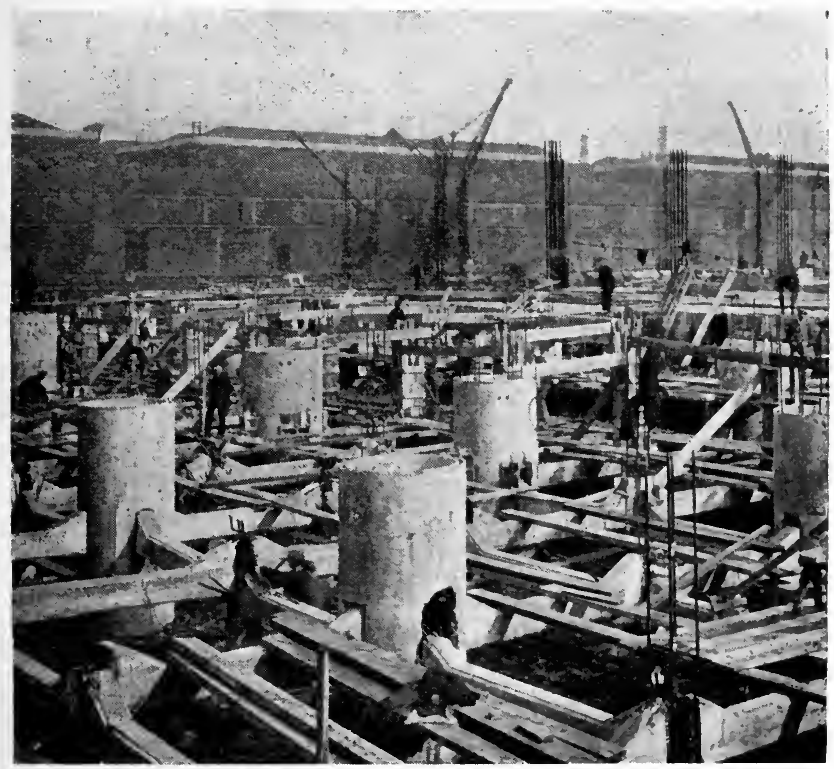

FIG. 15. CYLINDER PIERS WITH PRECAST BRACING

to be partially submerged in the sea, have been built completely on land, a noteworthy example being the torpedo testing station, known as the Batterie des Maures, illustrated in Fig. 14. Of late years also, the difficulty presented by the impossibility of bracing reinforced concrete piles and piers by ordinary methods of moulding and depositing concrete under water, has $5-(1+63 D)$ 
led to the employment of hollow cylinder piers prepared in advance on land, lowered into place, section by section, and connected up by filling concrete into the interior. The rigidity of piers so constructed is generally sufficient to obviate the need for subaqueous bracing. In cases, however, where such bracing is essential, it can be provided under the ingenious system patented by Messrs. Mouchel and Partners in the form of precast frames monolithically connected with sections of the cylinder piers (see Fig. 15), and the whole lowered into place. This method of executing subaqueous bracing work has been adopted in numerous marine structures with every success.

Embankments of shingle or broken stone deposited under water may be converted into mass concrete by pumping liquid mortar, composed of Portland cement and sand, into the interstices by means of pipes let down from the surface of the water. 


\section{CHAPTER V1}

MOULDS AND SHUTTERING

As concrete is deposited in a semi-liquid or plastic state on the site of the work to be executed, some means must be provided by which it can be formed and maintained in place until the material has finally set or hardened in the required shape.

The means necessary for this purpose vary widely, according to circumstances. For example, if it is desired merely to form a foundation bed in the ground, the concrete can be filled and rammed into an excavation the bottom and sides of which will suffice to retain the material, and to constitute the most simple form of mould. Again, where concrete has to be spread in the form of a slab upon the ground, or deposited in a mass above ground level, the surface of the earth can be utilized to support the concrete, but timber or metal shuttering, or some form of curb, must be provided along the edges so as to confine the material within required limits. Where the concrete has to be employed in more complex forms, such as columns, arches, beams, girders, trusses, framed structures and complete buildings, bridges, reservoirs or ships, the temporary falseworks or moulds for the reception and support of the concrete, until such time as it has set hard enough to carry its own weight, are of somewhat elaborate character according to the nature of the work to be executed. This point is exemplified by Fig. 16, which shows part of the extensive timber work erected for the construction of a long range of two-storey dock sheds at Manchester. 
5 The fundamental principle underlying the design of a mould, or connected series of moulds, for any concrete structure is very simple, and merely involves the formation of a matrix capable of imparting the required shape to the concrete deposited therein, and of sustaining the concrete so long as it remains moist and soft. The realization of this elementary principle in everyday practice may be quite an easy matter for the merest beginner, or, on the other hand, a task calling for the aid of a designer with scientific training and much practical experience.

Two courses are open for adoption in dealing with the design of moulds, shuttering, centring and other falseworks for concrete and reinforced concrete construction. One is for the engineer or architect, as the case may be, to design all details, and the other is to leave everything in the hands of the contractor. The second of these two alternatives is almost universally followed, and there is certainly justification for the practice, because the falseworks are in reality contractors' plant, and after having been employed on one contract, should be available for use on many succeeding contracts. If the timbering is designed and constructed so that it can be taken down with a minimum amount of incidental damage, the cost of the falseworks can be spread over several contracts, and the owner of the building or structure benefits accordingly. Of course, a serious responsibility falls upon the contractor in respect of safety, and in the design of falseworks for important works it is necessary that he should possess the necessary technical qualifications, or act under the advice of a qualified engineer.

Timber used in the construction of moulds and shuttering should be properly seasoned, neither too dry nor too green. Trouble may arise in the former case from 


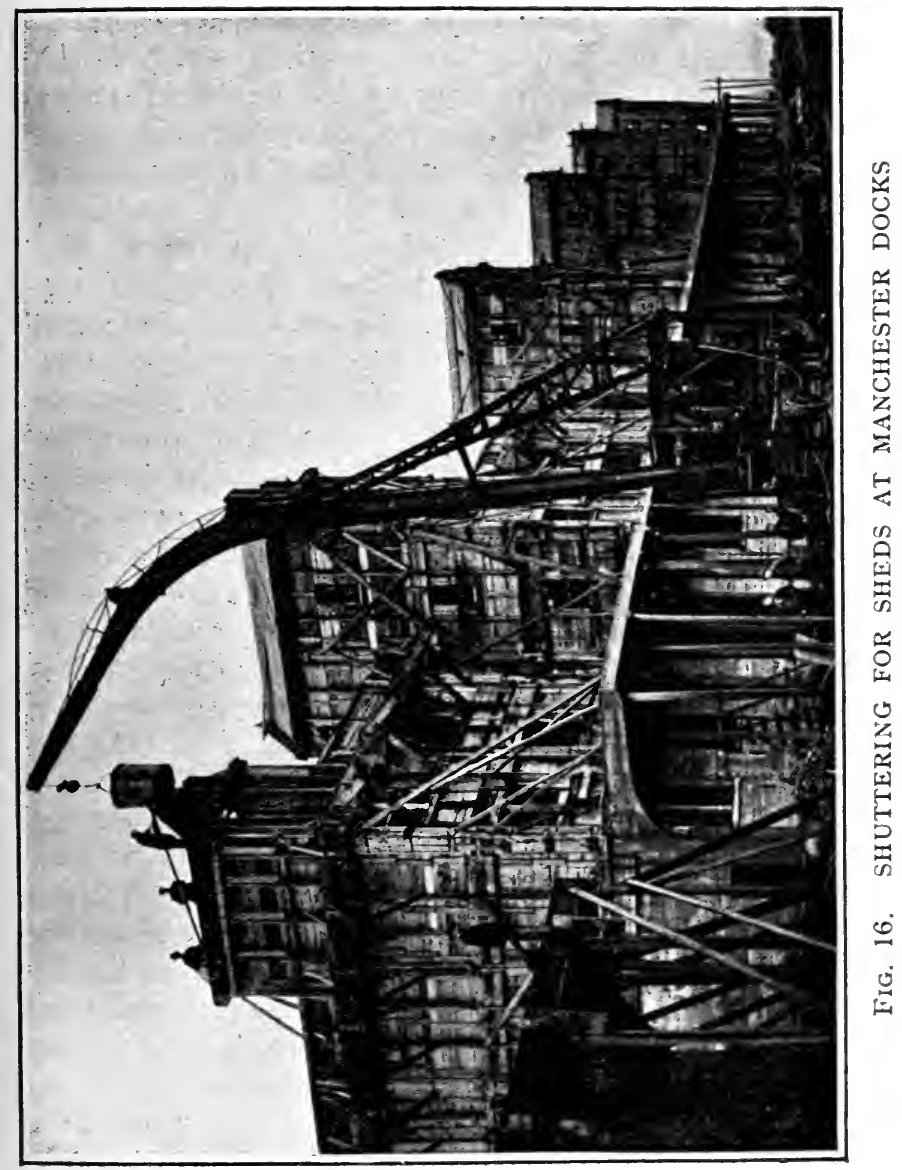


excessive swelling under the influence of wet concrete, and in the latter case leaky joints may give trouble, especially if the timber is of a variety which is not readily affected by moisture. All joints in facing boards must be close enough to prevent leakage, for if this takes place cavities may be left in the concrete.

Moulds and centring must be carefully aligned, and of rigidity sufficient to enable them to carry the wet concrete without suffering distortion. Struts and bracing must be applied to make the construction safe, and in open-air work, wind bracing is an important item. Considerable savings in timber and in the labour required for the erection and subsequent demolition of falseworks, can be effected by planning out all details beforehand in accordance with a well-considered scheme. As a rule, many of the moulds for beams, columns and other structural elements can be used repeatedly in different parts of the same contract, and if constructed so that they can be taken down without injury they are usually available, with suitable modifications, for succeeding contracts.

Nails should be sparingly used. It may not be easy to persuade an ordinary carpenter that wedges and clamps will hold the sides of a mouid together entirely without nailing. But the effort deserves to be made, and in places where nails are really necessary they should not be driven quite home, but left with the head projecting slightly, so that the nails can be drawn without the need for damaging the surrounding wood.

In buildings of several storeys, two or three sets of moulds enable the contractor to carry out his work with economy and despatch, as the timbering first used can be taken down as soon as the concrete has hardened sufficiently, and then erected at a higher level while 
intermediate sections of the concrete are setting in duplicate sets of moulds.

In order to facilitate the removal of timber from the surface of the concrete, the moulds are generally treated inside with oil, soft soap, or a coat of white wash, and before any concrete is deposited, care should be taken to clear away all sawdust, chips or other debrîs.

Moulds for columns should be built with at least

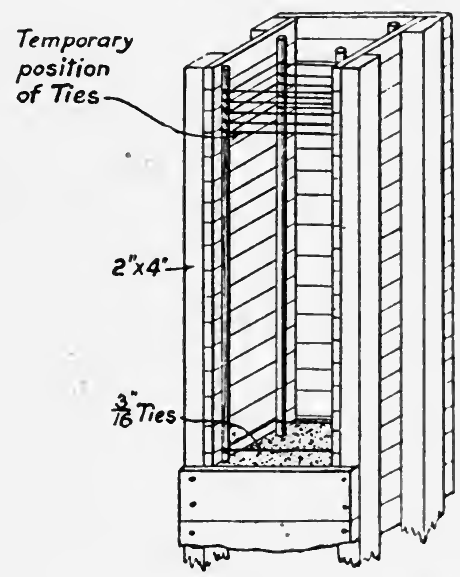

FIG. 17. MOULD FOR COLUMNS

one side open from bottom to top, as in Fig. 17, in order that the concrete may be deposited in successive layers and the opening filled in board by board, as successive layers are added. An alternative method is io form she moulds with corner posts, and to fill in the sides with thort boards as the work advances. This method permits the concrete to be rammed more effectively, and enables one to remove all the side boards after 
the concrete has partially set, leaving the corner posts in position for supporting the weight of the falseworks and materials above. In this way the face of the concrete is exposed all round at a comparatively early period, and the process of hardening is correspondingly expedited. Column moulds are sometimes made with all sides fixed in place, a mode of construction which involves the use of a very wet mixture of concrete. Apart from the risk that shavings, pieces of wood and

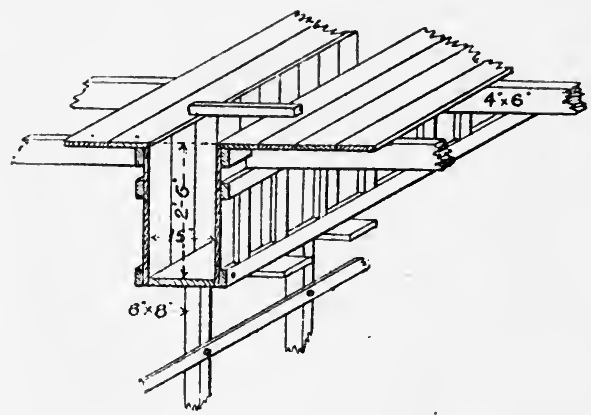

FIG. 18. MOULD FOR BEAMS

refuse may be dropped into such moulds and escape detection, there is always a tendency for concrete poured in at the top of a long closed mould to become disintegrated, the lower part containing an undue proportion of large pieces of aggregate, and the top part consisting chiefly of cement, sand, and the finer particles of aggregate. Further, as nothing is possible in the way of tamping, the concrete poured in at the top cannot be freed effectively from air bubbles, and consequently is apt to be more or less porous.

Beam moulds, Fig. 18, are virtually open troughs of predetermined dimensions, set up between column 
moulds where columns are employed as supports. The sides of the moulds should be attached in such manner that they can be taken away, when the concrete has partially set, without disturbing the bottom of the moulds. In this way the concrete can be exposed to the air as soon as the cement has set sufficiently to hold the mixture together, and the process of setting is thereby hastened. The sides should be clamped at intervals so that they may not be pushed outwards by the moist concrete, and the bottom of the moulds must be supported so as to guard against deflection under the weight of the material contained. The posts or struts placed under the moulds should be provided with wedges are the top and bottom for convenience in erecting and striking the supports, as well as for the purpose of testing the ability of the construction to bear its own weight without appreciable deflection before the struts are finally taken away.

Floor centring consists of boards laid between the beam moulds, stiffened by bearers, and properly supported by struts wedged in place, as in the case of beam moulds.

Walls of various kinds including boundary walls, the walls of buildings, retaining walls, sea walls, and others, are moulded between shuttering, attached to suitable framework and built up on both sides as the work progresses; or one side can be completed first and the other side built up concurrently with the deposition of the concrete. Walls are sometimes built by the aid of movable moulds, having either bolts or clamps permitting them to be secured to the upper part of the last wall section completed, and moved upwards after each section is concreted until the wall has reached the desired height. Part of a wall mould of this type is represented in Fig. 19 , 
The timbering required for the construction of concrete dams, domes, bridges, and other works of monumental proportions is generally of complex nature, and frequently has to support enormous loads for

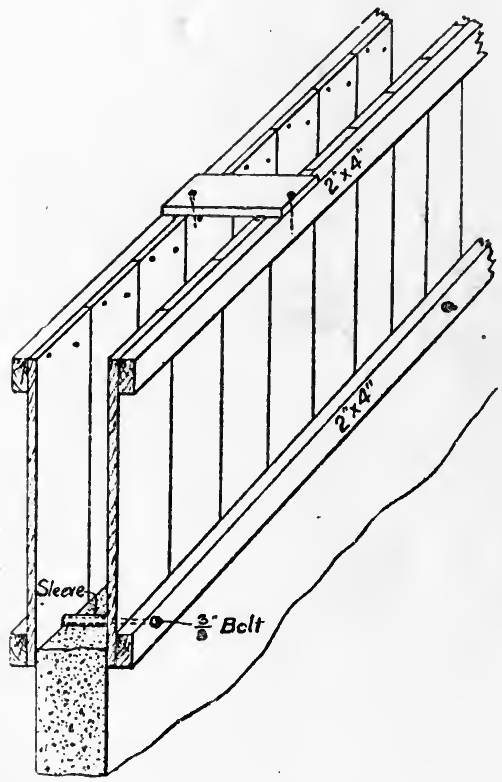

FIG. 19. MOULD FOR WALLS

considerable periods, particularly in the case of important highway and railway bridges.

Some idea of the work involved in the erection of a staging and moulds for such structures may be gathered from Fig. 20, which shows the falseworks for the Risorgimento Bridge, Rome, with an arch span of $330 \mathrm{ft}$. between the abutments. 


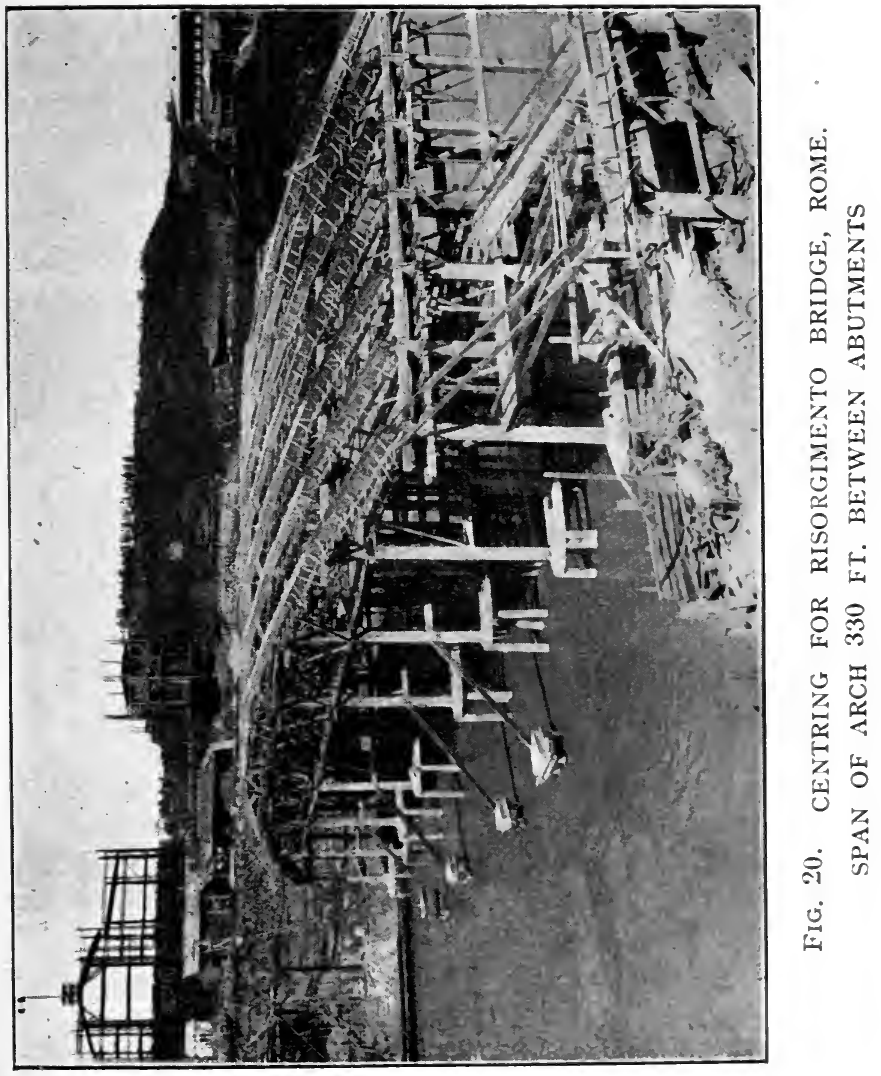


In concrete shipbuilding, again, the temporary framework and shuttering, erected before any concrete is put into place, virtually constitutes a full-size model of the vessel to be built, so far as the outer skin of the hull is concerned, as in Fig. 21, which shows the exterior shuttering and the moulds for the transverse frames in a 1,000 ton barge built at Greenock for the Admiralty. The shuttering faithfully reproduces the external form of the hull, and the inner sheath of shuttering is built up simultaneously with the deposition of the concrete.

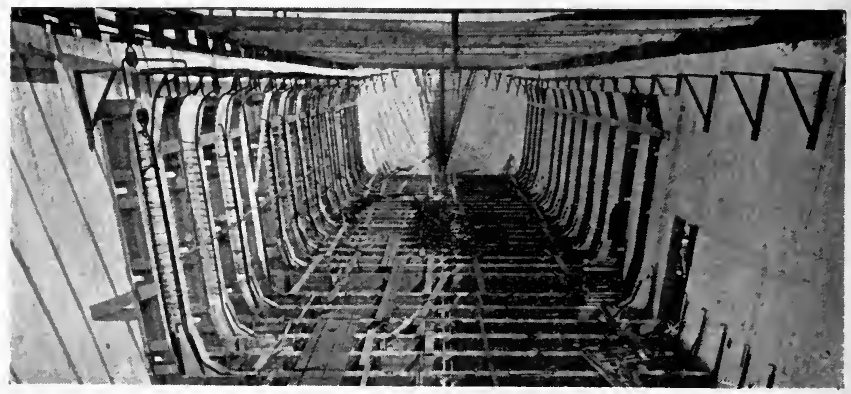

Fig. 21. SHUTTERING FOR 1000-TON BARGE

Timber is the material principally used in this country for the construction of moulds and shuttering for concrete. Steel moulds are largely employed in the United States and elsewhere, one great advantage secured being the superior nature of the surface finish, and another the greater durability of the falseworks. It is worthy of note that an entirely new system of metal shuttering for reinforced concrete work has been introduced, under the name of " Metaforms," into the United Kingdom. In this system, the moulds are built up of standard sized plates of graduated dimensions made of a special non-corrosive iron, various special plates 
being supplied for inside and outside corners, also a type of hinged corner connection so that offsets can be made at any given angle. Iron clamps are rivetted at one side of each plate and connection, so that firm, immovable joints can be secured. Standard stay rods are supplied to keep the inside and outside series of plates at the required distance apart. These iron moulds have been used extensively in America for. several years in the construction of large buildings, grain silos, water reservoirs, circular tanks, boiler chimneys, and many other classes of construction. Bearing in mind the high price of timber and the relatively short life of that material in the form of moulds for concrete, it is probable that iron or steel moulds and shuttering would enable contractors to effect considerable savings, even after allowing for their higher initial cost.

While failures of concrete work, whether plain or reinforced, are extremely rare after construction has been completed, many collapses have occurred, chiefly in America and on the Continent, owing to premature and unskilful removal of moulds and falseworks generally. Some batches of concrete occasionally require an abnormal space of time for setting, owing to special local conditions, and in exceptional cases it has been found unsafe to remove the moulds and strike the centring for several months after the work of concreting has been finished.

No fixed rules can be laid down concerning the length of time that should be allowed to elapse after concrete has been deposited for proper hardening of the material, as so much depends upon the nature of the work and the conditions under which it has been executed. If the atmosphere is damp, and the weather is rainy and cold, setting of the concrete will necessarily be a slow process, and it will be still slower where thick masses of 
concrete are involved, because the heart of the material is shielded from the seasoning action of the surrounding air.

In summer time, the centring can generally be removed from floors after a couple of weeks' time, providing the beams are adequately strutted. So far as beams are concerned, the side boards of the moulds should be taken away as soon as the concrete has set sufficiently to hold together, leaving the bottom boards and struts in position for not less than three weeks, or longer if the concrete sets more slowly than usual. In the case of wall panels which have no weight to carry, the side shuttering can usually be removed after the lapse of four or five days in summer, and after about ten days in winter, providing the setting of the concrete is not delayed by weather conditions or other causes. The sides of column moulds may be removed after seven days in average circumstances, providing the corner posts are capable of relieving the columns from any superimposed loading.

The removal of moulds, shuttering and struts should always be performed by a staff of specially trained men. Care must be taken to conduct the work so as to avoid shock or vibration calculated to injure the newly laid concrete, and to make sure that the timber is not damaged so as to render it unsuitable for employment on subsequent contracts. Finally, no moulds, centring, shuttering, or struts, should be removed without the direct authority of the engineer-in-charge, or the clerk of works, and the work of removal should be conducted under competent supervision.

In concluding this chapter, it may be mentioned that the high cost of constructing, erecting and demolishing timber and other moulds and shuttering, has led to various alternative methods of executing certain 
classes of concrete work. Several types of flooring have been devised, consisting of hollow tubes, moulded in advance, which can be readily and economically supported in position and connected by thin beams of reinforced concrete, the narrow boards supporting the successive rows of tubes, and the sides of the tubes themselves, forming moulds for the concrete. Another method proposed with the object of simplifying falseworks in building construction consists in the use of precast girders and beams, thoroughly seasoned before being hoisted and adjusted in position. The only drawback to this method is the great weight of the members to be so handled. Another idea which has been widely adopted in building construction, and to some extent in concrete shipbuilding, is to make use of selfcentring reinforcement to which the concrete is applied by plastering. Concrete blocks and slabs are also very extensively used in wall and partition wall construction, and several forms of reinforced concrete slab walls have been introduced within recent years in order to avoid the need for the customary timber or metal shuttering. 


\section{CHAPTER VII}

\section{SURFACE TREATMENT OF CONCRETE}

For many years architects have been trying to evolve a new style of architecture, and the search has certainly been encouraged by the development of concrete construction throughout the entire world.

Up to the present date, however, it may be said that, with a few notable exceptions, the most successful attempts in the way of appropriate architectural design for concrete structures have been made by engineers, who are sometimes characterized as a class paying very little attention to, and unqualified by training for, the production of artistic work. It is an undoubted fact, however, that many fine buildings, bridges, water towers, and other important concrete structures in all parts of the world have been designed by engineers in such a way as to comply satisfactorily with the canons of arta result directly attributable to the absence of any straining after effect, and to the simple revelation of the actual construction and material employed.

On the other hand, most of the buildings in which architects have made use of concrete and reinforced concrete are artistic failures, either because a monolithic material is wrongly applied as an unconvincing imitation of cut stone, or is covered by a veneer of other material hiding the true nature of the construction and suggesting something else which has no existence. A notable exception for which much credit is due to the architects, Messrs. Salmon Son \& Gillespie, of Glasgow, is illustrated in Fig. 22. The building in question is constructed 


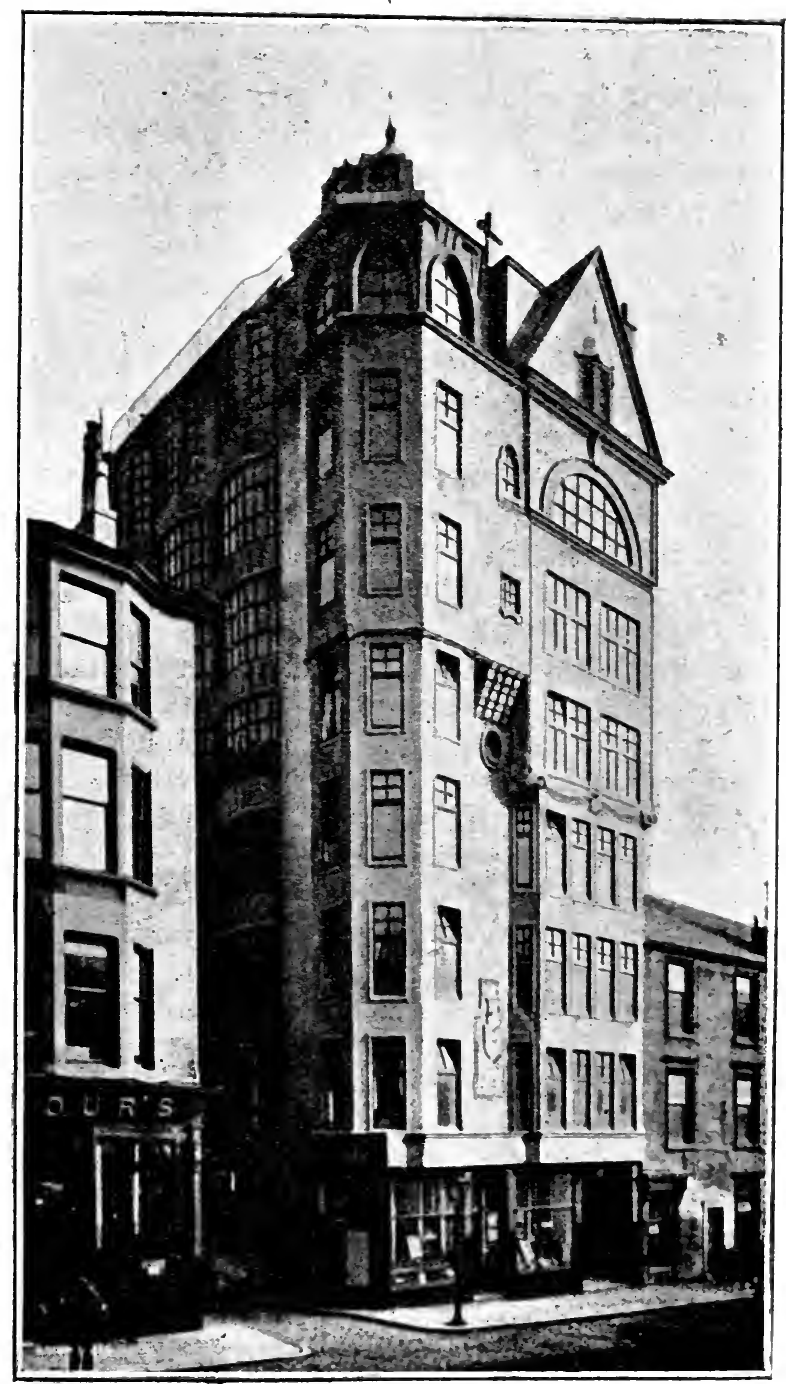

FIg. 22. LION CHAMBERS, GLASGOW $6-(1463 D)$ 
throughout in reinforced concrete. No attempt was made to hide the true meaning of the structural features or the nature of the material either outside or inside.

No doubt the architectural shams which are so widely used to hide concrete construction do not differ essentially from those commonly used for many generations to veil the ugliness of inferior brickwork. Nevertheless, the antiquity of what is inherently bad does not convert it into something good, although long familiarity may perhaps lead to its acceptance without protest. In any event, however, the common practice of disguising concrete in a fancy dress of masonry is one reason why modern architects have not hitherto felt so strongly as could be desired the need of means for the appropriate expression of concrete construction. Another reason may probably be found in the drab and uninteresting appearance of concrete as ordinarily produced. Therefore, it is highly desirable that improved methods of surface treatment should be adopted with the object of fitting concrete to take rank with other structural materials in the exterior surfaces, as well as in the interior economy of buildings.

The irregular surface, uneven texture, and discoloured appearances of concrete may be due to one or more of several causes. The boards entering into the construction of moulds and shuttering generally imprint knot and grain marks with exaggerated fidelity on the face of the concrete ; flaws, cracks, and the joints between the boards being reproduced even more strongly by ridges of cement or mortar. Careless or hurried deposition and the lack of proper tamping or spading after deposition may lead to cavities; badly mixed concrete may be evidenced by an outcrop of pebbles or fragments of aggregate in conspicuous places. The use of dirty moulds and shuttering may result in discoloration of 
the work, while efflorescence and surface cracks are frequently in evidence. Even where blemishes and defects of the kind enumerated do not occur, the general tint of the finished concrete may be, and generally is, of somewhat depressing character.

Taking the foregoing points seriatim, we will now consider briefly the best means of effecting improvements. Marks caused by the grain of the wood in the moulds can be reduced to a minimum by a liberal interior coating of thick oil against which fine sand is blown. Joint marks and cracks in the wood are best guarded against by clay or mortar filling, or by pasting strips of paper or cloth over the gaps. Cavities in the finished surface can obviously be avoided by careful workmanship, and concrete of irregular composition by greater attention to the operation of mixing. Discoloured surfaces should not occur where the moulds are properly cleansed before use. Efflorescence is a purely superficial blemish, due to the absorption of carbonic acid gas from the air by calcium hydrate which sometimes finds its way to the surface while the concrete is in process of setting. Where efflorescence occurs, it can be removed by washing with plain water, or by diluted hydrochloric acid. The fine hair cracks which sometimes appear on the surface of concrete, chiefly occur in the case of wet mixtures, the reason being that in wet concre ce some of the finest particles of the cement are carried to the surface, this very fine skin of cement tending to crack on exposure. A similar result is often found in finely trowelled surfaces. As such hair cracks are only skin deep they can be removed by brushing the surface or washing it with a weak solution of hydrochloric acid. The depressing hue of concrete can be modified by the use of coloured aggregate and sand, by the addition of colouring material to a facing 
layer of fine concrete, or by the application of a suitable wash or paint.

If concrete is correctly proportioned, thoroughly mixed, and carefully deposited and tamped into well made moulds, the exterior surface can be brought to a fine and satisfactory finish by rubbing it down and applying thick cement grout with a brush, or lightly skimming the surface with cement mortar. This is preferable to ordinary rendering, because the latter is
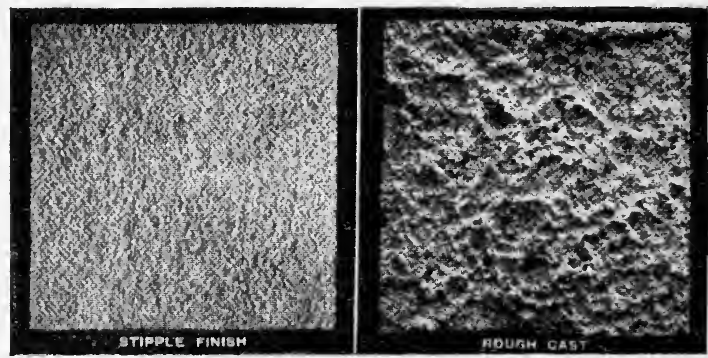

FIg. 23. STUCCO FINISHES

very apt to flake off in process of time owing to the impossibility of obtaining a really effective bond between the body of the concrete and the applied layer of mortar. Apart from this practical disadvantage, stucco finishes of very pleasing appearance can be produced. White Portland cement, a variety rarely employed in this country, can be used with beautiful effects in conjunction with white sand, or crushed marble. Various delicate tints are obtainable by the aid of coloured sands, or by the admixture of pigments with the cement. Stucco can be applied so as to give a smooth surface by floats made of timber, a still smoother 
surface being obtained by the use of a steel trowel or a wooden float covered with felt. One of the most popular finishes is that known as rough-cast, the mortar being applied by dipping a broom into the wet mixture, and jerking the mortar against the wall. A good, and somewhat unusual, effect can be obtained by using white mortar instead of the ordinary mixture. A variation of this finish is obtained by throwing the mortar against the surface by means of a trowel-an operation

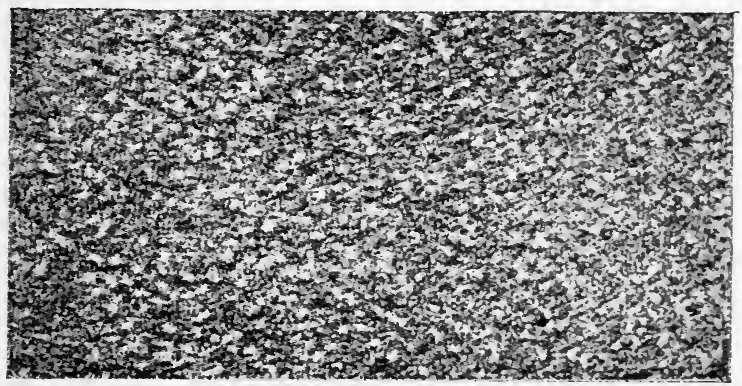

FIG. 24. GRANITE OR MARBLE CHIP FINISH

requiring considerable skill for the attainment of satisfactory results. Pebble-dash is another variety of rough-cast, and as the description implies, it is executed by throwing small stones into a soft coat of mortar laid on the surface to be treated. Two illustrations of stucco treatment are given in Fig. 23.

Concrete floor surfaces of agreeable appearance can be obtained by rolling granite or marble chips, or such fragments of any appropriate stone into the moist concrete (see Fig. 24), the result being a form of mosaic work capable of many variations, and lending itself admirably to the realization of colour schemes. 
Where it is desired to impart a pleasing tint to concrete surfaces, water paints can be used with satisfactory results, even if the concrete is not perfectly dry. Oil paint applied to concrete will be destroyed, unless precautions are taken to prevent the oil from coming into contact with free lime from the cement. With this object in view, the surface of the concrete should be neutralized by the application of diluted sulphuric acid ( 1 part of acid to 100 parts of water). The acid

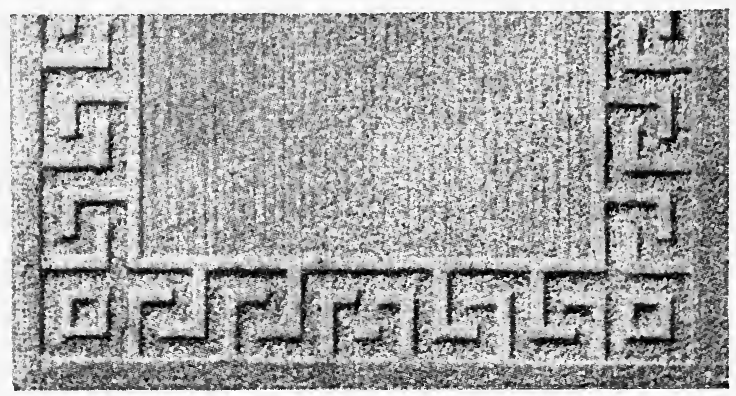

FIG. 25. ETCHED FINISH WITH KEY BORDER

has the effect of converting any free lime present into gypsum. After allowing time for the required chemical reaction, the surface is washed and allowed to dry before the application of paint. An alternative treatment is to apply a wash of zinc sulphate, in the form of a 1:5 solution, which produces a film of gypsum and zinc white of harmless character in relation to oil in the paint.

All the methods of treatment so far discussed relate to improvement of the surface, either by special care in the preparation and deposition of the concrete or by coatings of one kind or another applied after the moulds 
or shuttering have been removed. We will next deal briefly with methods of treatment involving removal of the exterior skin of the concrete. The outer film of cement or of cement and fine sand can be removed mechanically or by means of chemicals, leaving bare the particles of aggregate and the layer particles of the sand. The colour of the sand will naturally influence the tone and texture of the finished work, and if dark, it will give a pleasant tint, which may harmonize

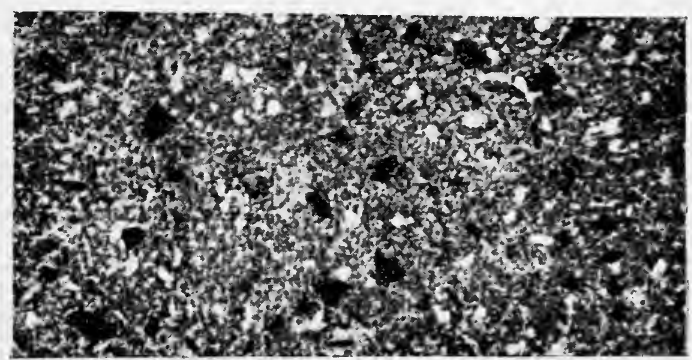

Fig. 26. EXPOSED AGGREGATE

or contrast well with that of the aggregate If a uniform tone is desired throughout crushed stone of the same variety as that used for aggregate should be used instead of sand Fig. 25 represents part of a panel with moulded key border and treated by acid to remove the outer film of cement.

A bold effect can be obtained by laying the aggregate quite bare, and almost any required tone can then be secured by the employment of selected varieties of stone. An example of treatment in this way is represented in Fig. 26. Numerous kinds of hard stone are available, possessing rich colours, capable of being used with highly artistic effects either separately or in 
combination. If architects who at present regard concrete as unworthy of use without a casing of brick, terra-cotta or masonry, would try a few practical experiments with concrete of natural rock surface, it is probable that their views on the question of the aesthetic possibilities of concrete would undergo radical alteration.

One great incidental advantage of methods involving removal of the cement film from the concrete is that the customary and almost unavoidable imprint of joints and grains from the timber moulds is completely swept away. By the use of a hand pick with a series of points, the outer surface of cement and sand can readily be removed, so as to expose the stone in the main body of concrete, the resulting texture varying with the hardness of the material and the direction of the blows given. Thus, when the concrete has not fully hardened, the thickness removed by the pick is relatively great, and some pieces of aggregate are apt to be chipped out, while harder concrete conduces to finer and more uniform texture. Again, perpendicular blows leave no perceptible marks on the surface, and oblique blows cause diagonal tool marks, the directions of which can be varied at pleasure.

A more frequent and generally preferable method is to wash off the outer film of cement or mortar by bristle or wire brushes, while the material is still soft, using a sufficient quantity of water. In this way the aggregates come out clean and bright, the result being very effective where coloured stone is employed.

The use of dilute hydrochloric acid and sulphuric acid, either separately or mixed together, assists the process of washing away the cement, but all traces of acid must be washed away afterwards to prevent permanent discolouration. It should be noted that 


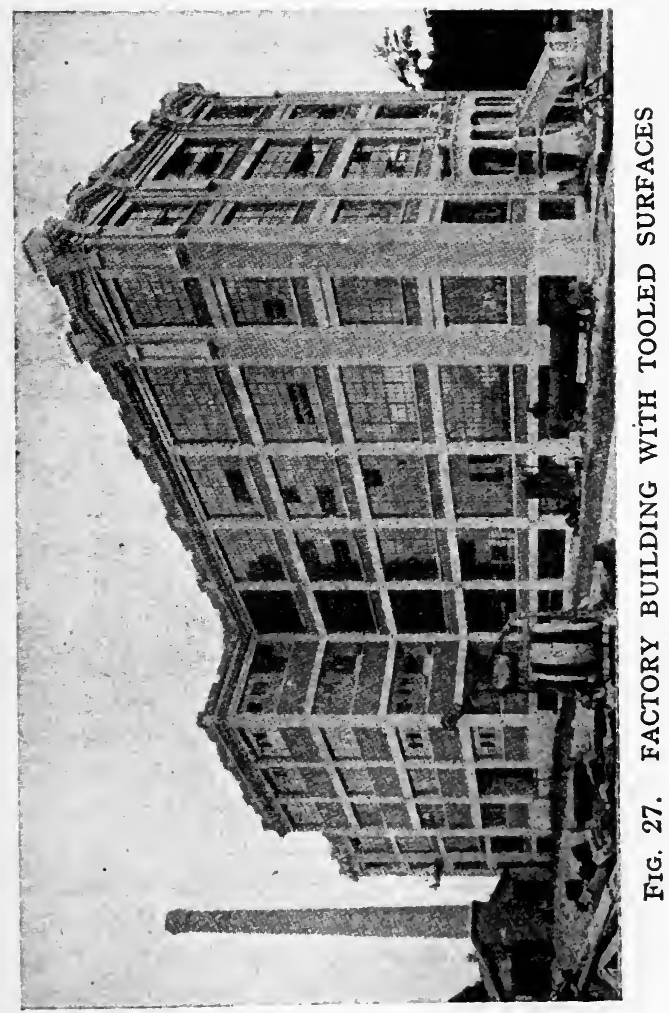


concrete which has fully set cannot be treated economically or satisfactorily either by scrubbing or by acid.

By rubbing down the surface with a piece of stone, using sand and water also, the outer film can be removed, and where the aggregate is of soft stone, the resultant surface has a terrazzo finish.

On works of sufficient magnitude to justify the installation of the necessary plant, the sand blast can be employed more effectively than chipping, scrubbing, or washing with acid for exposure of the aggregate.

In the design of large buildings and structures such as grain silos, water reservoirs and others where large unbroken surfaces would be dreary and monotonous, dignified and pleasing effects can be obtained by the introduction of pilasters, string courses, cornices, and panels, as well as by variations in the surface finish of the different architectural details.

Fig. 27 shows a factory building at Hartford, U.S.A., illustrating the artistic possibilities of concrete work. The building was constructed entirely in reinforced concrete, with the exception of the parapet and some brick curtain walls. The wide pilasters at the corners were tooled by hand picks, other exterior surfaces having been rubbed down with wood floats to remove grain and joint marks as soon as the shuttering was removed, and afterwards rubbed with carborundum and water. The entrance porch, at the right-hand of the view, and the parapet, were built up of precast blocks, and the window sills were moulded in place. Special aggregates were not selected in this case to secure colour or texture, the general excellence of the finished work being due to uniform mixing of the concrete, expert moulding, and careful rubbing down. The colour and texture of the rubbed surfaces are described as closely resembling 
sawn and rubbed limestone, while the tooled surfaces are of bluish tint owing to the exposure of the trap rock used as aggregate. The treatment of this building illustrates an entirely legitimate application of concrete in architectural design, and shows that concrete is quite worthy of consideration as a material for exterior surfaces.

Concrete surfaces, both in exterior and in interior work, can be appropriately decorated by carving, which

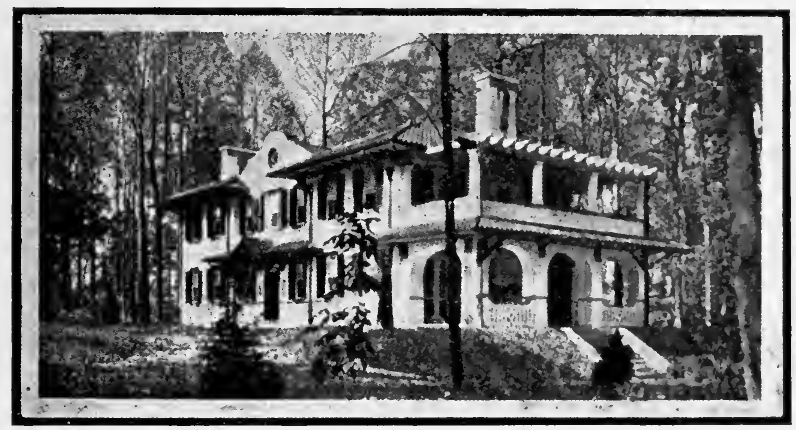

FIG. 28. A CONCRETE RESIDENCE

is best carried out before the material has thoroughly set. As soon as the concrete has hardened sufficiently to carry its own weight the shuttering is removed, and the required design can be readily carved out with steel tools. Decorative bands and panels of glazed or unglazed tiles constitute a ready and particularly effective means of relieving concrete surfaces in domestic architecture. On the Continent and in America, tiles have been extensively used for the enrichment of concrete. The rough texture of the material blends admirably with deeply coloured tiles, which can be obtained in sizes, shapes and colours affording wide 
scope to the architect who is willing to experiment in this comparatively unfamiliar and fascinating branch of artistic work. The tiles can be employed for the entirely legitimate purpose of emphasizing the lines of the actual construction, while at the same time converting the monotony of the concrete surface into an effective base for almost any suitable colour scheme. Fig. 28 is an exterior view of a concrete residence erected in Pennsylvania from the designs of Mr. Oliver R. Parry, a New York architect. In this building, the colour treatment of the exterior embodies pure white walls relieved by tiles in different tones of red; copings, chimneys, and other architectural features being emphasized by bricks and tiles of "old time" finish. The walls and floors of the interior are tastefully relieved and decorated by vitrified tiles, the general effect of the scheme being distinctly pleasing. 


\section{CHAPTER VIII}

\section{CONCRETE BLOCKS AND MOULDED PRODUCTS}

THE production of concrete blocks for building purposes has been developed to an enormous extent during recent years, such blocks forming an excellent substitute for brick and stone, if carefully made and properly used. As the penetration of moisture is the main disadvantage of concrete blocks, the general aim in the present day is to produce walls containing air chambers tending to prevent moisture from reaching the interior face of the construction. The air chambers, usually provided by means of hollow blocks, also have the effect of maintaining the interior of the building at an equable temperature.

Building blocks are either composed of sand and cement, or of concrete in which the aggregate is limited to about $\frac{1}{2}$ in. gauge, owing to the narrowness of the spaces in the moulds. Porous and otherwise unsatisfactory blocks made with unsuitable materials by inexperienced persons have been responsible for many complaints, the recurrence of which can only be avoided by scrupulous attention to the preparation of the concrete and its subsequent manipulation.

Building blocks can be made by the dry or the wet process. In the former, only enough water is used to give the concrete the consistency of damp earth, so that the mould of the block-making machine can be removed directly the concrete has been tamped. In the latter, sufficient water is used to produce a semi-fluid mixture, which must be allowed to remain in the mould until it has hardened. 
If the mixture is too dry, or insufficiently tamped, the blocks will be weak, and apt to crumble, however well they may be seasoned after the process of moulding. A wet mixture produces stronger and denser blocks, but causes delay and inconvenience. Therefore, the dry process is almost universally adopted.

Concrete blocks are generally produced either as one-piece blocks, each with one or more air spaces, and extending from face to face of the wall to be built, or as two-piece blocks, one half forming the face, and the other half forming the back of the wall. The two halves overlap so as to give a good bond, and provide interior space for air. Both varieties are made in different shapes and sizes, the standard dimensions being 32 in. long by 9 in. wide by 9 in. thick.

Block-making machines are produced in great variety, and new types are constantly making their appearance, each with some special claim to recognition. The four principal classes comprise-machines with vertical face-plate, machines with horizontal face-plate, machines for wet concrete, and machines for two-piece blocks.

Machines with vertical face-plates have removable hinged sides, and upright cores. After being tamped, the blocks, made under the dry process, are removed on iron pallets. In some machines the mould is rotated and the block turned out on a piece of board, in others the mould is lifted bodily from the block. Other machines are fitted with devices for raising and lowering the cores, and in others, again, the cores are stationary and the bottom and sides of the moulds are removable. Machines of this class are not convenient for making blocks with a facing of special concrete, as a vertical partition has to be used, and great care must be taken in bonding the two kinds of concrete.

Machines with horizontal face-plates are operated 
by filling in and tamping the facing mixture, sliding in the cores, then continuing the filling and tamping processes, and finally removing the block by rotating the mould.

Machines for making blocks from wet concrete are provided with a number of sheet metal moulds, which can be removed so that the blocks may remain in them until hardened.

Machines for the production of two-piece blocks are generally provided with arrangements for the application of mechanical or hydraulic pressure. The concrete is deposited in the mould, tamped by pressure, and immediately released. A facing layer can be formed by forming a space of about $\frac{3}{4}$ in. in front of the concrete deposited, and filling this with special concrete, or mortar. The whole is then pressed, giving a good bond between the two kinds of material, and since the pressure is applied to the face of the block an excellent surface finish is obtained.

The seasoning of blocks is a most important matter. Blocks should be protected from the sun and from dry winds, and kept wet so that the cement may have the amount of water necessary for the process of crystallization which is essential to the proper setting of the material. The blocks should be kept wet for at least ten days, and not used for building work until they are from 30 to 60 days of age.

Angle blocks for the corners of walls and all blocks of special form can quite easily be produced by the aid of suitable moulds. The surface finish of blocks is capable of infinite variation. Among the finishes generally adopted by makers of block machines arecorrugated, panelled, rock, and smooth faces. Any desired colour can be given to the surface by mixing suitable pigments with the cement, and a white surface 
can be obtained by using white Portland cement with white marble screenings in place of ordinary sand.

Apart from defects such as result from inferior concrete, poor workmanship in moulding and inadequate seasoning, the greatest objections to concrete blocks are the adoption of surface finishes constituting imitations of natural stone, and the unpleasing appearance of work executed with blocks pretending to be stones of rigidly fixed dimensions with a dreary uniformity of appearance throughout.

Brick manufacturers have never attempted to make their product look like anything but brick which, in consequence, has become a recognized building materia] used freely without masquerading as something else.

Concrete blocks makers would do well to follow this example, and to give up all attempts to produce more or less feeble and objectionable imitations of dressed stone.

In addition to its use in the form of building blocks, concrete is now employed very extensively in the production of bricks, partition slabs, roofing tiles, drain pipes, window sills, lintels, and miscellaneous architectural details, most of these being moulded either in machines of the kind used for making blocks or in machines of similar character.

Other moulded products include architectural details, garden furniture, fountains, vases, pergolas, water pipes, gate and fence posts, telegraph post, electric light standards, and many others serving to illustrate the artistic possibilities of concrete, as well as its acknowledged utility.

A bold example of statuary is illustrated in Fig. 29, this being reproduced from a photograph of the statute of St. Joseph, at Espaly, a fine piece of moulded work in reinforced concrete from the model of $\mathrm{M}$. Besquet, the well-known French sculptor, 


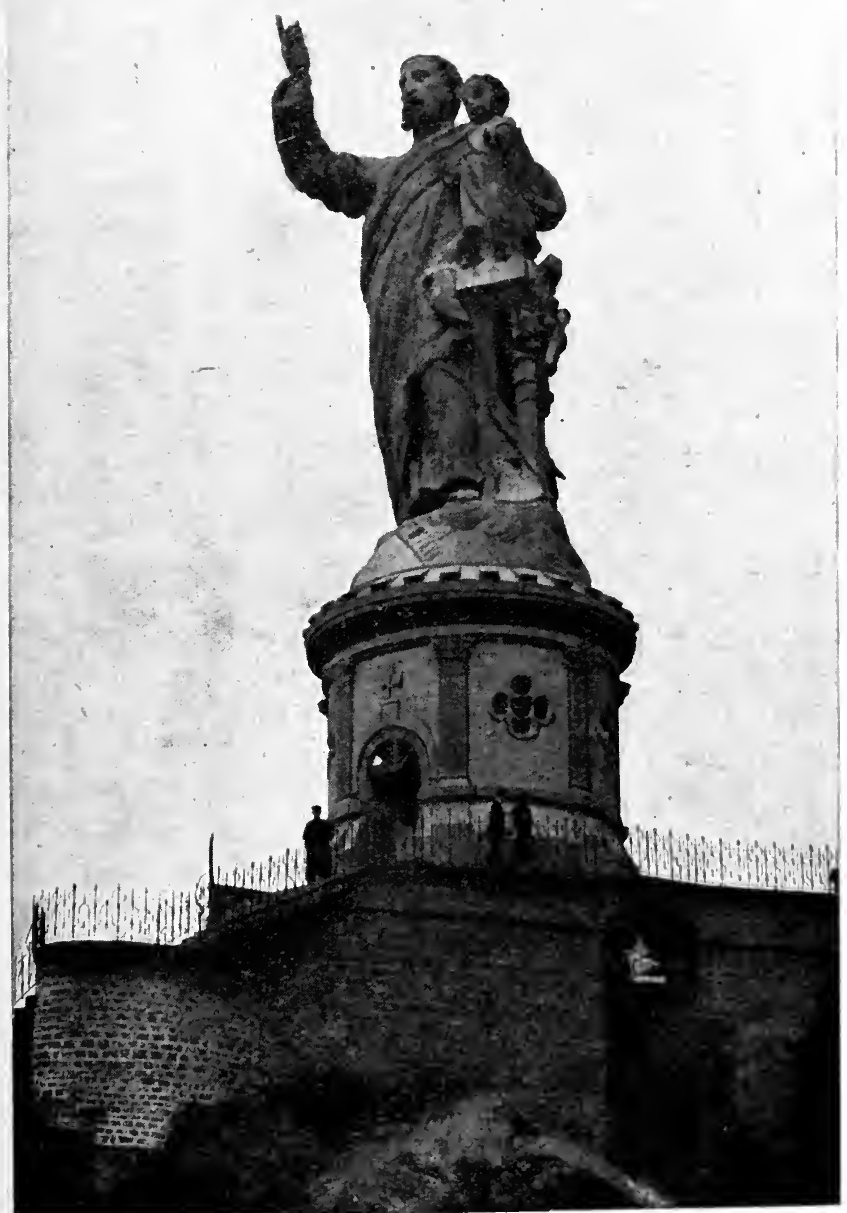

Fig. 29. Statue OF ST. JOSEPh, AT ESPALY 7-(1463D) 


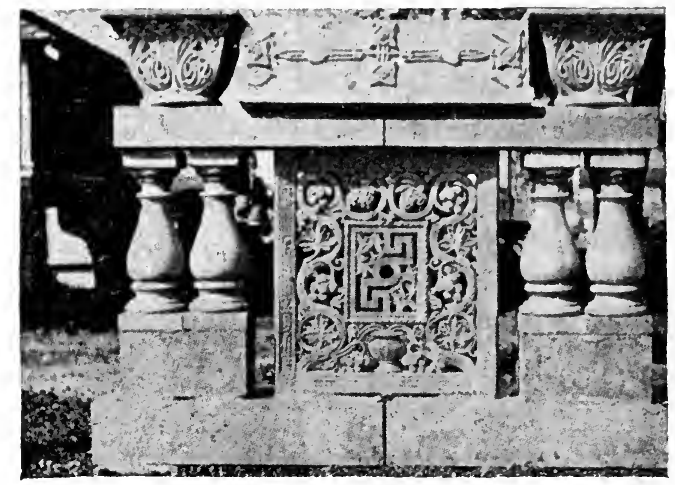

FIG. 30. MOULDED CONCRETE WORK

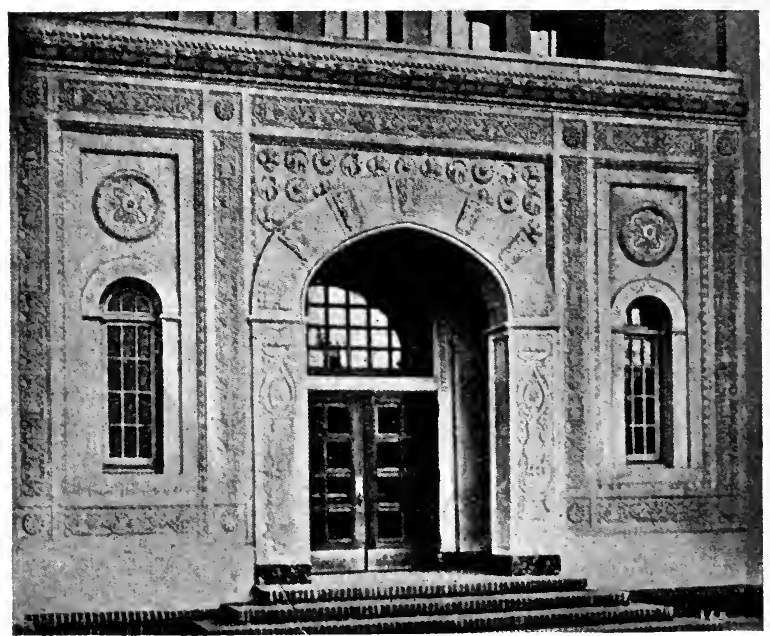

Fig. 31. MOULDED ENTRANCE FOR SCHOOL 
Fig. 30 shows the adaptability of moulded concrete to ornamental work, the actual effects obtained having been enhanced by different methods of colour treatment. The main feature of the design is the Byzantine panel

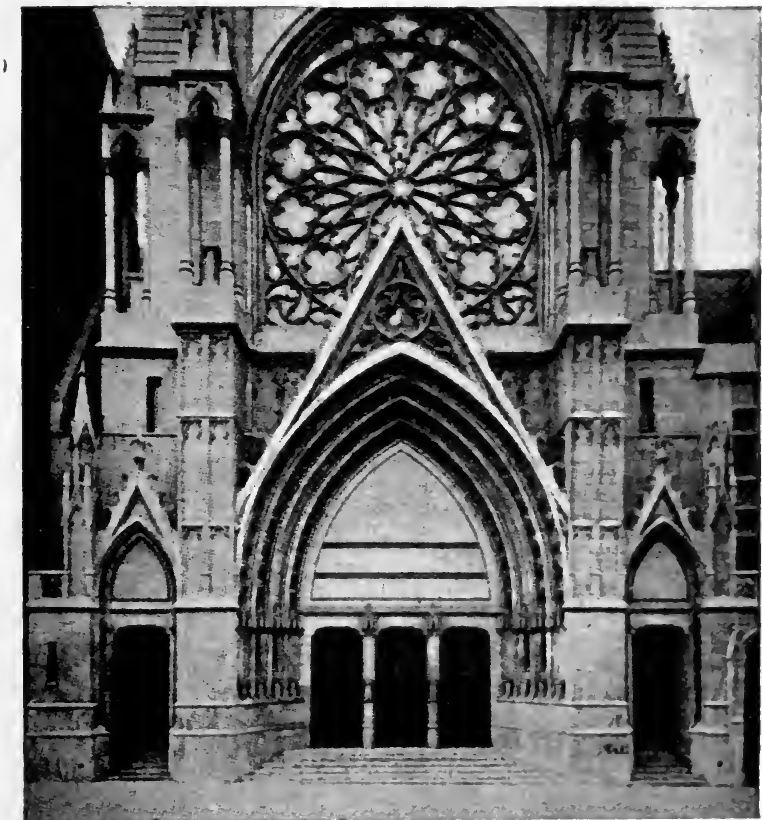

Fig. 32. CHURCH OF THE BLESSED SACRAMENT, NEW YORK

of white Portland cement and marble sand. The surface film of cement was washed away by an acid solution to show the sparkle of the marble, and the panel was dipped into a solution of sulphate of iron to give the warm tone of old Italian marble.

Fig. 31 shows the employment of moulded concrete 
for the delicate wrought details of the main entrance to a school building in the United States, in accordance with the design of Mr. W. E. Weeks, a San Francisco architect.

Fig. 32 is from a photograph of the west front of the church of the Blessed Sacrament, New York, an architectural masterpiece executed entirely in precast concrete units.

In applying concrete to ornamental work, the greatest care must be taken in the selection of the materials. The cement must be of the best quality and thoroughly sound, in order that sharp edges and details may be permanent. The sand must be quite clean, particularly if the concrete is to be coloured by the incorporation of pigments. The aggregate should be chosen with the desired effect in view. To obviate the dull and monotonous appearance of cement surfaces, the exterior of the objects moulded can be treated with advantage in accordance with one or other of the methods discussed in the preceding chapter 


\section{CHAPTER IX}

PHYSICAL PROPERTIES OF CONCRETE

THE strength and other physical properties of concrete are affected to a very important extent by various factors chief among which are those in the following groups-(1) The quality and quantity of cement.

The quality, proportions, and grading of the sand and aggregate. (3) The consistency, density, mixing, deposition and tamping of the material, and the conditions under which the process of hardening or seasoning takes place.

In view of the numerous factors involved, it is evident that the strength of concrete is by no means a fixed quantity, and that a definite standard of strength cannot be laid down even for concretes of nominally equal composition. Therefore, in these respects concrete differs essentially from structural materials, such as steel, for instance, which is prepared by manufacturing processes so exactly regulated as to enable steel of any particular grade to be produced of remarkably uniform quality.

It is not fair, however, to compare concrete with steel in this way. For one thing, concrete as employed in achitectural and engineering practice only appears in the finished structure, and has no previous existence as a manufactured product, except where precast members are used. The cement has such a previous existence, and is turned out by processes which give results as uniform as those employed in steel manufacture. The other constituents of concrete-water, sand and aggregate-are also obtainable in uniform qualities. 
Consequently the variations which occur in the strength and other physical properties of concrete may properly be regarded as the direct results of operations forming part of the work of actual construction and of the conditions prevailing while such work is in progress.

We cannot fairly compare concrete in any manufactured form, such as a finished structure or part of a structure, with steel bars or structural sections as turned out from the rolling-mill. To make an equitable comparison steel must also be considered as it exists in the form of steelwork, after the rolled bars or sections have been cut, riveted, welded, or otherwise treated in the workshop or on the site, and when the work of erection and construction has been finally completed. It will then be found that the practical strength of structural steelwork is subject to variations which are probably as far-reaching in their results as those occurring in the application of concrete to structural work.

Having made these preliminary remarks with the object of doing justice to concrete, we will now consider briefly the effects of various factors on the strength and properties of the material.

Effects of Proportion of Cement. In a general way the compressive strength of concrete varies with the proportion of cement per unit volume of the concrete. In illustration of this point we may quote the results of tests conducted by Messrs. W. B. Fuller and Sanford E. Thompson, at Jerome Park, U.S.A., and expressed for different percentages of cement as follows, the compressive strength of the mixture containing 8 per cent of cement being taken at unity.

Percentage of Cement Relative compressive strength at 140 days

\begin{tabular}{l|l|l|l}
\hline 8 & 10 & 12.5 & 15 \\
1 & 125 & 1.25 & 1.9 \\
\hline
\end{tabular}


In these tests the density of the concrete was practically constant, and the samples of concrete were of similar quality apart from the percentage of cement employed.

Effects of Size and Quality of Aggregates. Providing the aggregate is well graded, the density and strength of concrete generally increases with the size of the largest fragments, and the percentage of cement required decreases as the size of the largest fragments increases. The advantages to be obtained thus are confined to plain concrete work, because in reinforced concrete construction the aggregate must be fine enough to allow the concrete to pass between the bars or meshwork employed as reinforcement.

Aggregates of low compressive strength, such as soft varieties of stone, brick, cinder and some kinds of slag, necessarily yield weak concrete. The hardest and toughest qualities of rock generally produce concrete which is somewhat stronger than gravel concrete, but in average practice the difference between stone and gravel concrete is scarcely worth consideration. Gravel concrete is frequently preferred because the aggregate usually contains a smaller percentage of voids than broken stone, because the rounded pebbles slide better into place than angular fragments of stone, and because the resulting concrete is generally more impermeable than stone concrete.

\begin{tabular}{|c|c|}
\hline Kind of aggregate & Relative strength \\
\hline $\begin{array}{l}\text { Granite and Trap } \\
\text { Gravel, Hard Limestone and } \\
\text { Hard Sandstone } \\
\text { Soft Limestone and Soft } \\
\text { Sandstone } \\
\text { Cinder and other weak } \\
\text { materials }\end{array}$ & $\begin{array}{l}1.00 \\
0.90 \\
0.67\end{array}$ \\
\hline
\end{tabular}


As an approximate guide to the relative strength of concrete made with different. kinds of aggregate the table given on page 93 may be of interest, the strength of granite and trap concrete being taken at unity.

Effects of Consistency. So far as compressive strength, density and impermeability are concerned, the best results are obtained by mixing concrete with just sufficient water to make a mixture capable of flowing slowly in the moulds or shuttering. Dry mixtures develop greater strength than moderately wet mixtures at the outset, but after some five or six months have elapsed moderately wet mixtures attain superior strength. In the case of dry mixtures, it is difficult to obtain concrete of uniform consistency and to obviate voids. On the other hand, in very wet mixtures the cement and fine sand are apt to be carried away from the coarser sand and particles of aggregate, and the resulting concrete is weaker than that given by dry or moderately wet mixtures. Another disadvantage attending the use of very wet mixtures is that some of the cement is decomposed giving rise to a light coloured substance termed "laitance," which comes to the surface and, having no cementitious value, simply represents a loss of cement and strength.

Effects of Mixing. The consistency, or at any rate the workability, of concrete is affected by the thoroughness with which the materials are mixed, as well as by the actual amount of water used. Thorough mixing also has a very marked effect upon the strength of concrete. While good results can be obtained either by hand mixing or by mixing in a machine, it is difficult to get the work done properly by hand. The materials have to be turned over and over very thoroughly; the shovels must find their way down to the mixing boards and the mixture must be picked up from the 
very bottom, so that all the ingredients shall have a chance of being evenly distributed and mingled. This is hard work, and the men engaged upon it are only too ready to think their task is ended when in reality it may be only about halfway through. Machine mixing is always to be preferred for the reason that the work is more thoroughly done, and the resulting concrete is stronger than concrete of the same kind mixed by hand. If the machine is properly designed, and there is no difficulty in obtaining one that will comply with this requirement, every part of the mixture gets its proper share of treatment, whereas in hand mixing it may easily happen that some proportion of the ingredients may be missed by the workman's shovel.

Even if the machine is worked by hand, the whole of the materials must come in for their share of treatment and it is easy to ensure good results by seeing that the operation is continued for a sufficient length of time. The work of turning a handle or flywheel is obviously less laborious than shovelling, and when the mixer is operated by power there is not the slightest inducement for the man in charge to shorten the mixing period.

Tests conducted some years ago at the Watertown Arsenal, U.S.A., on hand and machine mixed concrete showed an average advantage of 11 per cent in favour of machine mixing, the basis of comparison being the compressive strength of test specimens made from the various batches of concrete mixed. Another series of tests at Watertown Arsenal indicated an advantage of more than 25 per cent in favour of machine mixing, while tests carried out at the University of Illinois on an extensive scale gave results showing that the average compressive strength of machine-mixed concrete was nearly 28 per cent greater than that of similar concrete mixed by hand. 
On large contracts, machine mixing is adopted as a matter of course owing to its convenience and economy. On small contracts, hand mixing is generally more economical. In some cases, where working space is of very limited extent, the contractor has no choice in the matter and must perforce adopt hand mixing. In order to compensate for the lower strength of hand-mixed concrete it is well to increase the proportion of cement by from 10 to 15 per cent.

Effects of Handling. Unless concrete is used while quite fresh, that is to say before the cement has begun to set, and while the materials remain perfectly mixed, the strength of the concrete may be seriously impaired. The reasons are: (1) that the handling of concrete which has commenced to set has the effect of breaking up the crystals already formed and of reducing the interlocking of the crystalline structures, and (2) that if the constituents of the concrete have begun to separate before use, some portions will have an excess of aggregate or sand and other portions will have an excess of cement. Any such irregularity of distribution must involve the formation of areas or planes of weakness which may conceivably give rise either to excessive strain or to failure of a structure in which the concrete is used.

The strength of concrete is also influenced by the manner in which the material is deposited and tamped in the shuttering or moulds, and by the conditions prevailing while the process of hardening or seasoning is going on. The strength of concrete is increased by thorough consolidation in the intervals occurring between the deposition of successive layers of material.

Concrete seasoned in air should be kept moist, especially in hot and dry weather, for the reason that moisture is conducive to the process of crystallization, and therefore tends to promote increased strength. An excess of 
water is to be avoided either during mixing or after deposition of the concrete, because it reduces the strength of the concrete and may give rise to the formation of the inert substance known as "laitance." The latter is often liberated from concrete deposited under water, and wherever it is likely to occur the proportion of cement should be increased to make up for loss of strength.

Effects of Age. Concrete is the only structural material in existence which continues to increase in strength with its age, all other materials slowly deteriorating with the efflux of time. As shown by numberless experiments, the increase of strength in the case of concrete is very rapid at the start and gradually becomes slower until the increase either stops or becomes almost imperceptible. The results of experimental records exhibit considerable divergence, although all of them establish the progressive increase of strength, the average rate of which is given in the subjoined table.

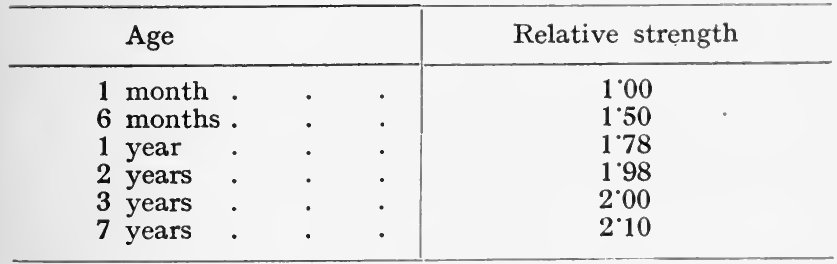

Compressive Strength of Concrete. As the strength of concrete in resistance to compression is the most important characteristic from the standpoint of the user, it may be useful here to give some figures as a general guide. The reader will, of course, bear in mind the fact that as the proportions of concrete can be varied to an infinite extent, the compressive strength of the material is necessarily subject to an infinite number of variations. The same kind of thing happens in the case of stone, 
timber, and other materials, occurring in widely different qualities. For the purposes of this book it will suffice to state the conclusions of a few leading authorities relative to the strength that may be expected of concrete mixed in proportions very frequently adopted in practical work.

The London County Council Regulations give minimum values for concrete composed of cement, sand and aggregate consisting either of gravel or hard stone and mixed in different proportions, as stated in the following table.

Compressive Strength of Concrete (L.C.C. Regulations)

\begin{tabular}{|c|c|c|c|c|}
\hline \multicolumn{3}{|c|}{ Proportions by Volume } & \multicolumn{2}{|c|}{$\begin{array}{l}\text { Ultimate Compressive Strength } \\
\text { (minimum) } \\
\text { In pounds per square inch }\end{array}$} \\
\hline Cement & Sand & Aggregate & Age 1 month & Age 4 months \\
\hline $\begin{array}{l}1.0 \\
1.2 \\
1.5 \\
2 \\
2\end{array}$ & $\begin{array}{l}2 \\
2 \\
2 \\
2\end{array}$ & $\begin{array}{l}4 \\
4 \\
4 \\
4\end{array}$ & $\begin{array}{l}1,600 \\
1,800 \\
2,000 \\
2,200\end{array}$ & $\begin{array}{l}2,400 \\
2,600 \\
2,800 \\
3,000\end{array}$ \\
\hline
\end{tabular}

The Regulations include an equation for calculating the minimum compressive strength of concrete in intermediate proportions, but do not provide for the economic use of concrete possessing more than the minimum strength specified for each mixture. Consequently these minimum values are also the maximum values permissible under the regulations.

The American Joint Committee on Concrete recommend maximum values for adoption as shown on the following page.

This table is far more useful than that of the London County Council, because it states values for concrete made from different kinds of aggregate, and it also gives more latitude to designers who are desirous of making the best use of high grade concretes. 
An excellent feature in the Report of the Joint Committee of the Royal Institute of British Architects is a recommendation to the effect that the actual strength of the concrete to be employed on any important work

\begin{tabular}{|c|c|c|c|c|c|c|}
\hline \multicolumn{2}{|c|}{ Proportions by } & \multirow{2}{*}{$\begin{array}{l}\text { Volume } \\
\text { Aggregate }\end{array}$} & \multicolumn{4}{|c|}{$\begin{array}{l}\text { Ultimate Compressive Strength (maximum) } \\
\text { In pounds per square inch. Age } 1 \text { month }\end{array}$} \\
\hline Cement & Sand & & $\begin{array}{l}\text { Granite } \\
\text { or Trap }\end{array}$ & $\begin{array}{l}\text { Gravel, or } \\
\text { Hard Lime- } \\
\text { stone or } \\
\text { Sand-stone }\end{array}$ & $\begin{array}{l}\text { Soft Lime- } \\
\text { stone or } \\
\text { Sand-stone }\end{array}$ & Cinder \\
\hline $\begin{array}{l}1 \\
1 \\
1\end{array}$ & $\begin{array}{l}2.0 \\
1.5 \\
1.0\end{array}$ & $\begin{array}{l}4 \\
3 \\
2\end{array}$ & $\begin{array}{l}2,200 \\
2,800 \\
3,300\end{array}$ & $\begin{array}{l}2,000 \\
2,500 \\
3,000\end{array}$ & $\begin{array}{l}1,500 \\
1,800 \\
2,200\end{array}$ & $\begin{array}{l}600 \\
700 \\
800\end{array}$ \\
\hline
\end{tabular}

should be ascertained by tests and that the figures so obtained should be taken as the basis of calculations. This provision is a direct encouragement to those who desire to produce the best possible concrete.

To give some indication of what is possible in the way of producing high-compression concrete we may refer to the results of two series of tests. One of these series was conducted by Messrs. Kirkaldy \& Son on 6 in. cubes of concrete as used in building H.M. New Stationery Office, London. The tests conducted on concrete at an age of 28 days gave the following results-

\begin{tabular}{|c|c|c|c|c|}
\hline \multicolumn{3}{|c|}{ Proportions by Volume } & \multirow{2}{*}{ No. of tests } & \multirow{2}{*}{$\begin{array}{c}\text { Average Compressive Strength } \\
\text { In pounds per square inch. } \\
\text { Age } 28 \text { days }\end{array}$} \\
\hline Cement & Sand & Aggregate & & \\
\hline $\begin{array}{l}1 \\
1\end{array}$ & $\begin{array}{l}1^{\circ} 6 \\
1^{\circ} 0\end{array}$ & $\begin{array}{l}3 \cdot 2 \\
2 \cdot 0\end{array}$ & $\begin{array}{l}18 \\
16\end{array}$ & $\begin{array}{l}3,658 \\
4,840\end{array}$ \\
\hline
\end{tabular}

Still higher results were obtained from the second series of tests, made upon very superior concrete for shipbuilding, a class of construction demanding concrete of the finest possible quality. The test specimens were in the form of 6 in. cubes prepared at Lake Shipyard, Poole, under the direction of Major J. H. de W. Waller, 
D.S.O., R.E., and were tested by Messrs. Kirkaldy \& Son with the following results-

\begin{tabular}{c|c|c|c|c|c}
\hline \multicolumn{2}{|c|}{ Proportions by Volume } & \multirow{2}{*}{$\begin{array}{c}\text { No. of Tests } \\
\text { Nement }\end{array}$} & $\begin{array}{c}\text { Average Compressive Strength } \\
\text { In pounds per square inch }\end{array}$ \\
\hline $1 \frac{1}{4}$ & 1 & Aggregate & & Age 8 days & Age 28 days. \\
\hline
\end{tabular}

Tensile Strength. It is sometimes thought that the tensile strength of concrete is of little practical importance because the material is chiefly used in compression and because its tensile resistance is neglected in the design of reinforced concrete beams. As a matter of fact, however, the tensile resistance of concrete comes usefully into play in withstanding tensile stresses of moderate intensity in various classes of construction, and notably in reinforced concrete beams and other members where diagonal tension is developed as a secondary result of flexure. Consequently this property of concrete is one deserving more attention than it has received up to the present.

The tensile strength of concrete is generally said to be about one-tenth of the compressive strength of the material. There is, however, no definite connection between the two. The nature of the sand and aggregate appear to produce more effect on the tensile than on the compressive strength of concrete, and the same may be said of the proportions of the ingredients and the workmanship. Owing to practical difficulties in the preparation and testing of specimens, the results hitherto obtained are generally lower than the true values, especially in the case of the superior qualities of concrete produced during recent years.

So far as existing records go, it appears that stone or gravel concrete made in the proportions of $1: 2: 4$ are 
generally capable of developing a tensile strength of between $200 \mathrm{lb}$. and $300 \mathrm{lb}$. per square inch at an age of one month, richer concretes showing proportionately higher results.

Shearing Strength. Until comparatively recent years, the shearing strength of concrete was very generally stated at little more than one-tenth the compressive strength. The reasons for so low a value appear to have been either (1) that the methods adopted for the determination of shearing stress permitted the failure of the test specimens by tension long before the ultimate resistance to shear had been reached, or (2) that the term "shear" was wrongly used to denote complex action such as that taking place in the web of a beam, where diagonal tension is a governing factor. In either case the result would be the same, namely : the substitution of the tensile resistance for the shearing resistance of the concrete.

Improved methods of testing which provide for elimination of the effects of diagonal tension and other extraneous stresses have demonstrated the fact that the strength of concrete in direct shear is actually from 60 to 80 per cent of its strength in direct compression, and that in some cases the percentage is still higher.

Elastic Modulus. This coefficient is of much importance in reinforced concrete design because it enters into the formulæ employed for the calculation of all classes of structural members. The elastic modulus of concrete is represented by the quotient of the stress per unit area divided by the strain per unit length, and where pounds and inches are adopted as the units of measurement the modulus is expressed in pounds per square inch.

Values of the elastic modulus of concrete range from $300,000 \mathrm{lb}$. to upwards of $7,000,000 \mathrm{lb}$. per square inch according to different investigators, these extremely 
varied results being due to the quality and age of the concrete and the basis upon which the modulus is calculated. Even if all existing data were of approximately uniform character, it would still be impossible to state in advance a precise value for the modulus of any given quality of concrete that might be used in actual construction. The average value of $2,000,000$ lb. per square inch is one very generally adopted by practical designers, and this value corresponds fairly well with the results obtained in numerous tests of beams.

Elastic Limit. Strictly speaking, concrete has no true elastic limit, but there is a point in test diagrams beyond which a marked change in behaviour is evidenced, and this point may be regarded as denoting what is equivalent to an elastic limit for practical purposes, the point in question occurring where the stress has reached from one-half to two-thirds the ultimate resistance of the concrete.

Coefficient of Expansion and Contraction. It is well known that all bodies expand under the influence of heat and contract with a reduction of temperature. These phenomena are sometimes forgotten, or have never been known, by people who ought to know about them. Others there are who erroneously believe the expansion of concrete under heat is so much greater than that of other structural materials as to render the use of concrete inadvisable in some classes of work, and others again appear to think that there is a considerable difference between the expansive properties of concrete and steel bars or rods embedded therein to act as reinforcement, although it does not occur to the same persons to raise any such objection to the employment of structural steel sections in brick, masonry or concrete structures.

For these reasons it is just as well that we should devote a little attention to the subject in the present 
book. The expansion and contraction exhibited by all substances in consequence of temperature variations are measurable in three directions : length, breadth, and thickness, and may be measured as linear expansion or contraction in one direction, superficial expansion or contraction in two directions, and cubical expansion or contraction in three directions. For our present purpose linear expansion and contraction alone need be considered.

Numerous investigations have been made by scientists with the object of determining the expansion and contraction of solids, liquids and gases, with the result that coefficients are available for use by engineers, architects, and others in calculations affecting the expansion or contraction of structural materials under any given temperature conditions. As expressed in British units of measurement, the coefficient of linear expansion or contraction of any solid substance is the extent by which a length of the substance originally measuring one inch is increased or decreased by a variation of temperature equal to one degree Fahrenheit.

In the case of concrete, the average value of the coefficient may be taken at $0^{\circ} 000006$. To calculate the total change of length in any part of a concrete structure owing to temperature variation, it is only necessary to multiply the coefficient by the product of the original length in inches and the number of degrees Fahrenheit above or below the original reading of the thermometer. Thus, for a piece of concrete 1 in. long subjected to an increase of temperature equal to 2,000 degrees $F$., the expansion would be : $0.000006 \times 1 \times 2,000=0.012$ in. (about $\frac{1}{84}$ in.), and for a piece of concrete $100 \mathrm{in}$. long subjected to an increased temperature of 50 degrees $\mathrm{F}$., the expansion would be : $0.000006 \times 100 \times 50=$ 0.03 in. (about $\frac{1}{32}$ in.).

8-(1463b) 
Fortunately for engineers and architects employing concrete in conjunction with steel the coefficients of expansion and contraction for the two materials are almost exactly of equal value. It may also be of interest to mention that the expansion and contraction of concrete are considerably less than the corresponding properties of most descriptions of stone employed for structural purposes.

Expansion and Contraction During and After Setting. If the setting of concrete takes place under water, the concrete tends to expand, while if setting occurs in the air the concrete shows a tendency to contract. In the latter case, internal stresses will exist. It appears probable that the expansion or contraction actually occurring is approximately proportional to the amount of cement per unit volume of the concrete, as the sand and aggregate cannot be affected to any appreciable extent.

Resistance to Heat and Fire. From an exhaustive series of tests on various kinds of concrete at Columbia University, Professor Woolson drew the conclusions briefly summarized below-

(1) All qualities of concrete possess very low thermal conductivity, wherein lies their ability to resist fire.

(2) When the surface of concrete has been exposed for hours to great heat, the temperature of the concrete 1 in. or less beneath the surface is several hundred degrees below that of the outside.

(3) At a point 2 in. beneath a surface exposed to an outside temperature of $1,500 \mathrm{deg}$. F. for two hours, the concrete will not be raised in temperature by more than $500 \mathrm{deg}$. to $700 \mathrm{deg}$., and at points 3 in. or more beneath the surface it will not be heated above the boiling point of water.

In a subsequent series of tests on steel bars embeddẹ 
in concrete, Professor Woolson found that when the temperature of the concrete and the projecting ends of the bars was 1,700 deg. F., the temperatures of the embedded steel were : 1,000 deg. at 2 in., 400 to 500 deg. at 5 in., and 212 deg. at 8 in.

As a general rule, the hardest and densest kinds of concrete are best for withstanding heat, but cinder concrete, if of non-combustible nature, offers considerable resistance to the transmission of heat owing to the low conductivity of air in the porous aggregate. Gravel and stone concretes may be relied upon for good results, but varieties of rock containing a large proportion of quartz are apt to split, and others, such as limestone, suffer disintegration when exposed to great heat.

Water-tightness. In some classes of work the impermeability of concrete is a matter of comparatively minor importance, but in others it is highly important, as in reservoirs, tanks, pipes, ships, underground chambers and others which need not be mentioned in detail.

There is, fortunately, no serious difficulty in the way of securing water-tightness, providing the constituent materials are judiciously selected, correctly proportioned and thoroughly mixed, and that the concrete is carefully deposited and tamped in place. Aggregates of non-porous character can easily be obtained, sand is non-porous, and cement paste is practically non-porous after it has set. Therefore, water can only pass through concrete if any voids exist between the particles of sand and the fragments of aggregate. The manner in which voids in the finished concrete can be eliminated has already been discussed in a previous chapter.

Waterproofing Compounds. Various foreign substances such as hydrated lime, powdered clay and clay products, alum and soap are much advocated by advertịing firms as a ready means of securing water-tight 
concrete. The opinion of the United States Bureau of Standards in regard to such substances is as follows-

"The addition of so-called waterproofing compounds will not compensate for lean mixtures, nor for poor materials, nor for poor workmanship in the fabrication of concrete. Since in practice the inert integral compounds are added in such small quantities they have little or no effect on the permeability of the concrete. If the same care be taken in making the concrete impermeable without the addition of waterproofing materials as is ordinarily taken when waterproofing materials are added, an impermeable concrete can be obtained."

A recent report by Professor Duff A. Abrams on an investigation which has been going on for the past four years at the Lewis Institute, Chicago, shows that the admixture of powdered substances in concrete reduces the strength of that material approximately in proportion to the quantity of the substance added, the loss of strength consequent. on the addition of 1 per cent, in terms of the volume of cement in the concrete, ranging from $0^{\circ} 08$ per cent in the case of powdered brick up to 4 per cent in the case of gypsum.

Resistance to Sea Water. It has been recognized for many years that chemical action takes place between the acids contained in sea water and the alkaline constituents of Portland cement, and that if concrete immersed in the sea is of permeable nature, the cement will gradually disintegrate.

An exhaustive investigation into the effects of sea water on concrete, conducted by Mr. R. J. Wig and Mr. L. R. Ferguson, led these well-known American engineers to the conclusions that all well-made Portland cements will resist disintegration if properly used, and that waterproofing compounds have no beneficial effect, 
A reinforced concrete pile exhibited at the 1913 International Road Congress by Mr. W. J. Taylor, the county surveyor of Hampshire, may be mentioned as practical evidence of the satisfactory behaviour of well made concrete in sea water. The pile in question was driven twenty-two years ago, and, after having been for fourteen years alternately submerged and exposed by the rise and fall of tides, it was drawn and carefully examined. The concrete was found to be in perfect condition, and on being broken away from the embedded reinforcement, the steel was seen to be free from any trace of corrosion, thus affording further evidence of the fact that the concrete had suffered no appreciable disintegration during its long exposure to sea water.

Resistance to Oils. As a general rule it may be taken that mineral, animal and vegetable oils are not harmful to good concrete which has thoroughly hardened. Some vegetable oils, such as cocoanut oil and olive oil, which contain acids have been found injurious, and the same effect has been observed in concrete buildings where animal oils are heated to high temperatures.

Electrolysis in Concrete. Most of the fears which have been entertained respecting the possible effects of electrolytic action in concrete appear to be due to the assumption that the severe conditions established for the purpose of laboratory tests are likely to be reproduced in practical work. So far as the United Kingdom is concerned, the safeguards provided by the Board of Trade regulations are sufficient to obviate the risk of injury to concrete by stray electric currents. Negative evidence to this effect may be found in the fact that the inquiries made by the Institution of Civil Engineers' Committee on Reinforced Concrete failed to bring to light a single instance of electrolytic injury in this country. 


\section{CHAPTER X}

\section{REINFORCED CONCRETE}

As mentioned in a previous chapter, the principles of reinforced concrete were known by the ancient Romans, by whom timber, as well as copper, bronze, and iron, was employed as reinforcement. Similar applications of reinforcing material were made at different times in the middle ages, but the development of reinforced concrete on scientific lines was not commenced until the nineteenth century.

In 1830 the construction of reinforced concrete roofing was suggested by Loudon, and ten years later two systems of reinforced plaster floor construction were introduced, the method of applying the metal being very much akin to some methods adopted in the present day. In 1849, the first reinforced concrete boat was built by a Frenchman named Lambot, and it is interesting to know that this craft is still afloat and in excellent condition. In 1855 Wilkinson and Coignet patented their systems of reinforced concrete construction, and in 1861, Monier, a French gardener, commenced moulding boxes and vessels for horticultural purposes, his system being extended later to all kinds of architectural and engineering construction.

Another notable pioneer was Thaddeus Hyatt, by whom a book was published in 1877 giving full details of a most valuable series of experiments conducted on "Portland cement concrete combined with iron." Among other inventors who appeared between 1855 and 1895, Hennebique, of Paris, deserves mention as an engineer who went to work on thoroughly scientific 
lines, and has probably done more than any man to bring about the extensive use of reinforced concrete which is now evidenced in all parts of the world. Although British engineers may fairly claim to have taken an equal share with their confrères on the Continent in the development of reinforced concrete, after progress was very slow in this country until the material was re-introduced by the late L. G. Mouchel, a French engineer interested in the work of Hennebique. Subsequent to the establishment of what is now known as the Mouchel-Hennebique system, many other forms of reinforced concrete have sprung up, some imported from the Continent and the United States, and others devised by British engineers.

The designation reinforced concrete is not altogether a happy one, for the reason that it does not indicate or suggest the combination of two materials in such a way as to enable them to work in harmonious co-operation. The nature of the combination was far better expressed by the early and now obsolete term concrete-steel, and also by the designation ferro-concrete, which is still employed to a considerable extent.

Concrete is a material characterized by permanent durability and high resistance to compression, while steel is very susceptible to corrosive influences, although possessing great advantages in respect of elastic strength. The object aimed at in the combination of these two materials is to utilize the most valuable properties of each in the most effective manner possible.

The principles involved can be most clearly explained by considering the case of a plain concrete beam supported at both ends and carrying a load either concentrated at the centre or distributed uniformly along the whole of the upper surface. In either case, the effect of the load is to cause the beam to bend or deflect 
downwards, the stretching of the material at the lower surface tending to tear apart the concrete, and the pressing together of the material at the upper surface tending to crush the concrete.

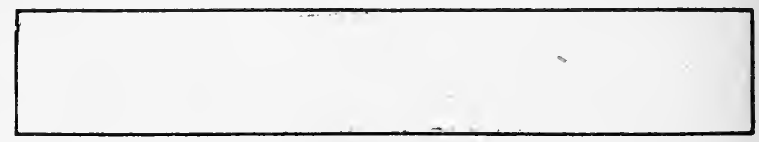

FIG. 33

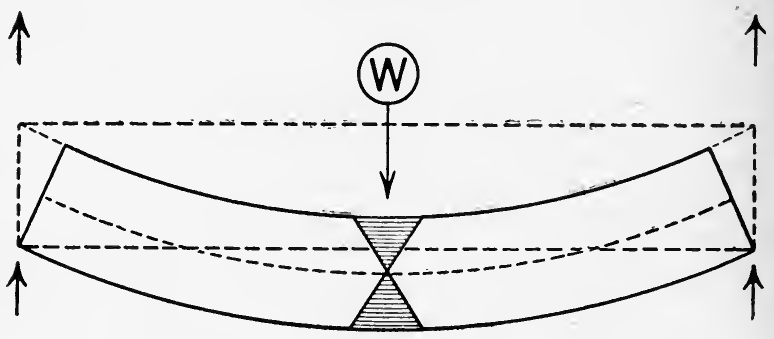

FIG. 34 .

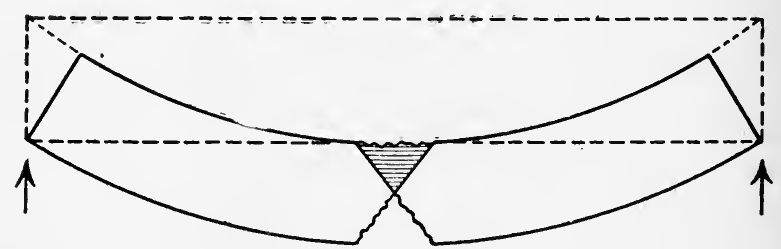

FIG. 35

These effects are represented in Figs. 33 and 34, the former showing a beam supported at the ends, and the latter showing the same beam as bent by the action of a load W, the amount of deflection being purposely exaggerated so as to make things clear.

A little consideration will show that as there is tension at the bottom, and compression at the top of the beam, 
there must be a plane at which each kind of stress disappears, or merges into the other kind. The tensile and compressive stresses are represented in Fig. 34 by two triangular shaded areas, and the intersecting boundary lines of these areas may be regarded as acting something like a pair of scissors, the movement of the arms decreasing towards the central pivot, where there is no movement whatever. This central pivot corresponds with a point in the neutral plane, or neutral axis as it is more generally termed, of a beam, where there is no stress owing to the progressive diminution of tension and compression upwards from the bottom and downwards from the top, respectively.

If the concrete were capable of resisting an amount of tension at the bottom equal to the amount of compression it is able to resist at the top, the beam would be economical. But it happens that the resistance of concrete to tension is only about one-tenth of its resistance to tension. Consequently, if a beam such as that in Figs. 33 and 34 were loaded to an extent sufficient to develop the full resistance of the concrete in compression above the neutral axis, the concrete below the same axis would be cracked and pulled apart by tension, as indicated diagrammatically in Fig. 35 .

The net upshot is that the load on a beam of plain concrete must be proportionate to the strength of the material acting in tension. Thereby, nine-tenths of the strength of the concrete acting under compression must be wasted, and the beam is very uneconomical.

Let us now see how this drawback can be overcome by the aid of steel. With the object of making things clear we will assume that the concrete beam measures 10 in. broad by 12 in. deep, as in Fig 36, the neutral axis being at the depth of 6 in., or midway between the top and the bottom. The concrete is assumed to 
be capable of withstanding compression at the upper edge to the extent of 500 pounds per square inch, and our aim is to arrange matters so that stress to this intensity may be safely developed. As the stress diminishes progressively towards the neutral axis, where its value is 0 (see Fig. 37), the mean stress over the area of 10 in. by 6 in. (shaded in Fig. 36), can only be $(500+0) / 2=250$ pounds per square inch, and the total compression in the same area amounts in consequence to $10 \times 6 \times 250=15,000$ pounds. Since the concrete at the bottom of the beam would be ruptured by tension before the safe stress of 500 pounds per square inch in compression could be reached at the top of the beam, it is obvious that all the concrete in the lower area of 10 in. by 6 in. (left white in Fig. 36), must be written off as a loss, so far as concerns resistance to tensile stress. But the same concrete can be utilized as a medium for holding in place and bringing into play one or more steel bars, which may be employed to supply the necessary resistance at the bottom of the beam.

If we take the safe resistance of steel of tension at 15,000 pounds per square inch, which is a very moderate value, one square inch ot steel will be capable of balancing the 15,000 pounds of compressive force in the concrete occupying the upper area of the beam. This area of steel can be applied in the form of a bar placed at $1 \frac{1}{2}$ in. above the bottom of the beam. To be strictly correct, rather more than one square inch of steel would be required for this position of the bar.

Then, assuming for the moment, that the position of the neutral axis is unchanged, the cross section of the beam will be as represented in Fig. 38. We now have a reinforced concrete beam, where the concrete is employed exclusively in resisting compression, and the steel solely in resisting tension. 

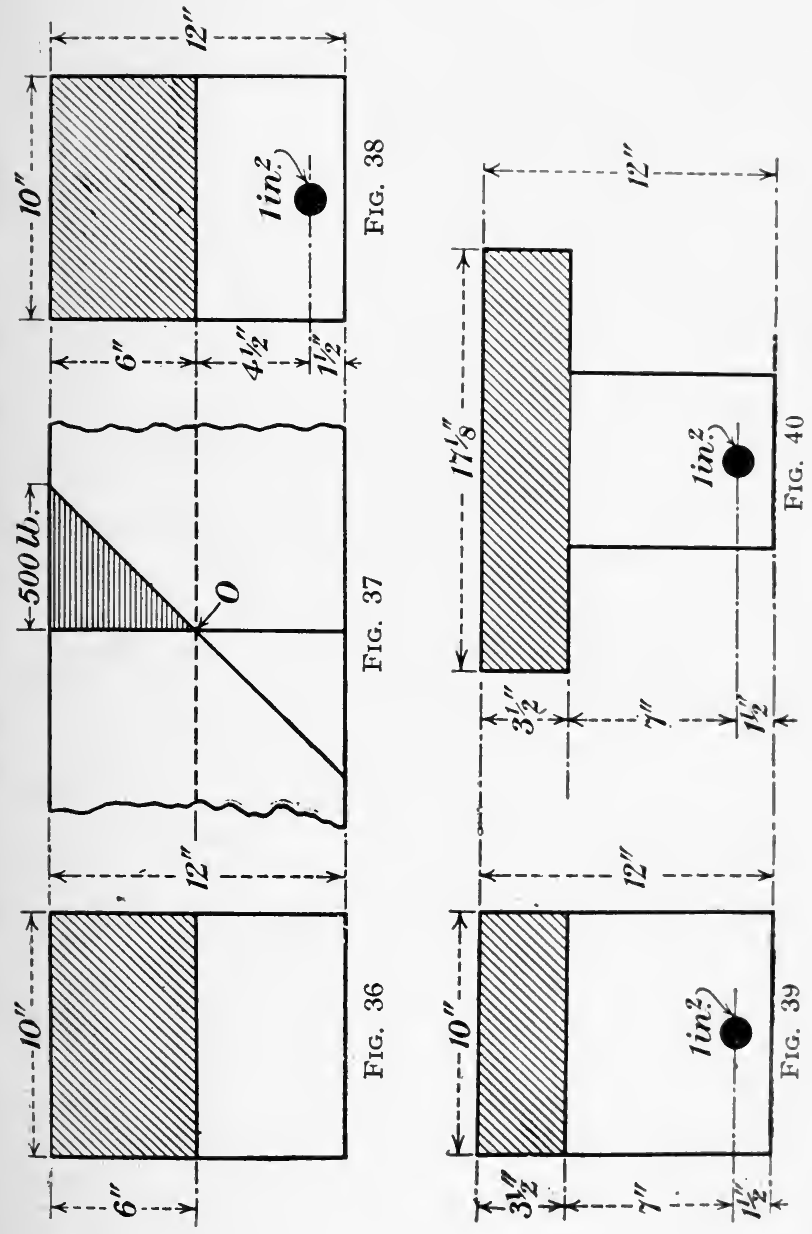
The efficiency of the concrete acting in compression has been increased ten-fold. Against this, however, we have to set the cost of the steel bar and the virtual loss of the concrete in the lower area. Therefore, the net result is that the efficiency of the beam is raised to about seven times, instead of ten times, that of the plain concrete beam originally considered. This is on the assumption that the position of the neutral axis has remained where it was at the start.

As a matter of fact, the laws of mechanics involve a change, and under the conditions stated the new position of the neutral axis will be at a depth of $3 \frac{1}{2}$ in. from the top of the beam, as represented in Fig. 39. Hence the effective area of concrete is reduced from $(10 \times 6)=60$ (square inches) to $\left(10 \times 3 \frac{1}{2}\right)=35$ (square inches) and a proportionately larger area of concrete in tension is wasted, with a correspo iding reduction of the efficiency assumed to have been secured.

Fortunately, this loss of efficiency and economy can be obviated by changing the sectional form of the beam to that shown in Fig. 40. Here the upper part is extended on either hand to form a projecting flange measuring $\left(17 \frac{1}{8} \times 3 \frac{1}{2}\right)=60$ (square inches), and the width of the lower portion, or rib, is reduced from $10 \mathrm{in}$. to 7 in., so that the area measures $\left(7 \times 8 \frac{1}{2}\right)=59^{\circ}$, say 60 (square inches). This reduction of width can be effected with perfect safety because the only object of the concrete is to provide accommodation for the steel, and to act as a connecting link between the tensile and compressive forces below and above the neutral axis. Thus, we have arrived at the form of what is termed a $T$-beam, the most efficient and economical type of a reinforced concrete member, and we have been able to retain the increased efficiency which appeared 


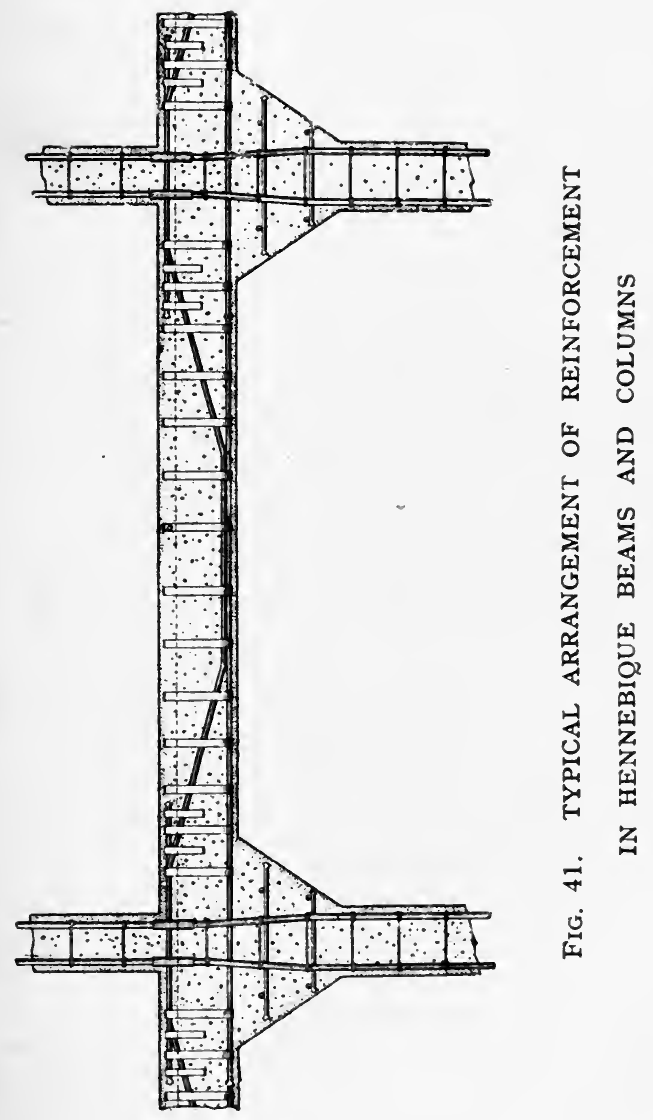


to be threatened by the change in the position of the neutral axis.

In actual practice, the bars used for resisting tension are supplemented by steel rods arranged so as to form a metallic connection between the tension and compression areas of the beam. The steel so employed is termed web reinforcement, and besides linking together the primary stresses of tension and compression, it is of great value in resisting secondary stresses which are developed in various directions throughout the concrete. Fig. 41 shows a typical arrangement of Hennebique reinforcement in beams and columns.

Steel bars are frequently used near the upper surface of reinforced concrete beams, in cases where it is desirable to reduce the amount of concrete acting in compression and consequently to limit the dimensions of the beams. Compression reinforcement is also applied to beams carried over one or more intermediate supports, for the reason that in such cases, the stresses in any of the spans may be reversed as a result of unequal loading, the upper part normally acting in compression becoming subject to tension, and the lower part normally acting in tension being called upon to act in compression.

Although steel employed as compression reinforcement is not so economical as that applied for resistance to tension, its use in this way is often most advantageous and in some cases absolutely necessary.

Turning now to columns and other structural members intended principally for the support of loads resulting mainly in compressive stress, it must be evident from what has been said, that the use of steel as reinforcement cannot be attended with anything like the economy obtained by the use of reinforcement in beams.

Steel acting simply under pressure is necessarily more economical than concrete similarly used. But in 
buildings and kindred structures where fire risks have to be considered, the protection by steel columns or stanchions by means of concrete, brickwork, terra cotta, and other materials, practically brings the cost of steel up to that of reinforced concrete, the protective casing making the final dimensions of the two classes of members approximately equal. Moreover, where columns or other compression members are relatively slender, and where the loading is more or less eccentric, bending stresses are developed in addition to simple compressive stress, and under such conditions reinforced concrete becomes distinctly economical. It should be remembered also that anything in the nature of hybrid construction is not to be recommended, and that the strength and rigidity gained by adopting reinforced concrete throughout any structure, thus constituting what is known as monolithic construction, is a really valuable asset.

In a book of this character, it would be out of the question to enter upon a technical discussion of reinforced concrete design. Those of our readers who wish to make a study of that interesting branch of engineering can obtain full information from any of the numerous treatises now available. We may point out, however, that the principles underlying the design of the three classes of members briefly discussed in this chapterbeams, compression members, and members subject to combined stresses-constitute the basis of reinforced concrete construction.

It cannot be too clearly recognized that reinforced concrete differs essentially from structural steel merely encased in concrete as a protection against fire and rust, and that the scientific combination really places a new material at the disposal of the engineer and the architect. 
Toughness and genuine elasticity are two special characteristics of reinforced concrete, for although the properties of the constituent materials are not actually changed, the combination behaves very much as if such a change had taken pla e in the concrete.

Some years ago, the remarkable elastic strength exhibited by reinforced concrete structures, and the absence of visible cracks in beams under loads causing considerable deflection, led to the belief that, when working in combination with steel, concrete could be stretched to a far greater extent than plain concrete, and without causing actual rupture. This theory was supported by $M$. Considère, an Inspecteur-Général des Ponts et Chaussées, who claimed, in a communication to the Académie des Sciences in 1902, that his tests of reinforced concrete members proved the ultimate extensibility of the concrete to be from ten to twenty times that of plain concrete tested in a similar manner. Subsequent investigation has shown that this conclusion was not literally correct, the fact being that the greatly increased extension of the concrete was accompanied by a large number of invisible cracks distributed along the surface. Nevertheless, there is a great difference between the behaviour of plain and reinforced concrete. In the former, failure takes place suddenly, and is preceded by the opening of one or more large cracks, while in the latter failure takes place gradually, and only after ample warning, numerous small cracks developing in such a manner that the total elongation at final rupture is from ten to twenty times that of plain concrete.

Thus by the addition of steel as reinforcement the extensibility of the concrete is greatly developed, instead of being limited to the amount possible at any one point, as in plain concrete.' This valuable property is largely 
the outcome of the perfect adhesion of the two materials, the bond between them being undisturbed by variations of load and temperature. As the coefficients of expansion of concrete and steel are of practically equal value, the two materials continue to work together at all temperatures.

In the case of a fire the steel is protected from excessive heat by the insulating properties of the concrete in which it is embedded. Similarly, the steel is most efficiently protected from corrosion by the film of cement which attaches itself to the surface of the metal, or if the steel is slightly rusted at the time of use it is protected by an impervious coat formed as the result of chemical combination between the metallic oxide and the cement.

Among the advantages of reinforced concrete as a structural material one of the most important is its property of increasing in strength and durability with age. It also possesses the advantages of rigidity, impermeability, resistance to fire, and economy both as regards first cost and the elimination of the maintenance charges which are necessary in the case of all other materials.

Reinforced concrete structures differ from those carried out in accordance with ordinary methods in the respect that the entire fabric is of monolithic character, the concrete being continuous throughout all parts of the work, the steel giving an additional measure of continuity and contributing to mutual co-operation between the various members and structural elements. Therefore, a well designed and properly built reinforced concrete structure is capable of acting as a single unit in case of emergency, and if unexpected strains are suddenly developed by earth movements or any accidental cause, the integrity of the structure will be $9-(1463 \mathrm{D}) 20 \mathrm{pp}$. 
maintained in consequence of the aid rendered to the part affected by contiguous structural members.

Thus, as happened to each of the three buildings, near Tunis, illustrated in Fig. 42, a well-designed reinforced concrete structure may settle down at one side and be levelled up again without suffering the least damage. The photograph here reproduced shows two buildings after restoration to a vertical and the third at an inclination of about 25 degrees. The subsidences in this case were due to a depression caused by reduction of the water level in an adjoining lake.

Another marked characteristic of reinforced concrete construction is that of lightness or slenderness in all its parts, as compared with the heaviness and massiveness of plain concrete, brick and masonry structures. Owing to the elastic strength of the combination, the engineer or the architect, as the case may be, is enabled to depart from the time-honoured customs of employing material in heavy masses, so as to provide for stability by sheer dead weight and mass, and is at liberty to adopt forms of design akin to those typical of steel construction.

Apart from the gain of interior space in buildings, reservoirs, coal bunkers, and other structures intended for storage purposes, important economies are effected by the slenderness of reinforced concrete construction. The saving of material in the superstructure is in itself a sufficiently important item, but it naturally has the further effect of reducing the loads to be transmitted to the foundations, thereby automatically reducing the cost of the substructure, and very frequently obviating difficult problems in the way of foundation work.

Reinforced concrete construction has been developed to a remarkable extent during the past twenty-five years, and, after having passed successfully through a 


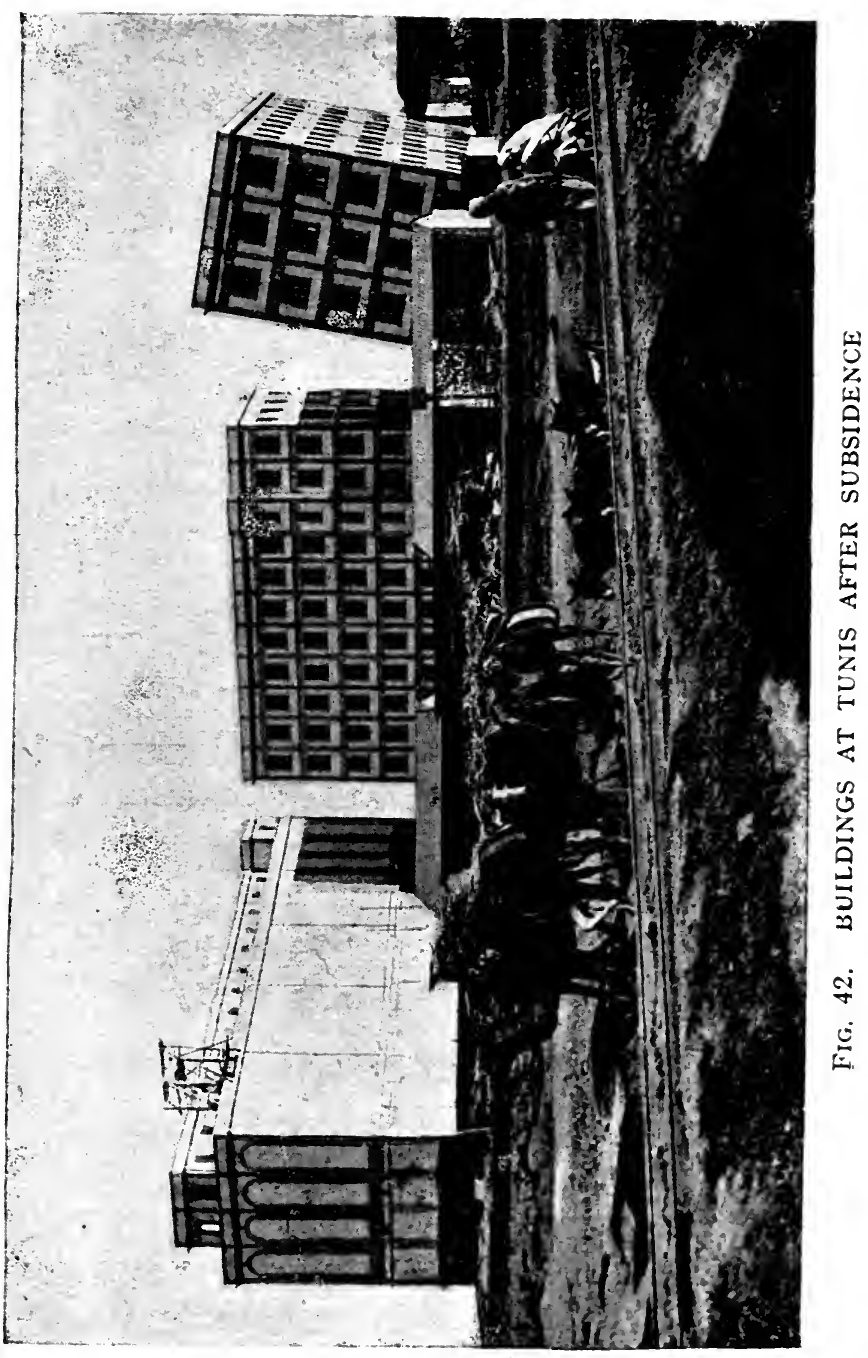


period when it was regarded with much suspicion and prejudice, is now accepted by engineers and architects throughout the world as a reliable form of construction, worthy of adoption in almost every class of work.

A point which should not be overlooked is that the somewhat rough and ready methods of calculation

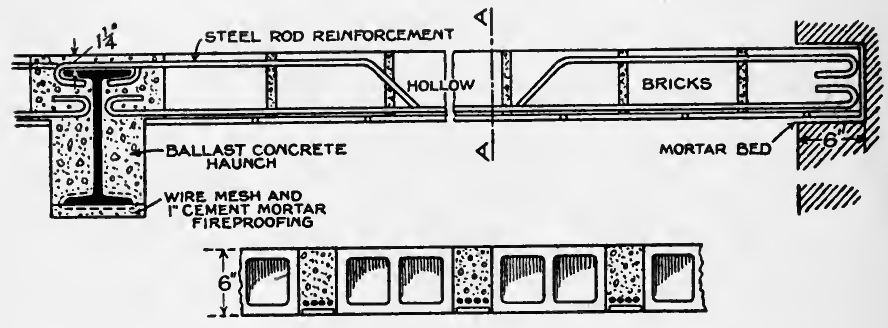

FIG. 43

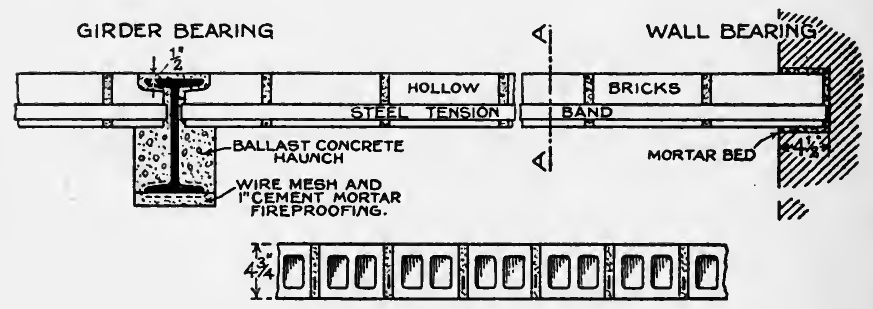

FIG. 44

employed years ago by the pioneers of reinforced concrete have given place to scientific methods of design complying more closely with theoretical principles than the methods adopted in the design of masonry and steel structures.

It would be impossible in this book, as well as beyond its scope, to describe and illustrate the numerous classes of construction to which concrete is applied, whether plain or in combination with steel as reinforcement. Some of the illustrations given in this and preceding 
chapters indicate a few important uses of the material, which is employed throughout the world in the construction of buildings, bridges, viaducts, marine and river works, colliery structures, aqueducts, culverts, drainage conduits, water and sewage reservoirs, swimming baths, grain silos, ships, and other floating structures, bunkers for the storage of coal, ore, stone, and other materials, and many other types of construction too numerous for individual mention.

The principles discussed in this chapter have been applied in an interesting way to the design of reinforced brickwork. Walls of this combination have been adopted in many industrial buildings, notably in the works of Messrs. Rowntree \& Co., at York, and in the South Lambeth goods station of the Great Western Railway. The reinforcement is in the form of netting with tension strands throughout, and laid in the joint of every alternate course of brickwork. Another variety of reinforced brickwork is represented by the Kleine floor system, of which illustrations are given in Figs. 43 and 44 . This type of construction embodies the use of hollow bricks with closed ends, set in cement mortar wherein are embedded tension bands or rods. Fig. 43 includes sections of a floor with small bricks, the reinforcement consisting of mild steel hooping strips; Fig. 44 shows the construction of a floor with larger bricks, the mortar joints being wide enough for the insertion of the requisite amount of reinforcement, in the form of round rods, for spans of considerable length.

The remarkable properties of reinforced concrete have led to the adoption of the combination in almost every branch of architectural and engineering work, and even to its use in building railway carriages and waggons, motor car bodies, canal and river barges, and sea-going steamships. 


\section{CHAPTER XI \\ CONCRETE SHIPBUILDING}

THE building of ships in reinforced concrete is one of the most remarkable developments of the present century in the way of concrete construction. Yet the principle is [a very old one. In various sacred writings, 2,000 years or more old, references are made to stone coffins floating on the waters, and if stone will float there is surely nothing to prevent concrete from doing the same.

Years ago, when iron ships were proposed, a conservative-minded engineer said that he could not understand how an iron ship could float at all. In fact, he said that it could not, and would not float. Another equally reactionary person offered to eat the boiler of the first steamship that crossed the Atlantic, the only result being that he ate his words instead of the boiler.

Concrete ships are no longer the subject of controversy so far as the question of buoyancy is concerned, and concrete shipbuilding passed the experimental stage as long as thirty or forty years ago. The historic rowing boat (Fig. 45) built by the French engineer Lambot in the year 1849 still floats on a lake near the town of Miravel, apparently none the worse for nearly three-quarters of a century's exposure.

- Following the construction of this pioneer vessel, many craft of larger dimensions were built in France, Italy, Holland, and other countries, and towards the conclusion of 1917 more than 200 concrete vessels had been completed, including lighters, barges, sailing ships 
and motor boats Three or four of these were constructed in this country, the most notable example being a large lighter of 200 tons capacity launched in 1912 on the Manchester Ship Canal, where it is still in service for pumping sludge dredged from the channel of that waterway.

When the great European war was in progress, and the need for more ships became acute, energetic measures

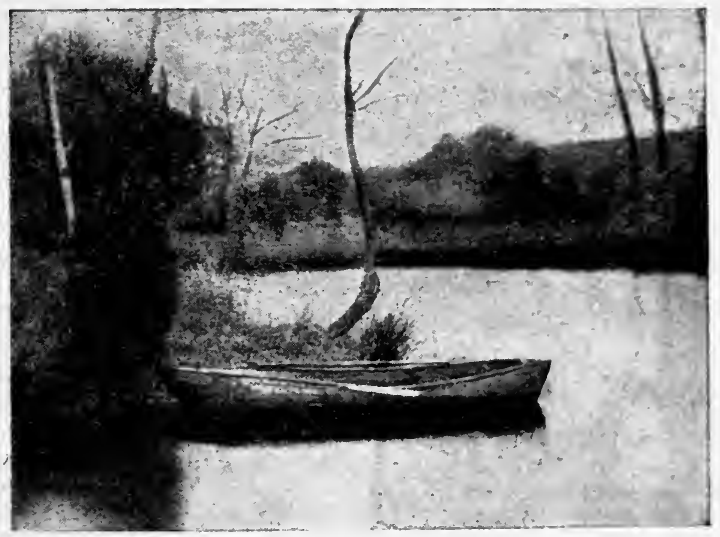

FIG. 45. THE LAMBOT BOAT, BUILT 1849

were adopted by the British, French and American Governments to encourage the production of sea-going concrete barges, steam-tugs and cargo steamships. The first series of contracts made by the British Admiralty provided for the construction of over 200 ships, including sea-going barges of 1,000 tons capacity and steam-tugs of 750 horse-power. A score of new shipyards were promptly established and equipped by firms with special experience in reinforced concrete 
work, with the co-operation either of qualified naval architects or of practical shipbuilders. Notwithstanding the large amount of preparatory work entailed, and various difficulties connected with the supply of materials and labour, the first 1,000-ton barge was launched in August, 1918, and by the end of the year some fifteen vessels of the same class were completed. Equally rapid progress was kept up until the conclusion of hostilities, when the Admiralty programme was abandoned. Fig. 46 illustrates a representative example of the barges turned out from the British shipyards.

The war programme of the French Admiralty provided for the construction of more than 750 barges, steam tugs and motor boats. Large numbers of these vessels were built in different parts of France, and operations were continued actively until the termination of the war.

In the United States, the original concrete shipbuilding scheme covered the construction of over forty-two steamships, of $3,000,3,500$ and 7,500 tons capacity, to say nothing of barges, lighters, and other craft of comparatively small dimensions. After the Armistice the construction programme was reduced to eight 7,500-ton tank steamers, and six cargo steamships, including two of 7,500 tons, three of 3,500 tons, and one of 3,000 tons capacity.

A sincere tribute is undoubtedly due to the United States Government and their technical advisers for the energy and courage they displayed in the unprecedented task of building concrete ships of the dimensions stated. The enterprise of the Government was probably encouraged by the previous completion and satisfactory record of the 5,000-ton steamship Faith, built at San Francisco in 1916 by a private company. This pioneer 


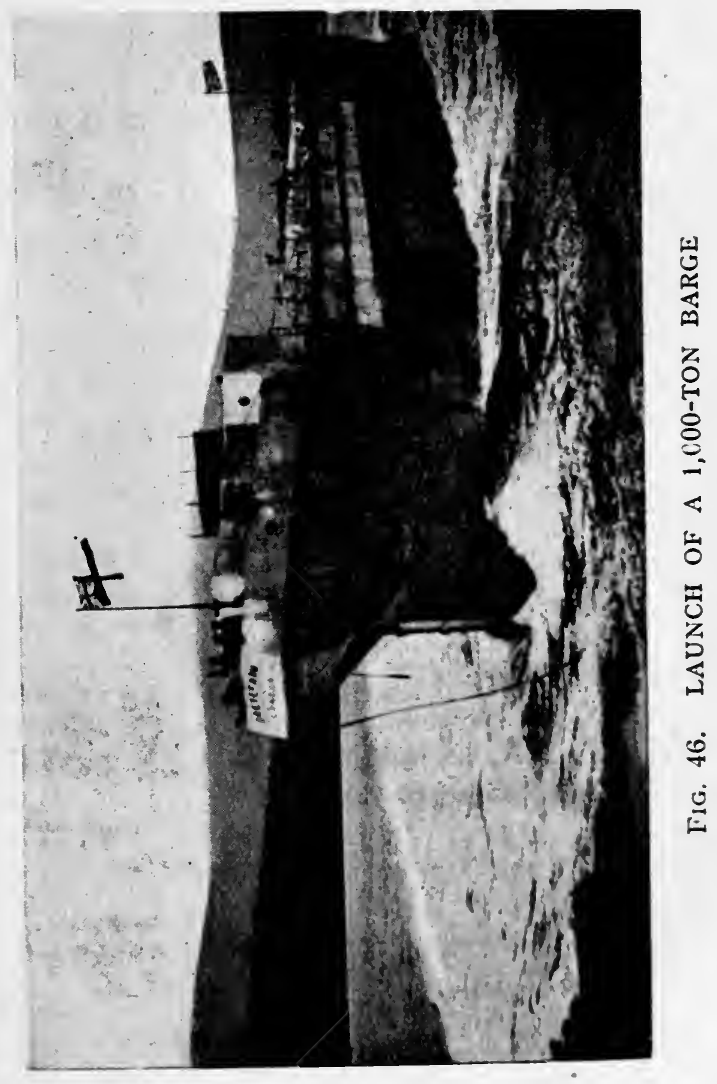


concrete ocean-going steamer has been carrying cargoes continuously since her trials, having completed voyages covering between 15,000 and 20,000 miles in all kinds of weather with perfect satisfaction to all concerned.

In addition to the ships turned out for the Governments mentioned, many concrete vessels have been constructed by private builders in different countries. The first British-built concrete steamship, the Armistice, is a vessel of 1,150 tons deadweight capacity, now owned by Messrs. Leopold Walford, Ltd., of London. Fig. 47 is a recent view of the vessel, which has behaved admirably in the roughest weather, and proved a most remunerative investment owing to her relatively great freight-earning capacity.

Several cargo motor boats, up to 1,000 tons capacity, have been built in France for Channel and other services, and a good many similar vessels have been turned out from Scandinavian shipbuilding centres. In Australia, a pontoon of 800 tons displacement was completed in 1915 for the harbour authorities of Sydney ; at Singapore a concrete train ferry boat is in regular use across the Straits; a concrete motor boat was put in service not long ago at Shanghai ; a similar vessel was built about the same time at Barcelona ; many motor boats, lighters, and other craft have been constructed of late in the Dutch East Indies; and there have been considerable activity in the concrete shipbuilding industry in various parts of South America, as well as in the United States and Canada.

Fig. 48 illustrates two remarkable concrete floating structures, built near Shoreham towards the end of the war, and which became known as " mystery ships." Each of the towers is $180 \mathrm{ft}$. in height, the lower part being constructed of reinforced concrete blocks. Nearly 


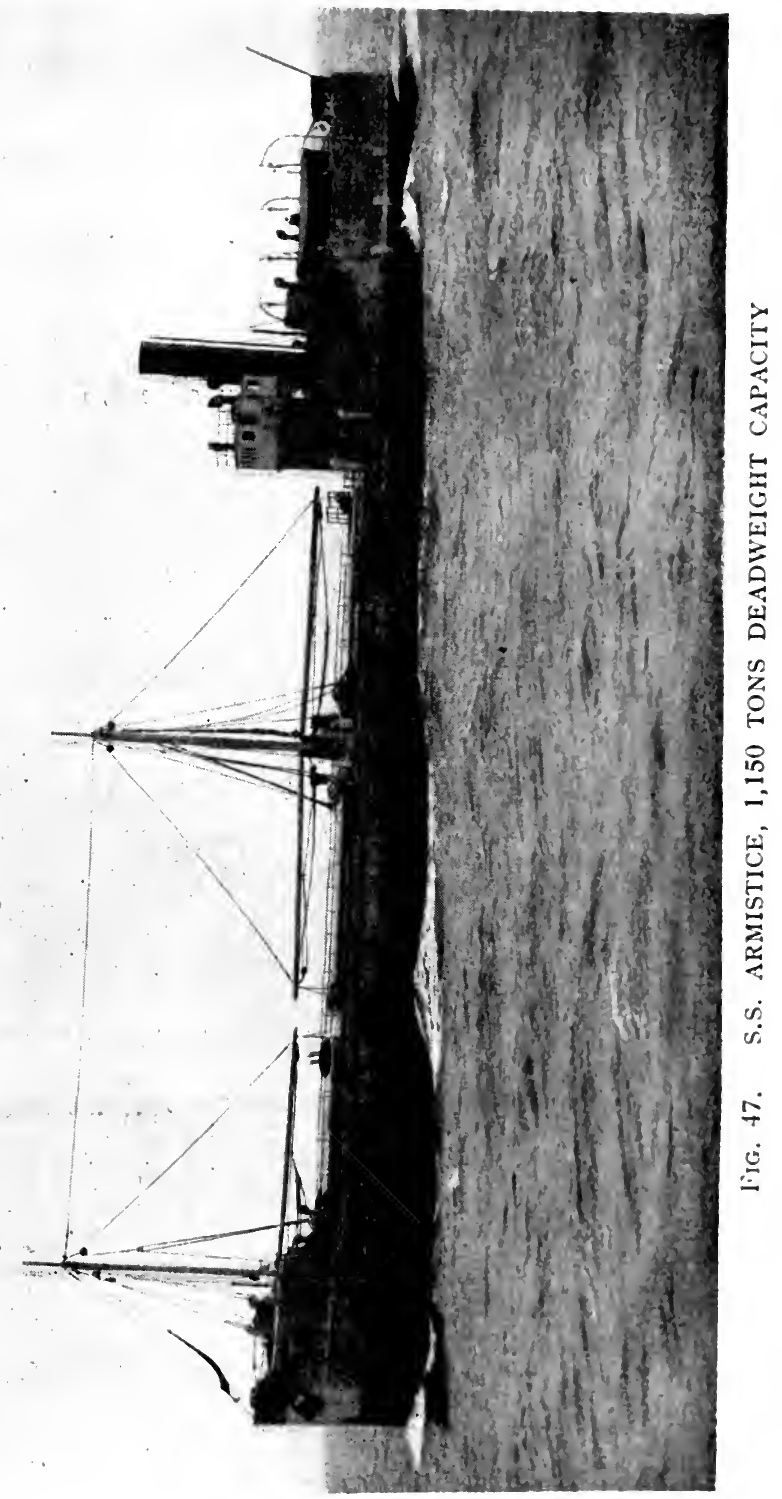


100,000 of these were used in each vessel, and the total weight of concrete was about 9,000 tons, the steelwork of the superstructure weighing nearly 1,000 tons. In spite of these weights, the draught of the structure was only $14 \mathrm{ft}$. when afloat. Therefore, the tower rose to a height of $166 \mathrm{ft}$. above the surface of the water. Originally intended for ship salvage work, the craft are now being employed as navigation marks and signal towers. One of them has been towed away and sunk near the Nab Lighthouse in $70 \mathrm{ft}$. of water, the top of the superstructure projecting $110 \mathrm{ft}$. above the sea.

Turning now to structural considerations, concrete ships may be conveniently classed in accordance with the methods of construction adopted. There are three principal methods-monolithic, unit, and skeleton construction.

In the first of these the object is to make the concrete work perfectly monolithic - as if it were formed from a single piece of stone-by following the practice which long experience has shown to be satisfactory for concrete structures on land.

The various operations involved in the building of a ship on the monolithic system may be briefly outlined as follows - The floor of the building berth, or slipway, is laid on lines of concrete blocks. The hull is moulded entirely in shuttering, the outer shell of which is built up first so as to form a huge mould, determining the exterior shape of the hull. In this mould the steel bars and network, employed for reinforcement of the concrete, are assembled and fixed in position. The reinforcement for the transverse frames and longitudinal stringers is partly enclosed in timber moulds, and the inner shell of the general shuttering is built up, board by board, as the concrete is deposited. Bulkheads, decking, hatchway coamings, deck-houses, and all other details are 


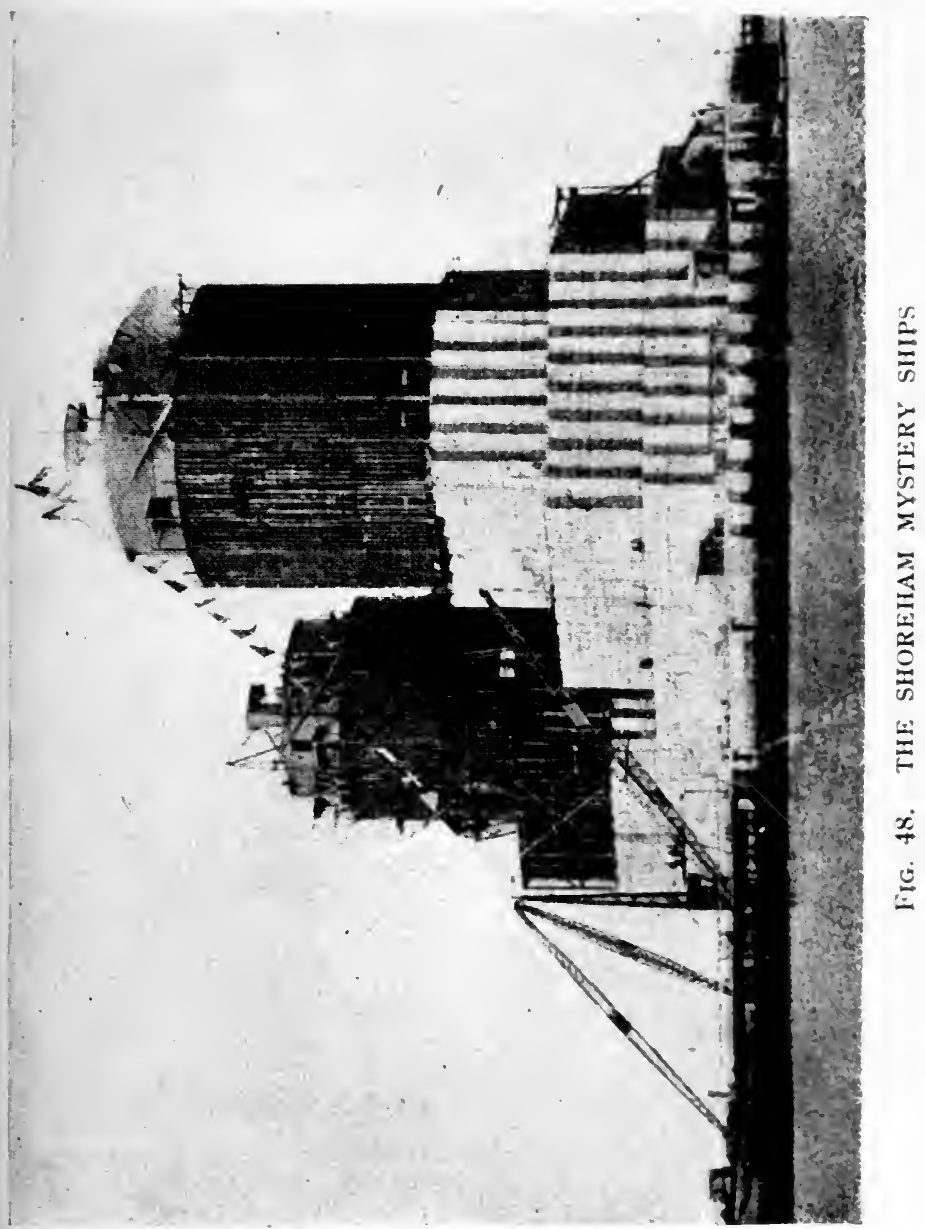


constructed in a similar manner after the exterior of the hull has been well advanced towards completion.

The unit system of construction has been followed in various British shipyards. The hull may be built up of separate panels cast and finished in advance, and afterwards incorporated with frames moulded in the usual way. Again, the frames may be prepared as precast units and connected with monolithic concrete forming the general shell of the hull.

The skeleton system of construction is carried out by building a cage of steel rods, or steel rods and network, the cage being plastered on both sides with fine concrete. The historic Lambot boat was so built, and the system has been extensively adopted in Italy, where the art of plastering has reached a high stage of development. An elaborated variety of the skeleton systems involves the building up of a double framework of steel, concrete being deposited between the two layers of steel as well as being plastered on the inside and the outside.

Experience shows that satisfactory results can be obtained under all three systems of construction, each of which possesses characteristic advantages and disadvantages. Therefore the choice of a system for adoption must be governed to a considerable extent by the dimensions and intended use of the vessel to be built. For large ocean steamships the monolithic system naturally commends itself as the strongest and most reliable, while for light river craft the skeleton system is distinctly attractive.

The cost of a concrete hull may be put without serious error at about 70 per cent the cost of an all-steel hull of equal deadweight carrying capacity. Actual figures published by the United States concrete shipbuilding department show that the cost of concrete tank steamers 
at war rates was from 20 to 40 per cent less than that of steel vessels of equal capacity.

In comparing concrete and steel ships, it must be borne in mind that the size of a concrete hull is necessarily greater than that of a steel hull of equal cargo capacity in terms of deadweight. Therefore, the concrete hull is capable of accommodating a greater volume of cargo, an advantageous feature in the transport of light and bulky merchandise, for which freight is charged by measurement and not by weight. To take a specific case in illustration of this point the Armistice, on her first trip to London brought 900 tons of oats, or some 200 tons more than could have been loaded into a steel ship of the same deadweight capacity, not because the steel ship would be incapable of carrying an additional weight of 200 tons, but simply for the reason that it would be absolutely filled by the 700 tons of grain. Thus one of the disadvantages of concrete becomes a positive advantage where light and bulky materials are concerned.

In this brief review of concrete shipbuilding it would be impossible to discuss even briefly the many technical problems involved. It may safely be said that the behaviour of the many vessels constructed during the past quarter of a century, and particularly of ships up to 7,500 tons capacity launched during the past two or three years, is sufficient to prove that all structural problems have been solved. The future of the industry, which has been carried on chiefly abroad since the closing down of the Admiralty shipyards, depends entirely upon the perfection of methods and organization conducive to rapid and economical construction. The adaptation of reinforced concrete to the building of large ships has involved a good deal of tentative work. Naval architects and builders have generally adopted 
the prudent course of using more concrete and more steel than appeared to be absolutely necessary, leaving practical experience to indicate future economies. Several noteworthy improvements due to recent shipbuilding operations have been of direct benefit to those engaged in concrete construction on land. Among these may be mentioned improved methods of designing and erecting moulds and shuttering, the production of concrete characterized by exceptional strength, density and impermeability, improvements of procedure in applying reinforcement and the placing of concrete, the development of construction on the precast unit system, and the introduction of light-weight concrete.

Whatever may be in store for the industry in years to come, it has been clearly proved that concrete ships offer advantages which cannot be overlooked in respect of steadiness and seaworthiness in all weathers, the readiness with which repairs can be executed after collision or other accidental damage; freedom from vibration, leakage and extremes of temperature variation, and resistance to fire and shock.

Although there is no probability that it will displace steel in general shipbuilding practice, reinforced concrete can certainly be employed usefully in the building of cargo boats, coasting steamers, steam tugs, motor boats, lightships, barges, and other classes of floating structures too numerous for individual mention. 


\section{INDEX}

Abrams, Prof. D. A., 20, 106 Advantages of concrete ships, 134

Age, effects on concrete, 97

Aggregate, 4, 21, 33, 37, 93

American Joint Committee, 98 Ancient concrete, 4, 5

Architecture, concrete in, 76, 80

Armistice, S.S., The, 128, 133

Ashes, 21

Aspdin, Joseph, 12

Batterie des Maures, 55

Beam moulds, 62

Beams, concrete, 109 reinforced concrete, 111

Belgian cement, 18

Block-making machines, 62

Breeze, 22

Brickwork, reinforced, 123

British-built concrete steamship, first, 128

British standard specification, 12

Building blocks, 83

CaIsson construction, 54

Cargo capacity of Sh ps, 133

- motor boats, 128

Carving concrete, 81

Cement -

Chemical composition, 15

Definition, 12

Fineness of grinding, 14

Manufacture, 16

Measuring, 37

Medina, 17

Natural, 17

Parker's, 17

Portland, 9, 12, 74
Cement-(Contd.)

Quick-setting, 16

Roman, 17

Scott's or Selenitic, 19

Setting time, 16

Slag, 18

Slow-setting, 16

Soundness, 17

Standard specification, 14

Storage, effect of, 33

Tensile strength, 15

Testing, 16, 17

White, 74

-

Church, New York, 89

Clinker, 21

Coal residues, 21

Coke, 21

Column moulds, 61

Concrete-

Antiquity, 4

Blocks, building, 83

Compressive strength, 97

Consistency, 94

Definition, 1

Density, 23

Durability, 6, 7

Depositing, 45, 47, 49

Elastic limit, 102

- modulus, 101

Expansion and contraction, 102

Fire resistance, 104

Handling, 96

History, 1

Light-weight, 22

Materials for, 11, 33

Mixers and plant, $38,40,41$, $42,48,94$

Mixing, 33, 36, 38, 40, 42, 94

Monolithic, 52 
Concrete-(Contd.)

Motor boats, 126, 128

Oil, effects of, 107

Origin, 1

Physical properties, 91

Proportioning, 23

Sea water, resistance to, 106

Shearing strength, 101

Ships, advantages, 134

Surface treatment, 70

Tamping, 96

Tensile strength, 100

Water-tightness, 105

Conglomerate, 2

Considère, 118

Density of concrete, 23

Depositing concrete, $45,47,49$

Dome of Pantheon, 6

Durability of concrete, 6,7

Egyptian concrete, ancient, 4 Elastic limit, 102 modulus, 101

Etched surface finish, 76

Expansion and contraction, 104

FACTORY building, U.S.A., 79 Faith, S.S., 126

Ferguson, L. R., 106

Ferro-concrete, 109

Fineness of grinding cement, 14

Fire resistance, 104

First British-built concrete steamship, 128

Floor centring, 63

Flooring, 69, 122

Fuller, W. B., 29, 31, 92

Granolithic finish, 75

Gravel, 21, 22

Gravity deposition, 45, 47, 49

Grecian concrete, ancient, 5

HAND mixing, 36

Handling concrete, 96
Heat and fire resistance, 104 Hennebique system, 108 Hyatt, Thaddeus, 108 Hydrated lime, 19 Hydraulic lime, 18

Inst. C.E. Committee, 107

Kirkaldy \& Son, tests, 99 Kleine floor system, 123

\section{Laitance, 94}

Lambot boat, 108, 124

Le Chatelier test, 17

Lewis Institute, Chicago, 20, 33

Light-weight concrete, 22

Lime, 18, 19

Lion Chambers, Glasgow, 71

L.C.C. regulations, 98

MACHINE mixing, 38

Manchester Dock, sheds, 59

- Ship Canal, lighter, 125 .

Materials for concrete, 12,33 .

Measuring materials, 37

Mechanical analysis, 29

Medina cement, 17

Metal moulds, 66

Mixing concrete, $33,36,38,40$, 42,94

- machines and plant, 38, $40,41,42,48,94$

Monier, 108

Monolithic work, 52, 119, 130 .

Mouchel, L. G., 109

Motor boats, concrete, 128

Moulded products, 83,86

Moulds and shuttering, 57, 61, 66,67

“ Mystery ships," 128

Natural cement, 17

Neutral axis, 111

OIL, effect on concrete, 107

Origin of concrete, 1

Ornamental details, 89 
Painting concrete, 76

Pantheon, dome of, 6

Pebble-dash, 75

Physical properties of concrete, 91

Pontoon construction, 128

Poor lime, 19

Portland cement, 9, 12, 74

Pozzuolana, 19 works, Cambridge, 13

Precast work, 5, 56

Proportioning concrete-

Arbitrary standards, 28

Mechanical analysis, 29

Trial mixtures, 27

Voids, 25

Pudding stone, 3

Quicklime, 19

Quick-setting cement, 16

Ramming concrete, 52

Raw materials, 12

Reinforced brickwork, 123

- concrete, 10, 108

Reinforcement, 111, 115

Residence, a concrete, 81

R.I.B.A. Committee, 99

Risorgimento Bridge, Rome, 64

Roman cement, 17

- concrete, ancient, 5

Rotary kilns, Rugby, 14

Royal Liver building, 38

SAND, 4, 22, 23, 33

, washing and screening, 34

Sandstone, 2

Saxon Cement Works, Cambridge, 13

St. Joseph, statue of, 86

Sea water, resistance to, 106

Scott's cement, 18

Selenitic cement, 18

Setting time of cement, 16

Shearing strength of concrete, 101

Shipbuilding, 66, 99, 124

- monolithic, 130

- , skeleton, 130,132
Shipbuilding, unit, 130, 132

, skeleton construction, 134,136

- Structural considerations, 132

Shuttering, 57, 66

Sieves for mechanical analysis, 30

Sieving and screening, 31

Slag, 21

- cement, 18

Slaked lime, 19

Slow-setting cement, 16

Soundness of cement, 17

Standard specification, 14

Stationery Office, New, 45, 99

Statuary, 86

Stone-breaking machines, 35

Stone, broken, 21, 22

Strength of concrete, 92, 97. 100,101

Stucco finish, 74

Surface treatment, 70

TAMPING concrete, 52, 96

Taylor, W. J., 107

Tensile strength, 15, 100

Terrazzo finish, 80

Testing cement, 17

Thames ballast, 22

Thompson, Sanford, E., 29, 31,92

Timber for shuttering, 58, 66

Tunis, buildings at, 120

Vicat needle apparatus, 16

Voids in sand and aggregate, 25

Wall moulds, 63

Washing sand, 34

Water, 19

Waterproofing compounds, $10 \overline{5}$

Watertightness, 105

Watertown arsenal, 95

White Portland cement, 74

Wig, R. J., 106

Woolson, Prof., 104 


\title{
A LIST OF BOOKS
}

\author{
PUBLISHED BY
}

\section{Sir Isaac Pitman \& Sons, Ltd.}

(Incorporating WHITTAKER \& CO.)

PARKER STREET, KINGSWAY, W.C.2.

\section{A complete Catalogue giving full details of the following books will be sent post free on application.}

\section{ALL PRICES ARE NET.}

Aerofoils and Resistance of Aerodynamic Bodies,

The Properties of. A. W. Judge. . . . 180

Aeronautical Engineering. A. Klemin. . . . 150

Aeronautical Design and Construction, Elementary

Principles of. A. W. Judge . . . . 76 Aeroplane Structural Design. Jones and Frier. o 210 Aeroplanes and Airships. W. E. Dommett . . 30 Aircraft and Automobile Materials of Construction.

A. W. Judge

Vol. I, Ferrous . ${ }_{\text {Vol. II, Non-Ferrous and Organic. (In preparation) }}$

Airship Attacks on England. Kapitan-Leutnant Von

Buttlar

Alignment Charts. E. S. Andrews . . . . 20

Alternating Current Maciunery. Papers on the Design

of. C. C. Hawkins, S. P. Smith, and S. Neville . . 210

Alternating-Current Work. W. Perren Maycock d 106

Arithmetic of Electrical Engineering. Whittaker's 36

Arithmetic of Alternating Currents. E. H. Crapper . 60

Architectural Hygiene, or Sanitary Science as

APPlied to BuIldings. B. F. and H. P. Fletcher . 76

$\mathbf{w}-2$ 
Armature Construction. H. M. Hobart and A. G. Ellis s. $d$. Art and Craft of Cabinet Making. D. Denning . . Artificial Silk. J. Foltzer-T Woodhouse. (In the Press) Astronomy, for General Readers. G. F. Chambers . Automatic Pistols. Capt. Hugh Pollard

Automobile Ignition and Valve Timing, Starting and

Lighting, Including Ford System. J. B. Rathbun Automobile Students and Mechanics, Questions and ANSWERS FOR. 'T. H. Russell .

Baudôt Printing Telegraph System. H. W. Pendry Bookbinding and the CARE of Books. D. Cockerell

Calculus for Engineering Students. J. Stoney . Carpentry and JoInery: a Practical Handbook for Craftsmen and Students. B. F. and H. P./Fletcher Central Station Electricity Supply. A. Gay and C. H. Yeaman

Ceramic Industries Pocket Book. O. B. Searle .

Chemical Engineering, An Introduction to. A. F. Allen

CoIl Ignition For MOtor CARs. C. Sylvester. (In the Press)

Colour in Woven Design: a Treatise on Textile Colouring. R. Beaumont . . . . .

Commercial and Technical Terms in the ENglish and Spanish Languages. R. D. Monteverde. .

Compressed Air Power. A. W. and Z. W. Daw . .

Conversion of Heat into Work. Sir W. Anderson . Continuous-Current Dynamo Design, Elementary Principles of. H. M. Hobart

Continuous Current Motors and Control Apparatus.

W. Perren Maycock

Design of Aeroplanes, The. A. W. Judge .

Design of Alternating Current Machinery. J. R.

Barr and R. D. Archibald

Dictionary of Aircraft, A. W. E. Dommett

Direct Current Electrical Engineering. J. R. Barr

Dissections, Illustrated.

C. G. Brodie

\section{Diving Manual. R. H. Davis}

Drawing and Designing. C. G. Leland

Dynamo: its Theory, Design and Manufacture, The.

C. C. Hawkins and F. Wallis. In two vols. Each

Electric Light Fitting: A Treatise on Wiring for Lighting, Heating, \&c. S. C. Batstone. 
Electrical Instrument Making for Amateurs. S. R. Bottone

Electric Bells and All About Them. S. R. Bottone. Electric Traction. A. T. Dover. Electrical Engineers' Pocket Book. Edited by R. E. Neale

Electric Motors and Control Systems. A. T. Dover. Electric Motors-Continuous, Polyphase and Single-

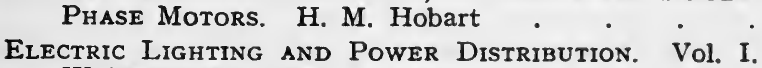
W. Yerren Maycock $\quad . \quad$. $\quad$. ?

Electric Lighting and Power Distribution. Vol. II.

W. Perren Maycock $\quad$. $\quad$. $\quad$. $\quad$. 106

Electric Mining Machinery. S. F. Walker . . 150

Electric Wiring, Fittings, Switches and Lamps. W.

Perren Maycock

Electric Wiring Diagrams. W. Perren Maycock .

Electric Wiring Tables. W. Perren Maycock

Electric Circuit Theory and Calculations. W.

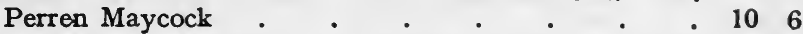

Electrical Instruments in Theory and Practice.

Murdoch and Oschwald . . . . . . 126

Electro Motors: How Made and How Used. Revised by C. Sylvester

Electro-Platers' Handbook.

Electro Technics, Elements of. A. P. Young .

Elementary Geology. A. J. Jukes-Browne . • .

Elementary Telegraphy. H. W. Pendry • • •

Elementary Aeronautics, or the Science and Practice

of Aerial Machines. A. P. Thurston . • 86

Elementary Graphic Statics. J. T. Wight . . - 50

EMbroidery and Tapestry Weaving. Mrs. A. $\mathrm{H}$.

Christie

Engineer Draughtsmen's Work: Hints to Beginners in DRAWING OFFICES .

Engineering Workshop Exercises. E. Pull • . 36

Engineers' and Erectors' Pocket Dictionary: English,

German, Dutch. W. H. Steenbeek . . . 26

ENglish for Technical Students. F. F. Potter . - 20

Experimental Mathematics. G. R. Vine

Book I, with Answers

$$
\text { II, with Answers }
$$

Explosives Industry, Rise and Progress of the Britisu

Field Manual, The. A. Lovat Higgins 
Filles AND Filing. Fremont-Taylor . . . . 210

First Book of Electricity and Magnetism. W. Perren

Maycock . .

Flax Culture and Preparation. F. Bradbury . . 106

Furs AND Furriery $\quad$ C. J. Rosenberg . . . . 300

Fuselage Design. A. W. Judge . . . . . 30

Gas Engine Troubles and Installation. J. B. Rathbun .

Gas, Oil and Petrol Engines: including Suction Gas Plant and Humphrey Pumps. A. Garrard . . 60

Gas and Oil Engine Operation. J. Okill . $\quad 50$

Gas, Gasoline and Oil Engines. Including Glossary. J. B. Rathbun .

Gas Supply, in Principles and Practice: a Guide for the Gas Fitter, Gas Engineer and Gas Consumer.

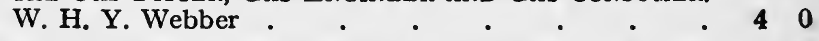

German Grammar for Science Students. W. A. Osborne . . . . . . . . .

HANDICRAFTS AND RECONSTRUCtION . . . . 26

Hand-Loom Weaving. Luther Hooper . . . 106

Handrailing for Geometrical Staircases. W. A. Scott . . . . . . . . 26

High-Speed Internal Combustion Engines. A. W. Judge 180 Historical papers on Modern Explosives. G. W. MacDonald . . . . . . . . .

Hosiery Manufacture. W. Davis . . . . 90

How to Manage the Dynamo. A. R. Bottone . 20

Hydraulic Motors and Turbines. G. R. Bodmer . 150

Induction CoILs. G. E. Bonney . . . . 60

Insulation of Electric Machines. H. W. Turner and

H. M. Hobart

Lay-out of Small Water Mains. H. H. Hellins . $\quad 76$

Leather Work. C. G. Leland . . . • 50

Lektric Lighting Connections. W. Perren Maycock . 9

Lens Work for Amateurs. H. Orford . . . 36

Lightning Conductors and Lightning Guards. Sir O.

Lodge . . . . . . . . .

Logarithms, Five Figure and Trigonometrical Func-

tions. W. E. Dommett. . . . . 16

LOGARITHMS FOR BEgINNERS . . . . . . 16

Magneto and Electric Ignition. W. Hibbert . . 36

MaNagement of Accumulators. Sir D. Salomons . $\quad 76$

Manual Instruction-Woodwork. S. Barter . . 76

DraWING $\quad$. . 40 
Manufacture of Explosives. 2 Vols. O. Guttmann . $50 \quad 0$

Marine Screw Propellers, Detail Design of. D. Jackson

Mathematical Tables. W. E. Dommett

Mechanical Tables, showing the Diameters and CirCUMFERENCES OF IRON BARS, ETC. J. Foden . . 20

Mechanical Engineering Detail Tables. J. P. Ross . (In preparation)

Mechanical Engineers' Pocket Book. Whittaker's . 60

Mechanics' and Draughtsmen's Pocket Book. W. E.

Dommett

Metal TuRning. J. Horner

Metal Work-Repousse.

C. G. Leland

Mrtal Work. (Handbook). J. S. Miller • . . 40

Metric and British Systems of Weights and Measures.

F. M. Perkin

Metric Conversion Tables. W. E. Dommett • •

Mineralogy: the Characters of Minerals, their

Classification and Description. F. H. Hatch . 60

Mining Mathematics (Preliminary). G. W. Stringfellow 16

Modern Illuminants and Illuminating Engineering.

Dow and Gaster

Modern Practice of Coal Mining. Kerr and Burns.

Part I, 5s. Parts 2, 3 and 4 . . . . . 60

Modern Optical Instruments. H. Orford • . . 40

Modern Milling. E. Pull . . . . . . 90

Motor BoATs, Hydroplanes and Hydroaeroplanes.

T. H. Russell .

Motion Picture Operation, Stage Electrics and

Illusions. H. C. Horstmann and V. H. Tousley.$\quad 76$

Motor TRUCK aNd Automobile Motors and Mechan-

ISM. T. H. Russell . . . . . . $8 \begin{array}{llll}8 & 0\end{array}$

Moving Loads on RaIlway under Bridges. H. Bamford 56

Optics of Photography and Photographic Lenses.

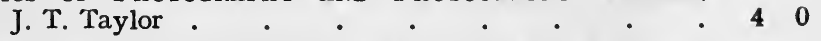

Pipes and Tubes: their Construction and Jointing.

P. R. Björling .

Plant World: its Past, Present and Future, The. G.

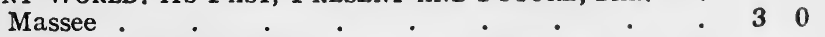

Plywood and Glue, Manufacture and Use of. B. C.

Boulton . . . . . . 76

Polyphase Currents. A. Still . . . . . 76

Power Wiring Diagrams. A. T. Dover . . . 76 
Practical Exercises in Heat, Light and Sound, J. R. Ashworth

Practical Electric light Fitring. F. C. Allsop
Practical Exercises in Magnetism and Electricity. J. R. Ashworth

Practical Sheet and Plate Metal Work. E. A. Atkins

Practical Ironfounding. J. Horner 26

60

Practical Testing of Electrical Machines. L. Oulton and N. J. Wilson

Practical Telephone Handbook and Guide to the Telephonic Exchange. J. Poole . . .

Practical Advice for Marine Engineers. C. W. Roberts

Practical Design of Reinforced Concrete Beams and

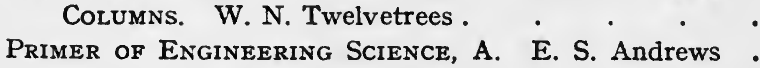

Principles of Fitting. J. Horner

Principles of Pat'Tern-Making

Radio-Telegraphist's Guide and Log Book. W. H. Marchant

Radium and All About It. A. R. Bottone .

Railway Technical Vocabulary. L. Serraillier • 76

Reinforced Concrete. W. N. Twelvetrees . . . 210

Reinforced Concrete, Detail Design In. E. S. Andrews

Researches in Plant Physiology. W. R. G. Atkins Roses and Rose Growing. Kingsley, R. G.

ROSES, NEW

Russian Weights and Measures, Tables of. Redvers

Elder

Simplified Methods of Calculating Reinforced Con-

CRETE BEAMS. W. N. Twelvetrees

Slide Rule. A. L. Higgins

Slide Rule, C. N. Pickworth

Small Book on Electic Motors, A. C.C. AND A.C.

W. Perren Maycock.

SPANish IDIoms with their ENglisi Equivalents. R.

D. Monteverde

Silverwork aNd Jewellery. H. Wilson • . 86

Stained Glass Work. C. W. Whall . . . . 106

Steel Works Avalysis. J. O. Arnold and F. Ibbotson . 126

Storage Battery Practice. R. Rankin . . . 76

Stresses in Hooks and Other Curved Beams, The.

E. S. Andrews 
Submarines, Torpedoes and Mines. W. E. Dommett . s. d. SURVEYing AND SURVEYing InStRUMENTS. G. A. T. Middleton $. \quad . \quad$. $\quad . \quad$. $\quad$.

Tables for Measuring and Manuring Land. J. Cullyer 30 Tables of Safe loads on Steel Pillars. E. S. Andrews

Teacher's Handbook of Manual Training: Metal Work. J. S. Miller • • • • • • • 440

Technical Dictionary. Webber . . . . 150

Telegraphy: an Exposition of the Telegraph System of THE BRITISH Post OfFice. T. E. Herbert .

180

Telephony, Elementary. By the Same Author. (In preparation)

Text Book of Botany. Part I-The Anatomy of Flowering Plants. M. Yates

Textile Calculations. J. H. Whitwam . . . 250

Transformers For Single aNd MUltiphase CURRENTs. G. Kapp

Trigonometry for Engineers, A Primer of. W. G. Dunkley

Trigonometry, Practical. H. Adams . . . 50

Triplane and the Stable Biplane, The. J. C. Hunsaker

TURRet Lathe Tools, How to Lay OUt

Union Textile Fabrication. R. Beaumont

Ventilation of Electrical Machinery. W. H. F. Murdoch

Ventilation, Pumping, and Haulage, The Mathematics

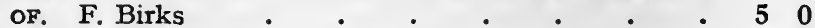

Volumetric Analysis. J. B. Coppock. - . 36

Weaving For Beginners. Luther Hooper. . . . 50

Wireless Telegraphy and Hertzian Waves. A. R. Bottone

Wireless Telegraphy: a Practical Handwork for Operators ANd Students. W. H. Marchant . . 76

Wood-Block Printing. F. Morley Fletcher. . 86 Woodcarving. C. G. Leland . . . . $\quad 50$ Woodcarving Design and Workmanship. George Jack. 76 WORKMANSHIP, ON. H. Wilson . . . . . 16 Writing, Illuminating and Lettering. E. Johriston • 86 


\section{TECHNICAL PRIMER SERIES}

Edited by R. E. NEALE, B.Sc. (Hons.), A.C.G.I., A.M.I.E.E.

IN each book of the series the fundamental principles of some sub-division of engineering technology are treated in a practical manner, providing the student with a handy survey of the particular branch of technology with which he is concerned. They should prove invaluable to the busy practical man who has not the time for more elaborate treatises. Each 2s. 6d. net.

The Steam Locomotive. By E. L. Ahrons, M.I.Mech.E.

Belts for Power Transmission. By W. G. Dunkley, B.Sc.(Hons.). Water-Power Engineering. By F. F. Fergusson, A.M.I.C.E.

Photographic Technigue. By L. J. Hibbert, F.R.P.S.

Hydro-Electric Developments. By J. W. Meares, F.R.A.S., M.Inst.C.E., M.I.E.E.

The Electrification of Railways. By H. F. Trewman, M.A. Continuous Current Armature Winding. By F. M. Denton, A.C.G.I.

Municipal Engineering. By H. Percy Boulnois, M.Inst.C.E., F.R.San.Inst., F.Inst.S.T.

FOUNDRY Work. By Ben Shaw and James Edgar.

Pattern-Making. By Ben Shaw and James Edgar.

The Electric Furnace. By Frank J. Moffett, B.A., M.I.E.E., M.Cons.E.

Small Single-Phase Transformers. By Edgat T. Painton, B.Sc., A.M.I.E.E.

Pneumatic Conveying. By E. G.Phillips, M.I.E.E., A.M.I.Mech.E. BoIler Inspection and Maintenance: By R. Clayton.

Electricity in Steel Works. By W. Macfarlane, B.Sc.

Modern Central Stations. By C. W. Marshall, B.Sc.

Steam Locomotive Construction and Maintenance. By E. L. Ahrons, M.I.Mech.E., M.I.Loco.E.

High Tension Switch Gear. By H. E. Poole, B.Sc., A.C.G.I., A.M.I.E.E.

High Tension Switch Boards. By the Same Author.

Power Factor Correction. By A. E. Clayton, B.Sc., A.K.C., A.M.I.E.E.

Tool and Machine Setting. By P. Gates.

Tidal Power. By A. Struben, O.B.E., A.M.I.C.E.

SEwers AND Sewerage. By H. Gilbert Whyatt, M.I.Inst.C.E., M.Roy.San.Inst., M.Inst.M. and C.E.

Elements of Illuminating Engineering. By A. P. Trotter, M.I.C.E.

Coal-Cutting Machinery. By G. E. F. Eagar, M.Inst.Min.E. Grinding Machines and Their Use. By T. R. Shaw, M.I.Mech.E. Electro-Pe.position of Copper. By Claude W. Denny,A.M.I.E.E.

\section{Catalogue of Scientific and Technical Books post free.}

London : Sir Isaac Pitman \& Sons, Ltd., Parker St., Kingsway, W.C.2 



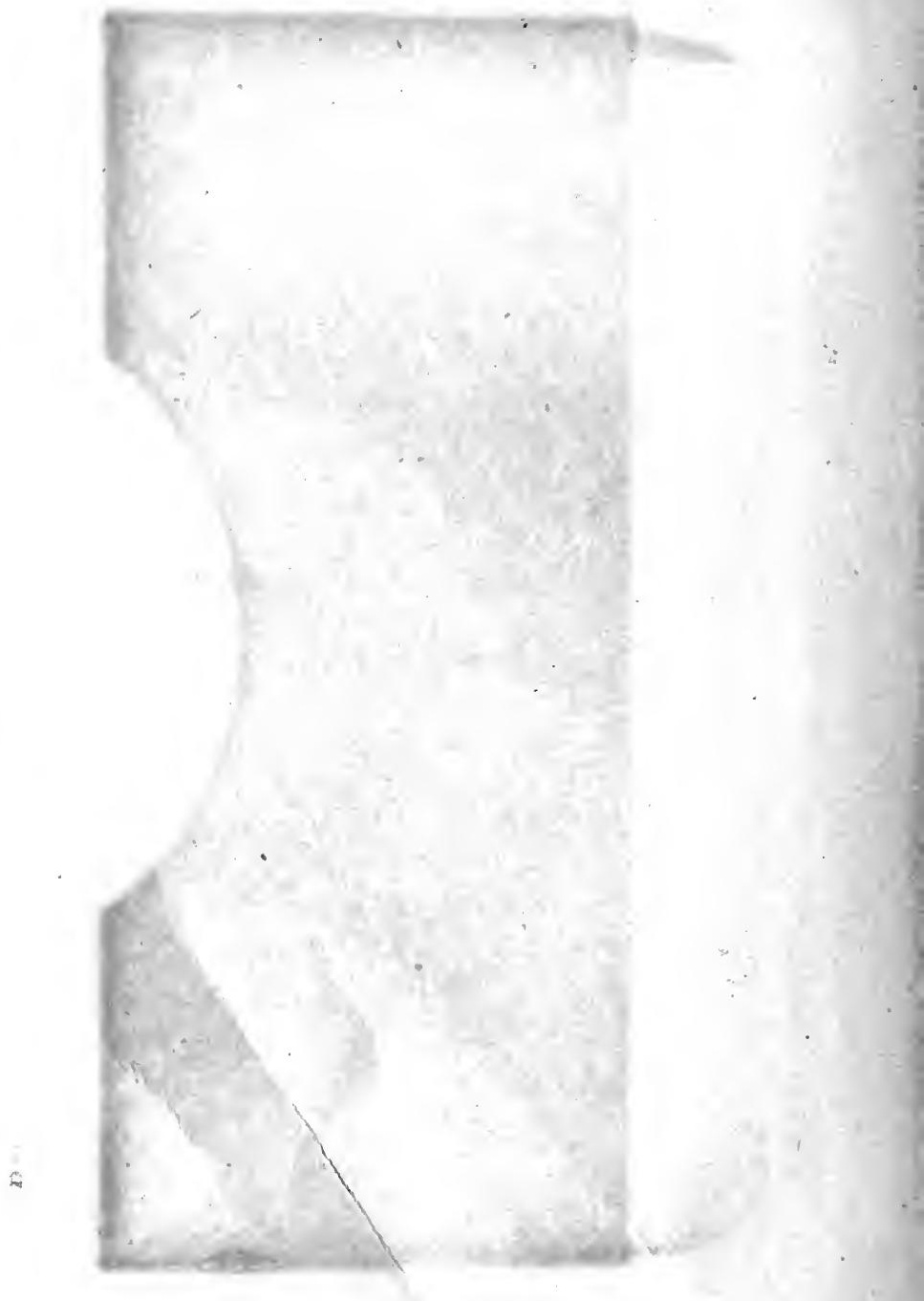




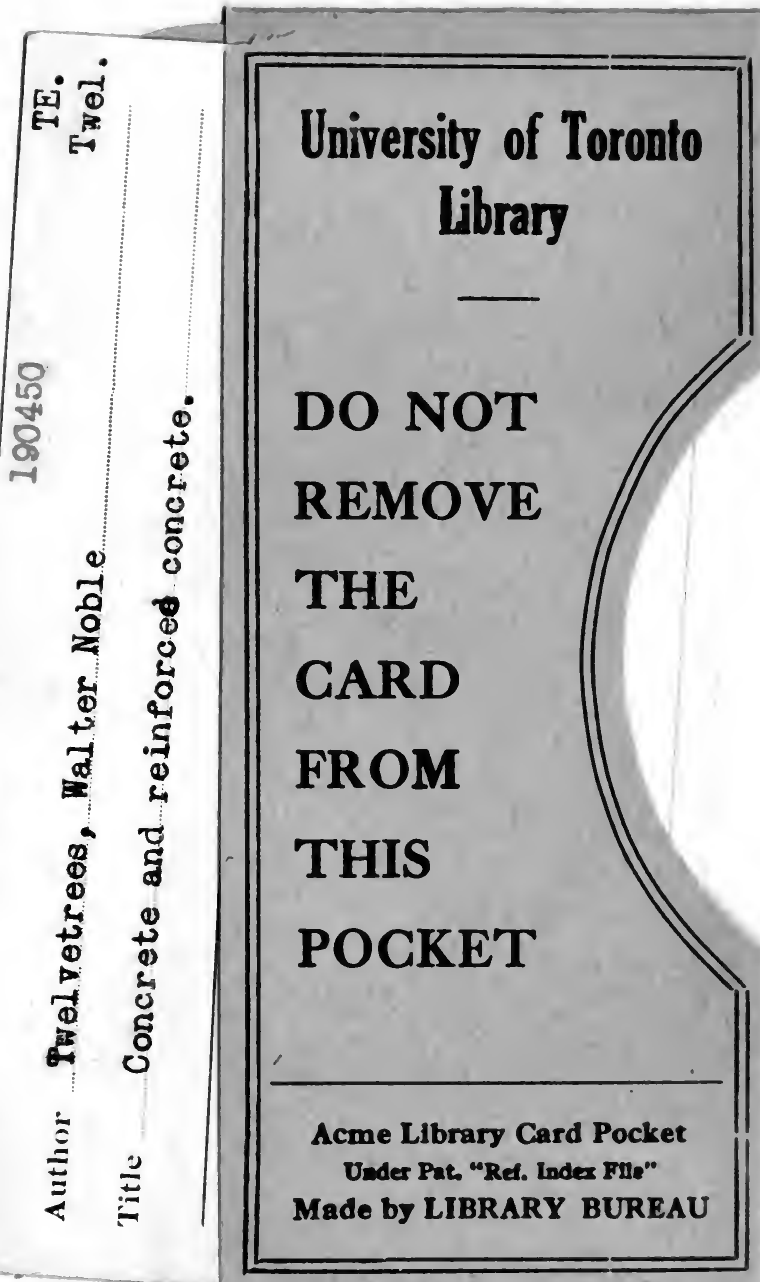


